University of Louisville

ThinkIR: The University of Louisville's Institutional Repository

Electronic Theses and Dissertations

$5-2007$

\title{
Mentoring African American men : a study of job satisfaction and organizational commitment.
}

Davis Marvin Robinson

University of Louisville

Follow this and additional works at: https://ir.library.louisville.edu/etd

\section{Recommended Citation}

Robinson, Davis Marvin, "Mentoring African American men : a study of job satisfaction and organizational commitment." (2007). Electronic Theses and Dissertations. Paper 1218.

https://doi.org/10.18297/etd/1218

This Doctoral Dissertation is brought to you for free and open access by ThinkIR: The University of Louisville's Institutional Repository. It has been accepted for inclusion in Electronic Theses and Dissertations by an authorized administrator of ThinkIR: The University of Louisville's Institutional Repository. This title appears here courtesy of the author, who has retained all other copyrights. For more information, please contact thinkir@louisville.edu. 
MENTORING AFRICAN AMERICAN MEN: A STUDY OF JOB

\title{
SATISFACTION AND ORGANIZATIONAL COMMITMENT
}

\author{
By \\ Davis Marvin Robinson \\ B.S., Western Kentucky University, 1990 \\ M.Ed., University of Louisville, 1996

\begin{abstract}
A Dissertation
Submitted to the Faculty of the

Graduate School of the University of Louisville

In Partial Fulfillment of the Requirements

for the Degree of
\end{abstract}

Doctor of Philosophy

Department of Education and Human Development

University of Louisville

Louisville, KY

May, 2007 

Copyright 2007 by Davis Marvin Robinson

All rights reserved 
MENTORING AFRICAN AMERICAN MEN: A STUDY OF JOB SATISFACTION AND ORGANIZATIONAL COMMITMENT

By

Davis Marvin Robinson

B.S., Western Kentucky University, 1990

M.Ed., University of Louisville, 1996

A Dissertation Approved on

April 6, 2007

by the following Dissertation Committee:

Dissertation Director 


\section{DEDICATION}

This dissertation is dedicated to a couple of people who were instrumental in my educational endeavors. First and foremost is my savior Jesus Christ. Thank you for making this possible. Secondly, I dedicate this to my Great-Grandmother, Hattie W. Jones. If it were not for her instilling the drive for higher academic achievement I would have stopped a long time ago. Thirdly, I dedicate this to my mother, Vera G. Parks, who sacrificed and conveyed early in my life the importance of a solid education foundation. Fourthly, I dedicate this to my GreatAunt, Ruth $\mathrm{H}$. Fears, who continued to support and encourage my educational and professional endeavors after the passing of her dear mother, Hattie. Lastly, I

dedicate this to my loving wife, Camille; my darling stepdaughter, Kamaria; and my first-born, Donovan. I love you all. 


\section{ACKNOWLEDGEMENTS}

I would like to thank my dissertation advisor Dr. Thomas G. Reio Jr. who I will always remember saying from the beginning, "We will get you through this". Thank you for your excitement, support, and encouraging words. I would also like to thank my graduate advisor, Dr. Carolyn Rude-Parkins, for her support and guidance from my M.Ed. to Ph.D. You have been wonderful and I truly appreciate you for all you done for me and your guidance. Dr. Petrosko, Dr. Haynes, and Dr. Wells, I truly appreciate your motivational constructive criticism, service, and guidance. Marji Settles, thank you for providing 10 years of exceptional assistance. Kelly Ising, your assistance was more than appreciated (thanks for the candy)! Last but not least, to Crawford Owens and the National Black Masters of Business Administration Association (NBMBAA) thank you for everything you did to help me attain this goal. 


\section{ABSTRACT \\ MENTORING AFRICAN AMERICAN MEN: A STUDY OF JOB SATISFACTION AND ORGANIZATIONAL COMMITMENT \\ Davis Marvin Robinson}

April 6, 2007

This dissertation is a correlational designed study that examined the strength and direction of the relationship between mentoring, job satisfaction, and organizational commitment, of African American men, exclusively in a business setting $(N=364)$, who were members of the National Black Masters of Business Administration Association (NBMBAA). Approximately $56 \%$ of the respondents were affiliated with the association. Participants completed a web-based survey via Zoomerang ${ }^{\mathrm{TM}}$, which included Mowday, Steers, and Porter's (1979) Organizational Commitment Scale and Spector's (1988) Job Satisfaction Scale, and employed Dillman's (2000) online survey protocol. This study used hierarchical multiple regression and mediational analysis to analyze the data. The hierarchical multiple regression analysis indicated that mentoring is a significant predictor of job satisfaction and a significant predictor of organizational commitment. The mediational analysis indicated that job satisfaction is a significant predictor of organizational commitment. Therefore, the results indicate that mentoring works through job satisfaction as a predictor of organizational commitment. 


\section{TABLE OF CONTENTS}

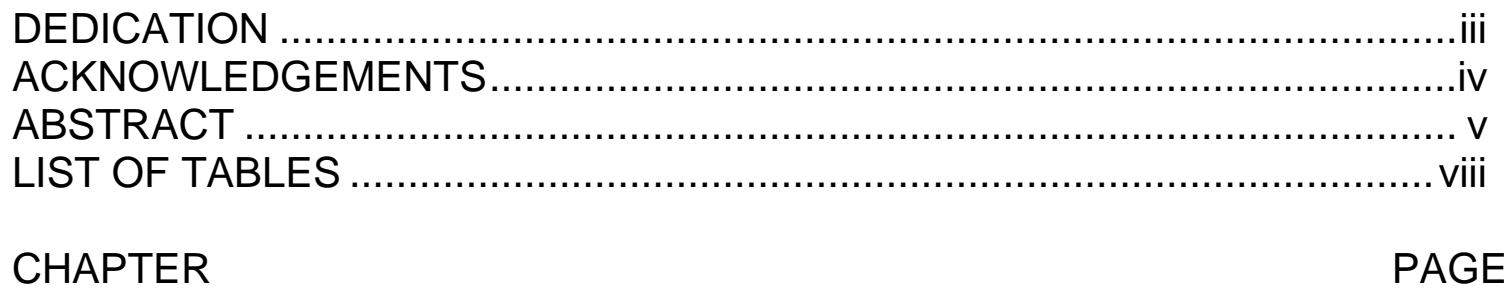

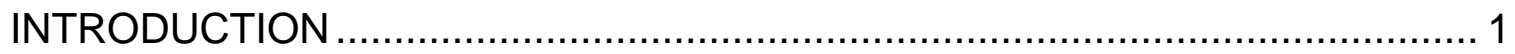

Statement of the Problem …….................................................... 5

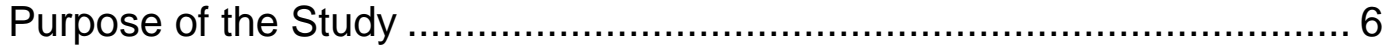

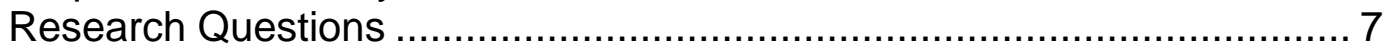

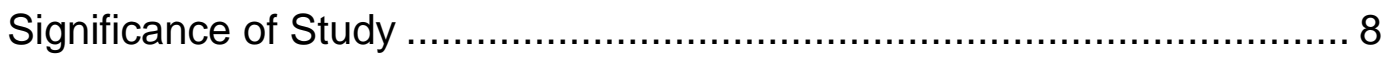

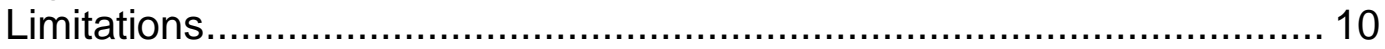

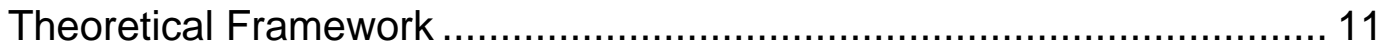

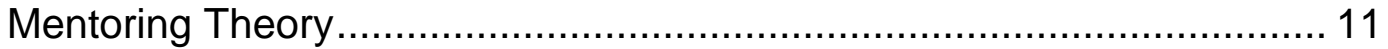

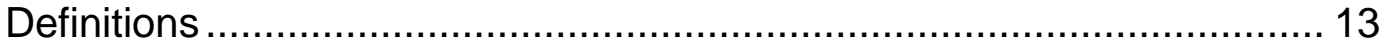

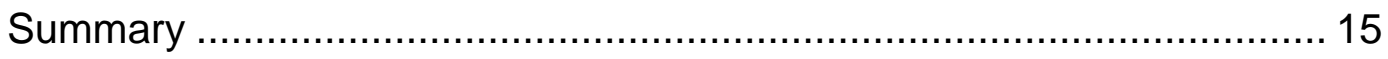

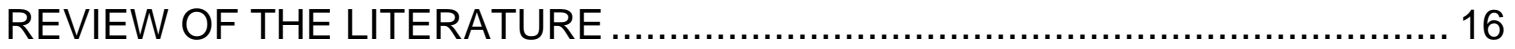

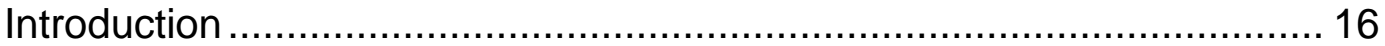

Mentoring and Race and Gender.................................................... 17

Mentoring, Job Satisfaction and Organizational Commitment ................. 41

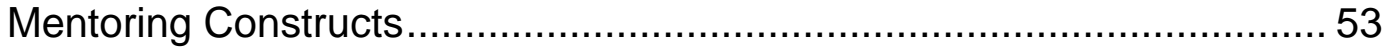

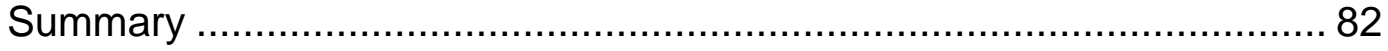

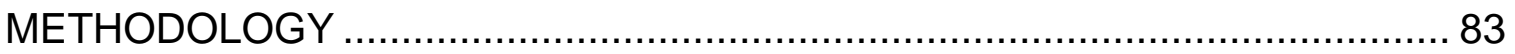

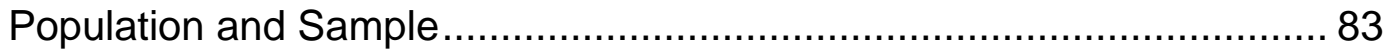

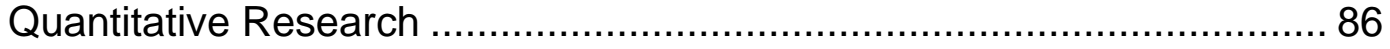

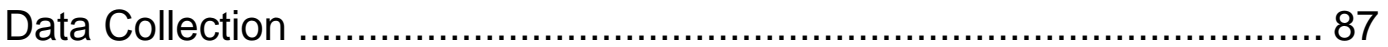

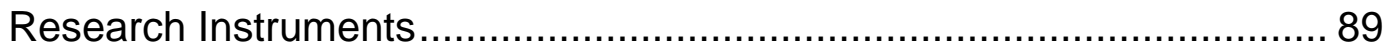

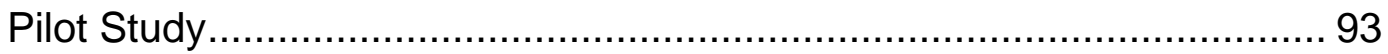

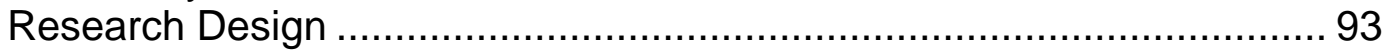

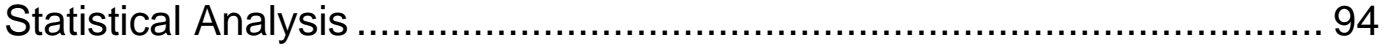

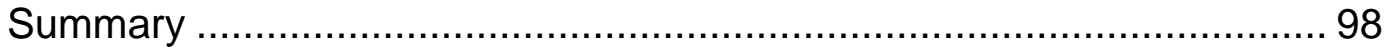

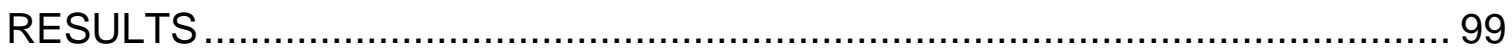

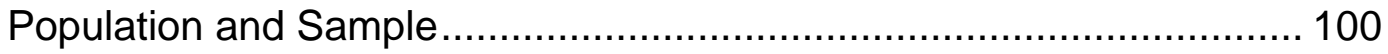

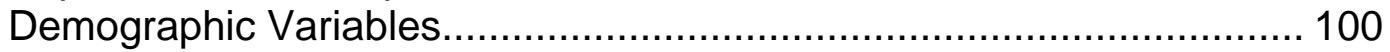




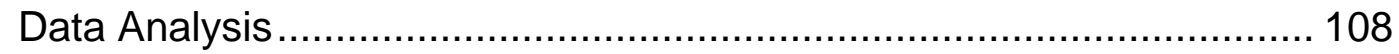

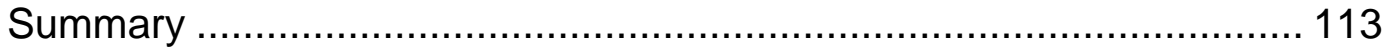

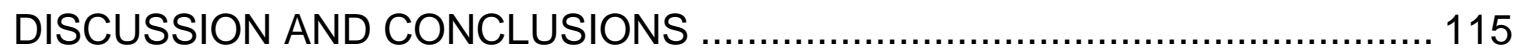

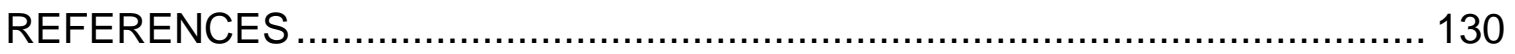

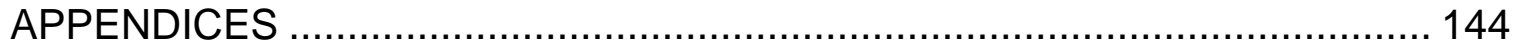

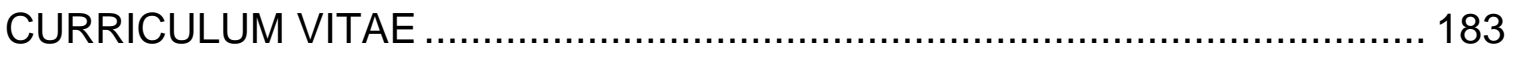




\section{LISTS OF TABLES}

\section{TABLE}

PAGE

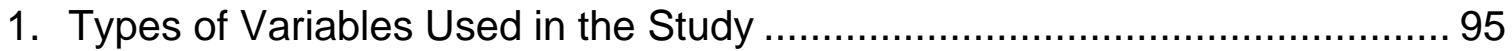

2. Source of Regression Coefficients for Mediation Analysis .......................... 97

3. Gender, Membership, Ethnicity and Age of Respondents.......................... 101

4. Job Title, Position Tenure, and Organization Tenure ............................... 102

5. Organization Size, Industry, Area of Specialty ....................................... 104

6. Type of Mentoring, Mentoring Effectiveness ........................................... 106

7. Mentor's Gender, Race, Age, and Meeting Frequency …......................... 107

8. Summary of Hierarchical Regression Analysis for Job Satisfaction Predicted

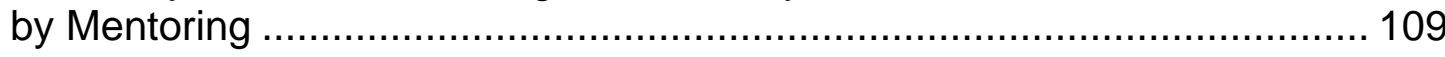

9. Summary of Hierarchical Regression Analysis for Organizational Commitment Predicted by Mentored and Job Satisfaction .......................................... 110

10. Summary of Hierarchical Regression Analysis for Organizational Commitment Controlling for Demographic Variables 


\section{CHAPTER I \\ INTRODUCTION}

Eby, McManus, Simon, and Russell (2000) suggested, "obtaining a mentor is an important career development experience for individuals" (p. 1). Studies conducted by Chao (1997), Dreher and Ash (1990), Fagenson (1989), Scandura (1992), and Whitely, Dolughtery, and Dreher, (1992) indicated mentored individuals perform better on the job, advance more rapidly within organizations, report more job and career satisfaction, and express lower turnover intentions than non-mentored individuals. Since researchers began to empirically research mentoring in the early 1980's (Burke \& McKeen, 1996), one group that is underutilized in the empirical mentoring literature is African American men. It is this group that this study examines. Specifically, the study examined mentoring among African American men and their level of job satisfaction and organizational commitment.

Mentoring can be traced back to Greek mythology in an epic titled, The Odyssey of Homer (Butler, 1944). In The Odyssey of Homer, King Odysseus was away from the land and while he was away, Athene, a Greek goddess, acted as a guide and counselor to his son, Telemachus.

Many organizations use mentoring as a means to develop, retain, and attract talent. Baugh \& Scandura (1999) suggested the public and private sectors 
primarily use mentoring as an intervention tool to enhance the personal and professional development of younger or less experienced professionals. Mentoring entails an older or more experienced professional providing developmental support for the purpose of providing feedback regarding career and interpersonal development (Kram, 1985). Additionally, organizations are known to use mentoring as a recruitment and retention tool and as an intervention to assist with succession planning (Hopkins-Thompson, 2000).

Mentoring is important to organizations and professionals in the private and public sector because of the benefits and outcomes it provides to both protégés and mentors. Aremu and Adeyoju (2003), Seibert (1999), and Stallworth (2003), examined mentoring and its impact on the protégé's organizational commitment, job satisfaction, intent to turnover, and career outcomes (compensation and career advancement). Mentors too receive benefits such as increased job satisfaction and a sense of fulfillment from fostering the development of the younger adult (Ragins \& Cotton, 1999).

Mentoring as defined by Carmin (1988):

Mentoring is a complex, interactive process, occurring between individuals of differing levels of experience and expertise that incorporates interpersonal or psychosocial development, career, and/or educational development, and socialization functions into the relationship. This one-toone relationship is itself developmental and proceeds through a series of stages which help to determine both the conditions affecting the outcomes of the process. (p. 10) 
The two types of mentoring most commonly referred to in the mentoring literature is informal and formal (Haynes, 2003; Packard, Walsh, \& Seidenberg, 2004; Ragins \& Cotton, 1999; and Sosik \& Godshalk, 2000). Eby and Lockwood (2004) referred to formal mentoring as organizationally initiated efforts to match mentors and protégés. Chao (1992) refers to informal mentoring as occurring in a spontaneous manner where the mentor and mentee take interest in each other and a relationship develops. While the development of the relationship occurs differently in formal and informal mentorships, the intent of the mentorship remains the same, which is career and psychosocial development (Kram, 1983).

Whether the mentorship is formal or informal, mentoring is important in the private and public sector because of the benefits it provides to the protégés, mentors, and organizations (Allen, Eby, Poteet, Lentz \& Lima, 2004; Ragins \& Scandura, 1999). According to Ragins and Scandura (1999), mentors create better support networks, receive satisfaction from helping others grow and succeed, and have greater access to information that facilitates job performance. Additionally, Dalton, Thompson, and Price (1997) suggested that mentors are provided an opportunity to make productive use of their knowledge and expertise. Many researchers examining mentoring focus on the outcomes of mentoring related to the protégé, specifically, organizational commitment, job satisfaction, intent to turnover, and career outcomes in terms of compensation and advancement (Aremu \& Adeyoju, 2003; Baugh \& Scandura, 1999; Donaldson, Ensher, \& Grant-Vallone, 2000; Fagenson, 1989; Joiner, Bartram, \& Garreffa 2004; Mobley, Jaret, Marsh, \& Lim, 1994; Seibert, 1999). 
The reason for choosing the variables of organizational commitment and job satisfaction for this study is because these two variables have been negatively correlated to employee's intent to leave the organization ( $\mathrm{Lu}$, Lin, $\mathrm{Wu}$, Hsieh, \& Chang, 2002; Stallworth, 2003). According to Holton and O'Neill (2002), these variables are important because organizations incur costs associated with recruiting, socializing, and training new hires. Therefore, instead of using monies to recruit, train, and socialize new employees, these monies may be useful in recruitment and retention interventions, such as mentoring, as a means to retain current employees. Zey (1984) and Wilson and Elman (1990) proposed the following mentoring benefits to the organization: (a) the integration or socialization of individuals into the operating norms and informal power structure, (b) increased organizational communication as mentors and protégés form alliances across levels and departments, (c) management development and succession planning information, and (d) increased productivity and decreased turnover.

While there are benefits to a mentorship, Eby and McManus (2003) found that mentoring experiences could be dysfunctional or negative. Eby, McManus, Simon, and Russell (2000) developed a taxonomy suggesting six causes for negative mentoring experiences. The causes were: (a) mis-match within the dyad (values, work-style and personality); (b) distancing behavior (neglect, selfabsorption, and intentional exclusion); (c) manipulative behavior (position power, tyranny, inappropriate delegation); (d) politicking (sabotage, credit-taking, deception); (e) lack of mentor expertise (interpersonal competency, technical 
incompetency); and (f) general dysfunctionality (bad attitude, personal problems). Therefore, while there are benefits to mentoring, the dynamics within the mentoring experience appear to be a factor in the related outcomes.

Statement of the Problem

According to the United States Census Bureau (2000), the black population in the United States increased faster than the total population between 1990 and 2000. A report from the United States Census Bureau indicated the Black population increase during these years was between $15.6 \%$ and $21.5 \%$ in comparison to the total population increase of $13.4 \%$. Because of the rapid increase, no longer can researchers remain satisfied with research examining one population and generalizing findings to the total population (even though research limitations are included in each study). As Ensher and Murphy (1997) suggested:

While mentoring has been shown to be very helpful for the career development of White males, upon whom most of the research has focused, only in the last few years have researchers begun to examine the importance of mentoring for women and people of color. (p. 461) Graham (1992) indicated that 3.9\% of empirical research articles were where African Americans were the population of interest. Sue (1999) suggested that the explanations for such a lack of empirical research on minority groups are because few researchers are interested in the topic and the field is unexposed. One problem that may exist for African American men is the availability or access to mentors. Viator (2001) conducted a study to examine whether African 
Americans were able to obtain mentoring support in the public accounting profession and found that African Americans were more likely to perceive barriers to obtaining a mentor than their White counterparts.

The review of literature revealed few articles related specifically to African American men and mentoring (Campbell-Whately, \& Algozzine, 1997; LaVant, Anderson, \& Tiggs, 1997; Utsey, Howard, \& Williams, 2003), however, most were non- empirical. Dreher and Cox (1996) and Thomas (1990) conducted empirical mentoring studies where, collectively, Black and White men were the population studied. Sue (1999) suggested "that there is a lack of psychological research on ethnic minority population and that research on ethnic minority groups is uneven" (p. 1070). Because of the lack of mentoring research designed to examine minority groups and specifically examine mentoring as it relates to African American men, this study examined mentoring among African American men and its relationship to organizational commitment and job satisfaction.

\section{Purpose of the Study}

The purpose of this study is to examine what is the relationship between mentoring and its relationship to African American men's job satisfaction and organizational commitment. Greenhaus, Parasuraman, and Wormely (1990) conducted a study on organizational experiences and found that Black managers reported having less job discretion and lower feelings of acceptance, were rated lower on both dimensions of job performance (relationship and task), received lower promotability assessments, were more likely to be at career plateaus, and were more dissatisfied with their careers than White managers. Researchers 
examining mentoring outcomes found there are positive relationships between mentoring, organizational commitment, and job satisfaction (Aremu \& Adeyoju, 2003; Baugh \& Scandura, 1999; Donaldson, Ensher, \& Grant-Vallone, 2000; Heimann \& Pittenger, 1996; Joiner, Bartram, \& Garreffa, 2004; Seibert, 1999; Stallworth, 2003). These studies examined specific industries and organizational levels that included each gender and various racial groups. This research study examined mentoring African American men. While there are mentoring studies that found a positive relationship between organizational commitment, job satisfaction, and mentoring, the review of literature indicated a lack of mentoring research specific to African American men and their levels of organizational commitment and job satisfaction. This study used the following conceptual model as a guide to conduct the study.

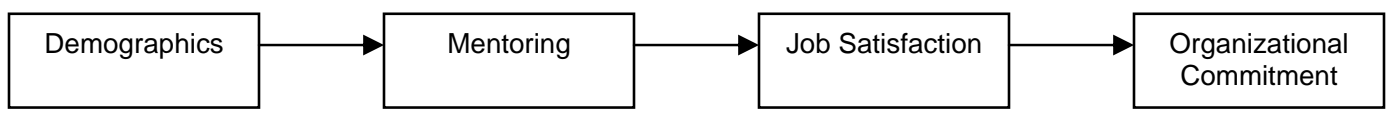

Figure 1. The relationship between mentoring, job satisfaction, and organizational commitment among African American men.

Research Questions

The study examined the mentoring experiences of African American men to determine how their mentoring experiences influenced their job satisfaction and organizational commitment. Specifically, the study will answer the following questions:

1. What is the relationship between mentoring and job satisfaction? 
2. What is the relationship between mentoring and organizational commitment?

3. After controlling for select demographic variables, what is the relationship between mentoring, job satisfaction, and organizational commitment? The first research question examined the strength and direction of the relationship between mentoring and job satisfaction among African American men. The second research question examined the strength and direction of the relationship between mentoring and organizational commitment of African American men. According to a review of the literature, researchers found positive relationships between mentoring, job satisfaction and organizational commitment (Baugh \& Scandura, 1999; Fagenson, 1989; Mobley, Jaret, Marsh, \& Lim, 1994; Seibert, 1999), yet statistically nonsignificant ones between mentoring and job satisfaction (Aremu \& Adeyoju 2003). The third research question examined the unique relationship between mentoring, job satisfaction, and organizational commitment after statistically controlling for select demographic variables, (age, tenure, etc).

\section{Significance of the Study}

As Atkinson, Casas, and Neville (1994) indicated, "Despite the widely acknowledged benefits to both protégés and mentor, mentoring has been restricted to a limited population, namely White men" (p. 37). Some studies (Blackwell, 1989; Cameron \& Blackburn, 1981; Clark \& Cocoran, 1986; Noller, 1982) found that European American women and ethnic minorities historically have been underrepresented in the mentoring process. Past research has 
examined mentoring outcomes related to an inclusive and general population (Burke, 1984; Kram, 1983; Noe, 1988). Recently, however, mentoring researchers have examined mentoring effects and outcomes related to men, women, Blacks and Whites separately (Atkinson, Casas, \& Neville, 1994; BlakeBeard, 1999; Burke \& McKeen, 1996; Collins, Kamya, \& Trouse, 1997; Crawford \& Smith, 2005; Dreher \& Ash, 1990; Dreher \& Chargois, 1998; Dreher \& Cox, 1996; Finkelstein, Allen, \& Rhoton, 2003; Greenhaus, Parasuraman, \& Wormley, 1990; Linnehan, 2001; Tharenou, 2005; Tillman, 2001; Thomas, 1990; Viator, 2001). It is the underrepresentation of mentoring research specifically examining African American men that this study attempts to address.

This study is important to the field of mentoring because it provides new information to the mentoring literature examining African American men. Additionally, it adds to existing research on two organizational outcomes linked to mentoring: job satisfaction and organizational commitment. According to Glatthorn (1998), there are certain criteria that need to be present to determine the significance of a study, which include: (a) extending existing knowledge, (b) changing prevailing beliefs, (c) suggesting relationships between phenomena, (d) extending a research methodology or instrument, and (e) providing greater depth of knowledge about previously studied phenomena.

How does this study meet the criteria? First, this study adds to previously conducted studies involving mentoring in that it examines underrepresented African American men's mentoring experiences as it relates to two organizational outcomes: job satisfaction and organizational commitment. Second, because 
there is a lack of mentoring research involving African American men, the findings of the study may change future researcher's beliefs about extending empirical research on African American men. Third, this study reveals the strength and direction of relationship between mentoring, organizational commitment, and job satisfaction. Fourth, this study extends the research methodology by using a hierarchical regression model to analyze the data, which has been used, but sparingly, in previous mentoring research. Lastly, the study provides a greater knowledge of mentoring because it examines an underrepresented group in the mentoring literature.

\section{Limitations}

As in any study, there are limitations to this study. While this study examined the effects of mentoring involving African American men, the first limitation is it excluded other minorities and women, which could extend the research for these populations as well. Because of the diversity in the United States and organizations, researchers should further their research to include specific groups such as, Asian American females, Hispanic males, for example. The last limitation is related the use of a questionnaire. Because the study retrieved its data from questionnaires exclusively, another limitation is associated with common method variance (Doty \& Glick, 1998). Nunnally and Bernstein (1994) suggested the following strategies to minimize common method variance:

(a) avoid implying that one responses is preferred over another, (b) make all responses of equal effort, (c) pay attention to details of item wording, (d) use 
items that are less subject to bias, (e) provide clear instructions, and (f) independently assess sources of expected bias.

Theoretical Framework

This study used Bandura's (1977) social learning theory as its foundation to assist in explaining the construct of mentoring. Bandura indicated that, "Social learning theory emphasizes the prominent roles played by vicarious, symbolic, and self-regulatory processes in psychological functions" (p. vii). The four distinct features of social learning theory are: attention, retention, motivation, and motor reproduction. According to Bandura, the vicarious process involves: observation, direct experience, and fosters developing patterns in which the individual continually learns through observing; the symbolic process involves the ability to analyze the conscious experience, to plan, create, imagine, and engage in foresightful action; and the self-regulatory process involves self-generated inducement and consequences to influence human behavior.

How does this relate to mentoring? The two functions of mentoring are: career development and psychosocial development (Kram, 1983). These functions involve coaching and role modeling for the protégé, which may include learning through modeling. For example, a mentor may need to coach and provide feedback to a protégé on the correct way to develop a budget, or the mentor may find an opportunity for the protégé to observe and engage in handson learning in developing a budget.

Mentoring Theory 
Kram's (1983) seminal work indicated the two functions of mentoring that are beneficial to both protégé and mentor are: career development and psychosocial development. Career development includes: sponsorship, coaching, protection, exposure-and-visibility, and challenging work assignments. For the career development function Kram indicated, "a young manager is assisted in learning the ropes of organizational life and preparing for advancement opportunities" (p. 614). The psychosocial function includes role modeling, acceptance-and-confirmation, counseling, and friendship. In this function, Kram indicated, "a young manager is supported in developing a sense of competence, confidence, and effectiveness in the managerial role" (p. 614). Additionally, Kram (1983) suggested there are four phases in the mentoring relationship: (a) initiation, when the relationship begins; (b) cultivation, when the range of functions (career and psychosocial) expands to maximum; (c) separation, when the established nature of the relationship is substantially altered by structural changes in the organizational context, and/or by psychological changes within one or both individuals; and (d) redefinition, when the relationship evolves a new form that is significantly different from the past, or the relationship ends entirely. Kram indicated the initiation phase lasts a period of 6 to 12 months, the cultivation phase lasts 2 to 5 years, the separation phase lasts 6 months to 2 years after a significant change in the structural role relationship, and the redefinition phase lasts for an indefinite period after the separation phase. 


\section{Definitions}

The following definitions are included to provide clarity to the reader. The definitions are based on the review of literature.

\section{Formal Mentoring}

A program designed and developed by the organization to facilitate structured mentoring relationships where an experienced organizational member provides career and psychosocial development to you as a lesser-experienced organizational member (Haynes, 2003).

\section{Informal Mentoring}

A naturally occurring relationship based on attributes, attraction and similar interests, where an experienced organizational member provides career and psychosocial support to you as a lesser-experienced organizational member (Haynes, 2003).

Job satisfaction

A pleasurable or positive emotional state resulting from the appraisal of one's job and job experiences (Locke, 1977).

\section{Mentee}

An interchangeable term for protégé.

\section{Mentor}

The mentor is usually a senior, experienced employee who serves as a role model, provides support, direction, and feedback to the younger employee regarding career plans and interpersonal development, and increases the 
visibility of the protégé to decision-makers in the organization who may influence career opportunities (Noe, 1988).

Mentoring

Mentoring is a complex, interactive process, occurring between individuals of differing levels of experience and expertise that incorporates interpersonal or psychosocial development, career, and/or educational development, and socialization functions into the relationship. This one-to-one relationship is itself developmental and proceeds through a series of stages which help to determine both the conditions affecting the outcomes of the process (Carmin, 1988). Mentorship:

The dynamic and interpersonal relationship, which exists between the mentor and protégé. The mentorship is also referred to as the mentoring relationship.

Non-Mentoring

Never having any involvement in a formal or informal mentoring relationship where an experienced organizational member provided career and psychosocial development to you as a lesser-experienced organizational member (Haynes, 2003).

\section{Organizational Commitment}

A psychological state that characterizes the employee's relationship with the organization and has implications for the decision to continue membership in the organization (Meyer \& Allen, 1991). 


\section{Protégé}

The individual in the developmental relationship receiving guidance and support from the mentor.

\section{Chapter Summary}

This study addressed the mentoring experiences of African American men and its relationship to their job satisfaction and organizational commitment. Specifically, the study examined mentoring among African American men who hold a chapter membership to the National Black Master Business Administration Association. The purpose of the study is: (a) to investigate the relationship between mentoring and job satisfaction, (b) to investigate the relationship between mentoring and organizational commitment, and (c) to investigate the relationship between mentoring, job satisfaction and organizational commitment after statistically controlling for select demographical variables (age, tenure, etc.). While the review of literature does support studies examining the relationships between these concepts, this researcher attempts to provide insight to an underrepresented group in the mentoring research, i.e., African American men.

This chapter is an overview of the study and provided the reader with a fundamental introduction to mentoring. The following chapter is the review of mentoring literature with the purpose of extending the reader's knowledge of mentoring research and theory. Following the review of the literature in chapter 2 is the methodology, results, and discussion sections. 


\section{CHAPTER II \\ REVIEW OF THE LITERATURE \\ Introduction}

Historically, the public and private sectors have used mentoring as an intervention tool to enhance the development of younger or less experienced professionals, where an older or more experienced professional provides developmental support. Noe (1988) specifically defined the mentor as:

The mentor is usually a senior, experienced employee who serves as a role model, provides support, direction, and feedback to the younger employee regarding career plans and interpersonal development, and increases the visibility of the protégé to decision-makers in the organization who may influence career opportunities. (p. 458) The two types of mentoring relationships that are referred to in most mentoring research is informal and formal (Haynes, 2003; Packard, Walsh, \& Seidenberg, 2004; Ragins \& Cotton, 1999; and Sosik \& Godshalk, 2000). Informal mentoring is when the relationship occurs naturally. Informal mentoring relationships develop on the basis of mutual identification and the fulfillment of career needs (Erickson, 1963). Formal mentoring is a relationship that is deliberately developed by members of an organization and is more structured than informal relationships. In formal mentoring relationships, a program coordinator typically pairs protégés and mentors on the basis of an application 
(Douglas, 1997; Gaskill, 1993; Murray, 1991). Mentoring relationships can take place inside or outside the organization. However, most researchers focus their research efforts on mentoring relationships that occur inside private and public organizations. Mentor relationships are sometimes referred to as mentorships and the individuals involved in the mentoring relationship are the protégé (sometimes referred to as mentee) and the mentor.

\section{Mentoring Literature Review}

This literature review consists of empirical studies of organizational mentoring and its outcomes. Specifically, the researcher is interested in investigating the strength and direction of the relationship between mentoring, organizational commitment, and job satisfaction. The major streams of the research addressed in this literature review include empirical research involving race and gender, job satisfaction and organizational commitment, and the constructs of mentoring. The following review of articles will chronologically highlight qualitative mentoring studies first, followed by chronological quantitative mentoring studies.

\section{Mentoring and Race and Gender}

Historically, mentoring research examined mentoring outcomes related to a general population (men, women, young, old, Black, White). Recently, mentoring research separated these various groups and examined the mentoring effects and outcomes exclusively to these groups. Atkinson, Casas, and Neville (1994) indicated, "Despite the widely acknowledged benefits to both protégé and mentor, mentoring has been restricted to a limited population, namely White 
men. European American women and ethnic minorities (irrespective of gender) historically have been underrepresented in the mentoring process" (p. 37). Dreher and Cox (1996) found that White MBA's reported forming mentoring relationships with White males, White and Black men with MBA's reported they were more likely to form mentoring relationships with White male mentors than women, and MBA's who established mentoring relationships with White men had higher compensation levels than those who did not. This appears to be an indication that mentors and protégés tend to select and participate in mentoring relationships with those who are similar to them. The following review of qualitative and quantitative articles examined the impact of race and gender as they relate to the mentoring relationship.

\section{Qualitative studies}

Crawford and Smith (2005) conducted a qualitative investigation to examine whether African American female administrators were given the opportunity to work with mentors at their institutions. The participants in the study were senior level African American women administrators $(N=7)$ located in New York. Crawford and Smith used open-ended interviews to operationalize the independent variable: mentoring experience. The dependent variable in the study was: job satisfaction (professional development, career development). Crawford and Smith used a qualitative two-tiered interview approach combined with field journals to analyze the data. Study findings indicated that respondents did not have a mentoring experience in their organization and believed they would have had greater job satisfaction if they did have a mentor in the organization. 
Tillman (2001) conducted a qualitative investigation to examine the experiences of African American faculty at predominately White institutions. The participants in the study were African American faculty $(N=10)$ from two different universities participating in a formal or informal mentoring relationship. Tillman used telephone surveys to operationalize the independent variables: current mentoring relationship, type of mentoring relationship (formal, informal), mentor's race, mentor's gender, willingness to participate, and number of mentors. The dependent variables in the study were: phases of relationship, mentor functions (career, psychosocial), and benefits of the mentorship. The researcher conducted unstructured in-depth interviews to measure the dependent variables.

The researcher used inductive analysis procedures involving reviewing interview recordings, transcripts, and field notes to analyze the data. Coding categories were used to analyze themes, patterns, and contradictions from the data. The coding categories were: (a) the five dimensions of mentoring, (b) the research questions, and (c) the narratives (language) of the participants. The study findings indicated that protégés benefited from the career and psychosocial functions provided by the mentors in terms of promotions and meeting tenured requirements, the mentoring relationship developed over time (e.g. Kram, 1985), and the participants whose mentors were White, reported feelings of isolation and alienation.

\section{Section Summary}

The qualitative articles in above section involved the concept of mentoring and the role of race and gender in mentoring relationships. The findings 
particular to race and gender were: African American female administrators reported not having a mentoring experience in their organization and believed they would have had greater job satisfaction if they did have a mentor in the organization. African American faculty at a predominately White institution indicated they benefited from the career and psychosocial functions provided by the mentors in terms of promotions and meeting tenured requirements. Protégés whose mentors were White reported feelings of isolation and alienation.

Quantitative studies

Dreher and Ash (1990) conducted an investigation to examine gender differences in mentoring experiences and the degree to which mentoring is differentially associated with the career outcomes of men and women. The participants in the study were business school graduates $(N=320)$ from the classes of 1976, 1977, 1978, 1981, 1982, and 1983. The participants were from two large universities located in the United States.

Dreher and Ash (1990) used a survey to operationalize the independent variable: gender. The dependent variables in the study were career outcomes (total income, promotions, pay level satisfaction, benefits satisfaction). The researchers used Heneman and Schwab's (1985) Pay Satisfaction Questionnaire (PSQ) scale to measure pay and benefit satisfaction and measured the scale on a 5-point Likert-type satisfaction scale ( 1 = very dissatisfied, $5=$ very satisfied $)$. Dreher and Ash used a correlational design involving multiple regression analysis to analyze the data. Study findings indicated men and women reported experiencing essentially the same frequency of mentoring activities from senior 
managers; individuals experiencing extensive mentoring relationships reported receiving more promotions, having higher incomes, more satisfaction with their pay and benefits than those experiencing less extensive mentoring relationships; and men reported higher levels of income earnings than women.

Thomas (1990) conducted an investigation to examine the experiences of Blacks and Whites who share the same organizational setting in gaining developmental relationships and cross-race and same-race relationships with regard to the kinds of support they receive. The participants in the study were public utility employees $(N=197)$. The researcher used a survey to operationalize the independent variable: race (Black, White), gender, and career experience. The researchers used the Career Experience Questionnaire to measure career experience. The researchers measured the questionnaire on a 5-point Likert-type scale ( $1=$ not at all, $5=$ very great extent $)$ to operationalize career development relationship. The dependent variables in the study were: psychosocial support (direction and guidance, affirmation of ideas, role modeling, mutuality and trust) and career support (exposure to upper level management, advocate for promotions, help in getting challenging work assignments, feedback on work, assistance in developing strategies). The researchers used the social support scales used by Ford and Wells (1985) and Malone (1985) to measure psychosocial support $(\alpha=.80)$ and career support $(\alpha=.80)$.

Thomas (1990) used a quasi-experimental design involving analysis of variance (ANOVA) and descriptive statistics to analyze the data. The study findings indicated Blacks reported having more developmental relationships 
outside their departments than Whites, $\left(x^{2}(4, N=454)=13.98, p=.001\right)$. Blacks reported having more developmental relationships with people who are not their immediate supervisors than Whites, $\left(x^{2}(4, N=454)=14.59, p=.001\right)$. Protégés reported receiving more psychosocial support from developmental relationships with persons of their own race than with persons of another race, $F(1,195)=$ $6.79, p<.001)$.

Atkinson, Casas, and Neville (1994) conducted an investigation to examine the mentoring experiences of ethnic minority clinical, counseling, and school psychologists who possessed a Ph.D. $(N=101)$. The researchers used a questionnaire to operationalize the independent variable: mentor ethnicity. The dependent variable in the study was the mentoring process/experience. To measure the dependent variable, the researchers used the four-part Mentor Experience Questionnaire to measure the dependent variable. The participants rated the mentoring relationship on a 5-point Likert-type agreement scale $(1=$ strongly disagree, 5 = strongly agree). The researchers used a quasiexperimental design involving one-way repeated measures analysis of variance (ANOVA) and the Tukey HSD post hoc test to analyze the data. The results of the study indicated that ethnic minority psychologists were prolific mentors of ethnic minority and European American protégés. More ethnic minorities indicated that helping another's career is a perceived benefit of mentoring and that it increases personal satisfaction.

Burke and McKeen (1996) conducted an investigation to compare the experiences of women who had female and male mentors and to examine the 
influence of cross-sex mentoring relationships. The participants in the study were female business graduates from a single university $(N=280)$ with a Masters of Business Administration (MBA) or bachelors in communication. Burke and McKeen used a questionnaire to operationalize the independent variables: mentor relationships (career development functions, psychosocial functions), descriptive characteristics of mentors and protégés, and descriptive characteristics of the mentor relationship. The researchers used an instrument developed by Pollack (1990) to measure career development and psychosocial functions. The coefficient alphas were: career planning (.84), taught skills (.56), sponsorship (.75), provided feedback (.78), and psychosocial functions (.81). The dependent variables in the study were work outcomes (job satisfaction, intention to quit, career satisfaction, job involvement, future career prospects). The researchers used an instrument developed by Quinn and Shepard (1974) to measure job satisfaction ( $\alpha=.84)$; an instrument developed by Burke (1991) to measure intention to quit ( $\alpha=.75$ ); an instrument developed by Greenhaus, Parasuraman, and Wormely (1990) to measure career satisfaction $(\alpha=.86)$; and future career prospects $(\alpha=.71)$; and an instrument developed Lodahl and Kenjer (1965) to measure job involvement $(\alpha=.70)$.

The researchers used a correlational design involving hierarchical regression analysis to analyze the data. The results of the study indicated that personal demographic characteristics (current marital status, year received bachelor's degree) were significant predictors of amount of career planning, $R^{2}=$ $.08, p=.05$, and visibility, $R^{2}=.16, p=.001$. There was statistical significance 
between demographic characteristics (worked part-time, had not worked continuously, obtained their Bachelor's degree earlier), $R^{2}=.06, p<.10$; organizational demographics (size of organization), $R^{2}=.14, p<.05$; and the sex of the mentor (female), $R^{2}=.17, p=.05$ with intention to quit.

There was statistical significance with organizational demographics (level of position) and job satisfaction, $R^{2}=.13, p<.01$. There was statistical significance with personal demographic (worked part-time), $R^{2}=.09, p<.01$, and with career satisfaction, $R^{2}=.20, p<.001$. There was statistical significance between organizational demographics (hours worked, level of position), $R^{2}=.21$, $p<.001$, and the sex of the mentor (female), $R^{2}=.23, p<.10$, with job involvement. There was statistical significance between personal demographics, $R^{2}=.12, p<.001$; organizational demographics (hours worked), $R^{2}=.18, p<$ .05; and mentor functions (work feedback), $R^{2}=.25, p<.05$, with career prospects. Additionally, managerial women with female mentors tended to receive more psychosocial functions, reported greater intentions to quit, earned lower salaries, tended to be in lower level managerial positions, had mentors who were significantly younger, and mentors tended to be closer to them in organizational level.

Dreher and Cox (1996) conducted an investigation to examine how race, gender, and mentoring experiences account for compensation outcomes among graduates of an MBA program. The participants in the study were African American, Hispanic American, Asian American, American Indians, and Anglo European American graduates $(N=1,018)$ from nine business schools in the 
United States. Dreher and Cox used a questionnaire to operationalize the independent variables: race, gender, and mentor-protégé hierarchal distinction. The dependent variable in the study was annual compensation. The researchers used a correlational design involving logistic regression analysis to analyze the data. Study findings indicated that White MBA's reported forming mentoring relationships with White males, men with MBA's reported they were more likely to form mentoring relationships with White male mentors than women, and MBA's who established mentoring relationships with White men had higher compensation levels than those who did not.

Collins, Kamya, and Trouse (1997) conducted an investigation to examine racial differences in mentoring relationships among White professionals and professionals of color in human service settings. The participants in the study were public and private sector employees $(N=430)$ working in urban, suburban, and rural Michigan and Ohio. Collins et al. (1997) used a questionnaire to operationalize the independent variables: race (White, non-White) and mentorship involvement. The dependent variable for the study was: mentor relationship (same-race, cross-race). The respondents reported their mentor's race. Collins et al. used a cross sectional study involving descriptive statistics to analyze the data. Study findings indicated that White respondents were slightly less likely to be mentored than participants of color. The percentage of social workers who were mentors was greater than social worker protégés of color. There was a significant association between the race of protégés than that of their mentors (race was an integral part of forming relationships), however, there 
was a stronger tendency for same race mentor relationships with White social workers. White social workers reported having mentors from all racial groups, African American and Asian American social workers reported their mentors were from within their own racial group, and Hispanic workers had more mentors who were White than Hispanic.

Ensher and Murphy (1997) conducted an investigation to examine the effects of similarity (race and gender), both actual and perceived, and the amount of contact between the mentor and protégé on the quality of mentor relationships. The participants in the study were summer intern protégés and volunteer staff mentors $(N=104)$ employed at a media organization. Ensher and Murphy used a questionnaire to operationalize the independent variables: mentorship (samerace, different-race), gender, perceived similarity of mentor/protégé, frequency of contact with mentor, and liking between mentors and protégés.

The researchers used a modified scale developed by Wayne and Ferris (1990) to measure liking between mentors and protégés $(\alpha=.86)$, used modified items developed by Turban and Jones (1988) and items developed by Liden, Wayne, and Stilwell (1993) to measure perceived similarity ( $\alpha=.95)$. The dependent variables in the study were: support (psychosocial, instrumental), satisfaction with mentor, and relationship maintenance.

The researchers used a modified version of Noe's (1998) Mentor Functions Scales to measure psychosocial support $(\alpha=.82)$ and instrumental support $(\alpha=.80)$. The coefficient alpha for satisfaction with mentor was .90. The researchers measured psychosocial support and satisfaction with the mentor on 
a 5-point Likert-type agreement scale ( 1 = strongly disagree, 5 = strongly agree $)$. The researchers measured likelihood of maintaining relationship on a 5-point Likert-type scale $(1=$ very unlikely, 5 = very likely $)$.

The researchers used an experimental design involving analysis of variance (ANOVA) and hierarchical multiple regression to analyze the data. The study findings indicated mentors paired with same-race protégés liked their protégés more than mentors paired with different-race protégés $F(1,52)=4.25, p$ $<.05,\left(\omega^{2}=.06\right)$. Results indicated protégés matched with same-race mentors gained more psychosocial and career support than protégés paired with differentrace mentors $F(1,72)=3.95, p<.05,\left(\omega^{2}=.04\right)$.

The result of the hierarchical regression indicated that perceived similarity accounted for a significant proportion of variance in satisfaction followed by liking of mentor, amount of career support, and psychosocial support, $R^{2}=.82$.

Additionally, perceived similarity and instrumental support predicted a statistically significant proportion of variance, $R^{2}=.27$.

Protégés who perceived themselves to be similar to their mentors reported a greater overall degree of satisfaction with the mentoring experience $r=.77, p<$ .001. Protégés who spent a greater amount of time with their mentors reported greater satisfaction with their mentor than protégés who had infrequent contact with their mentor $r=.48, p<.001$. Protégés who spent a greater amount of time with their mentor reported they were willing to maintain contact, after the program ended, with their mentor $r=.52, p<.001$. 
Dreher and Chargois (1998) conducted an investigation to examine the relationship between mentoring, the establishment of a mentoring relationship with a White-male manager, and the salary attainment of Historically Black College and University (HCBU) graduates. The participants in the study were graduates from Howard University School of Business $(N=170)$. The researchers used a survey to operationalize the independent variable: protégé status and mentor's race and gender. The dependent variable in the study was total annual compensation. The controlled variables in the study were: age, socioeconomic origin, occupational specialty, organization size, educational attainment, and racial-ethnic identity. Dreher and Chargois used a correlational design involving ordinary-least-squares regression to analyze the data. Study findings indicated that Black graduates with mentoring relationships with White males reported approximately $\$ 10,000$ income advantage over those without a mentoring relationship.

Blake-Beard (1999) conducted an investigation to examine the influence of mentoring on the career outcomes of Black and White women, specifically the effect of the race of the protégé on the mentoring received by Black and White women. The participants in the study were employed Black and White females ( $N$ = 195) who were graduates of Master of Business Administration (MBA) programs. Blake-Beard used a 42-item questionnaire developed by Dreher and Cox (1996) to operationalize the independent variable: mentoring relationship (career and psychosocial). The researcher measured the items on a 5-point Likert-type scale $(1=$ not at all, $5=$ to a very large extent). The dependent 
variables in the study were: compensation, promotion rate, compensation satisfaction, and satisfaction with career progress.

The researcher used Heneman and Schwab's (1985) Pay Satisfaction Questionnaire (PSQ) to measure compensation satisfaction $(\alpha=.96)$. The researcher measured the questionnaire on a 5-point Likert-type satisfaction scale $(1=$ very dissatisfied, $5=$ very satisfied $)$. The researcher measured satisfaction with career progress by asking how satisfied the participants were with their career progress and measured it on a 5-point Likert-type satisfaction scale ( $1=$ very dissatisfied, 5 = very satisfied).

The researcher used a correlation design involving multiple regression analysis to analyze the data. Study findings indicated that protégé race (White) was statistically significant to satisfaction of compensation, $\beta=.13, p<.001$, mentoring was statistically significant to predicting satisfaction with career progress, $\beta=.24, p<.01$, and protégé race (White) was a statically significant predictor of satisfaction with career progress, $\beta=.24, p<.01$. The standardized regression coefficients indicated that mentoring was significantly related to satisfaction with career progress, .24 $(p<.01)$. Protégé race was significantly related to compensation satisfaction, $.31(p<.001)$ and satisfaction with career progress .24 $(p<.01)$.

Ragins and Cotton (1999) conducted an investigation to examine the effects of gender composition and the type of mentoring relationships on mentoring functions and career outcomes. The participants in the study were male and female protégés and mentors $(N=614)$ employed in engineering, 
social work, and journalism. Ragins and Cotton used a questionnaire to operationalize the independent variables: prior mentoring relationships (formal, informal), mentor's gender, mentors position, and duration of relationship. The researchers used a 5-point Likert-type agreement scale ( 1 = strongly disagree, 5 = strongly agree) to measure the dependent variables: mentor functions (career development, psychosocial support) and mentoring outcomes (mentor satisfaction, career outcomes). The researchers used the Mentor Role Instrument, developed by Ragins and McFarlin (1990) to measure mentor functions.

The researchers used a correlational design involving hierarchical multiple regression analysis and a priori planned group contrast (Duncan Multiple Range test) to analyze the data. The researchers also used analysis of covariance (ANCOVA) to compare formal protégés, informal protégés, and individuals with no mentors on the career outcomes of compensation and promotion. Findings of the study indicated that protégés in informal mentoring relationships reported their mentors provided more career development functions; protégés with informal mentors received more psychosocial functions involving friendship, social support, role modeling and acceptance; and protégés with informal mentors received greater satisfaction with their mentors. Protégés with a history of informal mentors received higher levels of compensation, protégés with a history of male mentors received significantly greater compensation, and male protégés with female mentors reported less satisfaction with their mentors and were less likely to report their mentor accepted their professional development. 
Male protégés with female mentors received less challenging assignments and exposure, male protégés with male mentors received higher compensation, and protégés with a history of informal mentors received more compensation and promotion than individuals with no mentors and received more compensation than those with formal mentors.

Smith, Smith, and Markham (2000) conducted an investigation to examine: (a) if women and minorities make comparable use of mentors as do males and Whites, (b) if mentored women and minorities experience higher levels of affective commitment and lower intentions to turnover than nonproteges, and (c) if protégés in diversified mentoring relationships are mentored differently than protégés in homogeneous mentoring relationships. The participants in the study were university faculty $(N=765)$ who were either part of a mentoring relationship or were not part of a mentoring relationship. The independent variables in the study were: gender, race, and type of mentoring relationship. The dependent variables in the study were mentor functions (psychosocial, career-related), affective commitment, and intent to turnover.

Smith, Smith, and Markham (2003) used a questionnaire to operationalize the independent variables and used Noe's (1988) Mentoring Role Instrument to measure mentor psychosocial functions $(\alpha=.84)$ and career-related functions ( $\alpha$ $=.79$ ). The researchers measured the 21-item scale on a 5-point Likert-type extent scale $(1=$ from a very slight extent, $5=$ to a very large extent $)$. To measure affective commitment $(\alpha=.88)$ the researchers used Meyer and Allens's (1984) Affective Commitment Scale and used Cook, Hepworth, Wall and 
Warr's (1981) version of the Michigan Organizational Assessment Questionnaire to measure intent to turnover $(\alpha=.81)$. The researchers did not report the scaled anchors.

The researchers used a correlational design involving descriptive statistics (chi-square analysis) and analysis of variance to analyze (ANOVA) the data. Study findings indicated that female protégés reported they were more likely to be in a mentoring relationship than males. There was a statistical significance between mentoring and affective commitment, $r=.28, p<.009$, and mentoring and intent to turnover, $r=-.37, p<.001$, for White males. There was a statistical significance between mentoring and affective commitment, $r=.28, p<.004$, and mentoring and intent to turnover, $r=-.26, p<.007$, for White females.

Sosik and Godshalk (2000) conducted an investigation to examine the effects of gender composition of mentoring relationships on protégés' perceptions of the degree of role modeling and psychosocial and career development mentoring functions received. Participants in the study were adult students $(N=200)$ enrolled in a part-time Masters of Business Administration (MBA) program who were participating in a mentoring relationship (formal or informal). Sosik and Godshalk used a questionnaire to operationalize the independent variables: mentor gender and protégé gender. The dependent variables in the study were: idealized influence (behavior, attributes), career development, and psychosocial support. The researchers used the Multifactor Leadership Questionnaire (MLQ-5X) to measure idealized influence-behavior and influence-attributes and a scale developed by Noe (1988) to measure career 
development and psychosocial support. The researchers measured the MLQ-5X on a 5-point Likert-type frequency scale $(0=$ not at all, $4=$ frequently, if not always) and measured Noe's scale on a 5-point Likert-type agreement scale (1 = disagree strongly, 5 = agree strongly). The researchers used a quasiexperimental design involving multivariate analysis of covariance (MANCOVA) and analysis of covariance (ANCOVA) to analyze the data. Study findings indicated that protégés perceived mentoring relationships involving minority mentors provided fewer career development functions than relationships involving majority mentors.

Viator (2001) conducted a study to examine whether African Americans are able to obtain mentoring support in the public accounting profession. The participants in the study were: male and female African-American and White Certified Public Accountants (CPA's) and non-CPA's working in large public accounting firms $(N=293)$. Viator used a survey to operationalize the independent variables: mentor relationship (current, recent), mentorship (formal, informal), participant's race and organization level (African-American staff, African-American seniors, African-American managers, White managers), mentor and participant gender, mentor's race (White, African American), length of mentoring relationship, and mentor relationship (partner-mentor, senior managermentor, other-mentor). The dependent variables in the study were: perceived barriers (lack of access to potential mentors, lack of willingness by potential mentors), mentoring functions (career, psychosocial), and intentions to leave. The researcher used a scale developed by Collins and Killough (1992) to 
measure intention to leave $(\alpha=.85)$. The Cronbach alpha for the mentoring functions was .70. The researcher measured all items on a 5-point Likert-type agreement scale $(1=$ strongly disagree, $5=$ strongly agree $)$. Viator used a quasiexperimental design involving linear regression to analyze the data. Study findings indicated that compared to Whites, African American employees in public accounting firms were less likely to have informal mentors and were more likely to perceive barriers to obtaining a mentor. African American seniors and managers with formal mentors reported lower levels of protection and assistance. African American seniors and managers with formal mentors reported significantly lower levels of social support and African American protégés with African American mentors received more psychosocial support compared to African American protégés with White mentors.

Wallace (2001) conducted an investigation to examine the potential benefits of mentoring for female lawyers and to examine whether female protégés benefit more from having a male mentor or a female mentor in terms of the career and emotional outcomes. The participants in the study were male and female lawyers $(N=512)$. Wallace used a survey to operationalize the independent variables: protégé status, race (Black, White), and the protégé's and mentor's gender. The dependent variables in the study were: emotional outcomes (earnings, promotional opportunities, procedural justice, social integration) and career outcomes (career satisfaction, intent to stay in the profession, met expectations, work-non-work conflict). The researcher measured 
all dependent variables, besides earnings, on a 5-point Likert-type agreement scale $(1=$ strongly disagree, 5 = strongly agree $)$.

Wallace (2001)measured the dependent variables using the following scales: promotional opportunities (Price \& Muller, 1986), the coefficient alpha was .91; procedural justice (Muller \& Wallace, 1996), the coefficient alpha was .77; career satisfaction (Greenhaus, Parasuraman, \& Wormley, 1990), the coefficient alpha was .84; intent to stay in the profession (Price, 1990), the coefficient alpha was .85; and work-nonwork conflict (Kopelman, Greenhaus, \& Connolly, 1983), the coefficient alpha was .84 . The researcher did not identify scales that measured the dependent variables of met expectations $(\alpha=.88)$ and social integration $(\alpha=.80)$. The control variables in the study were: demographic characteristics, human capital investments, work context, and personality disposition.

The researcher used a quasi-experimental design involving ordinary leastsquares regression to analyze the data. Study findings indicated that protégés reported higher earnings, more promotional opportunities, greater procedural justice, and greater social integration than nonprotégés. Female protégés reported more satisfaction with their career and their professional expectations were met to a certain degree when compared to nonprotégés. Female protégés with male mentors reported more positive career outcomes than female protégés with female mentors. Female protégés with female mentors reported more positive emotional outcomes than female protégés with male mentors. 
Packard, Walsh, and Seidenberg (2004) conducted an investigation to examine whether the model underlying the mentoring of college women is dyadic in nature, as it is often in adolescence and school settings, or networking in nature as it is often in adulthood and workplace settings. The participants in the study were first-year students and seniors $(N=261)$ attending a liberal arts women's college in the New England region of the United States. Packard et al. (2004) used a survey to operationalize the independent variables: structure of mentoring (one mentor, multiple mentors, no mentors by choice), actual mentoring experience, and sources of mentoring (family, friends/peers, workcareer relations, extra-curricular adults, high school teachers, college professors, mental/physical health, formal mentor). The researchers measured structure of the mentoring and actual mentoring on a 6-point Likert-type agreement scale ( $1=$ strongly disagree, 6 = strongly agree). The dependent variables in the study were: functions of mentoring (career, psychosocial).

Packard, Walsh, and Seidenberg (2004) used a modified version of Ragins and McFarlin's (1990) Mentor Role Instrument (MRI) to measure the dependent variables. The variable's coefficient alphas were: sponsorship ( $\alpha=$ .78), counseling ( $\alpha=.91)$, challenge ( $\alpha=.91)$, and friendship $(\alpha=.95)$. Packard et al. used a quasi-experimental design involving descriptive statistics to analyze the data. Study findings indicated that first-year students were more likely to report they desired mentoring in the form of one mentor and college seniors desired multiple mentors; seniors were more likely than first-year students to report that they had multiple mentors; and college seniors used non-familial 
forms of mentoring relationships, whereas first-year students used mentors from their high-school environment. First-year students and seniors reported similar experiences of friendship, counseling, and sponsorship.

Ortiz-Walters and Gilson (2005) conducted an investigation to examine the mentoring experiences of African, Hispanic, and Native American protégés in academia. The participants in the study were students of color who possessed a Ph.D. $(N=163)$. The researchers requested the protégés to provide their mentor's e-mail address. If the mentor's e-mail addresses were not received, the protégés were encouraged to provide their mentor's demographic information. This activity yielded 99 demographically matched pairs and 74 matched pairs with full information. The mentors were the student's dissertation chair or a faculty member of the student.

Ortiz-Walters and Gilson (2005) used a questionnaire to operationalize the independent variables: surface-level similarity and deep-level similarity. The researchers used the 5-item, 7-point Likert-type agreement scale $(1=$ strongly disagree, 7 = strongly agree) developed by Ensher and Murphy (1997) to measure deep-level similarity for protégés $(\alpha=.93)$ and mentors $(\alpha=.87)$. The researchers used Tenenbaum, Crosby, and Gilner's (2001) 19-item scale to measure the dependent variables: psychosocial $(\alpha=.93)$, instrumental $(\alpha=92)$, and networking support $(r=.76)$. Exploratory factor analyses revealed eigen values greater than 1 for the separate factors. The researchers identified these three dependent variables as mentoring support. All mentoring support items were measured on a 7-point Likert-type scale $(1=$ not at all, $7=$ a great deal). 
For the remaining dependent variable, the researchers used a scale developed by Ragins, Cotton, and Miller (2000) to measure relationship satisfaction for protégés $(\alpha=.92)$ and mentors $(\alpha=.75)$.

To measure the mediating variable, interpersonal comfort, Ortiz-Walters and Gilson (2005) used two items from the 7-point Likert-type agreement scale (1 = strongly disagree, 7 = strongly agree) developed by Allen, Day, and Lentz (2002). The correlations for the items were .77 for the protégés and .86 for the mentors. To measure the mediating variable, commitment $(\alpha=.83)$, the researchers used a 4-item scale developed by Rusbult, Martz, and Agnew (1999). The researchers did not identify the scaled items. Mentor race, protégé and mentor gender, and gender similarity were the control variables in the study.

The researchers used a correlational design involving analysis of variance (ANOVA) and multivariate analysis of variance (MANOVA) to analyze the data. The study findings indicated that protégés of color with mentors who were of color reported more relationship satisfaction, interpersonal comfort, psychosocial, and instrumental support than protégés of color whose mentors were dissimilar. Protégés of color who perceived their academic mentors as more similar with regard to deep-level values reported more relationship satisfaction, interpersonal comfort, and support. Academic mentors of protégés of color who perceived their protégés as more similar with regard to deep-level values reported more relationship satisfaction, interpersonal comfort, and commitment; for protégés of color, interpersonal comfort mediated surface-level similarity and relationship satisfaction, psychosocial, and instrumental support. Protégés of color 
interpersonal comfort mediated perceived deep-level similarity and networking support.

Tharenou (2005) conducted an investigation to examine whether mentor career support assists women's career advancement more than it does men's and whether it has more positive effects than psychosocial support. The participants in the study were private and public sector employees $(N=3,434)$ in lower and middle levels of their organization. Tharenou used a survey to operationalize the independent variables: mentor gender and protégé gender. The dependent variables in the study were: career support (salary, promotions, managerial level, time since promotion, chance promotion, promotion last year), and psychosocial support. The researcher used the mentor support scale developed by Ragins and McFarland (1990) to measure mentor support and measured the scale on a 7-point Likert-type agreement scale $(1=$ strongly disagree, 7 = strongly agree). Tharenou used a correlational design involving moderated hierarchical regression analysis to analyze the data. Study findings indicated that the mentor's career support increased women's salary, $\beta=.05, p<$ .05 ; promotions $\beta=.06, p<.05$; time since promotion $\beta=.15, p<.01$; chance promotion $\beta=-.13, p<.001 ;$ and promotion last year $\beta=.11, p<.001$ more than it did men. The mentor's psychosocial support was less related to women's career advancement than career support in four of the six measures (salary, promotions, time since promotion, chance promotion, promotion last year). Section Summary 
The quantitative articles in the above section involved the concept of mentoring and the role of race and gender in mentoring relationships. Some findings particular to race and gender were: mentored White females reported greater levels of satisfaction with their compensation than Black females, reported greater levels of satisfaction with their career progress than Black women, and were slightly less likely to be mentored than participants of color. Female seniors attending an all women's college were more likely than first-year students to report that they had multiple mentors. There was a stronger tendency for same race mentoring relationships to develop between White social workers. African American and Asian American social workers reported their mentors were from within their own racial group. Female protégés reported they were more likely to be in a mentoring relationship than males. Men with MBA's reported they were more likely to form mentoring relationships with White male mentors than women and MBA's who had established mentoring relationships with White men had higher compensation levels than those who did not. Black business graduates with mentoring relationships with White males reported approximately a $\$ 10,000$ income advantage over those without a mentoring relationship. Academic mentors of protégés of color who perceived their protégés as more similar, with regard to deep-level values, reported more relationship satisfaction, interpersonal comfort, and commitment.

The findings of the qualitative and quantitative articles indicated that both race and gender are factors in mentoring relationships. It appears that when coupled together there is a negative relationship between mentoring relationships 
and race and gender. Depending on the race and gender of the protégé and mentor, the outcomes of the mentoring relationship may or may not be beneficial to the protégé.

Mentoring, Job Satisfaction, and Organizational Commitment Is there a relationship between organizational commitment and job satisfaction? Locke (1976) defined job satisfaction as “...a pleasurable or positive emotional state resulting from the appraisal of one's job and job experiences" ( $p$. 1307). Meyer \& Allen (1991) defined organizational commitment as, “...the view that commitment is a psychological state that (a) characterizes the employee's relationship with the organization and (b) has implications for the decision to continue membership in the organization" (p. 67). What impact does mentoring have on organizational commitment and job satisfaction? One could argue that the more a person is satisfied with their job the person might be more committed to the organization and less likely to leave the organization and vice-versa. Crawford and Smith (2005), Baugh and Scandura (1999), and Seibert (1999) measured job satisfaction as an outcome of mentoring. The findings indicated that job satisfaction is an outcome of positive mentorships. Heinmann and Pittenger (1996) found that the closeness of the relationship between the mentor and protégé was significantly related to organizational commitment. The following section chronologically highlights only quantitative mentoring articles that examined job satisfaction and organizational commitment.

Fagenson (1989) conducted an investigation to examine whether men versus women in higher versus lower level positions perceived equal benefits 
from being mentored or not being mentored in their career/jobs. The participants in the study were high and low-level positioned men and women $(N=246)$ working for a large healthcare organization. Fagenson used a questionnaire to operationalize the independent variables: organizational position (high level, low level), gender, mentor involvement, personality traits (masculinity, femininity), and mentor characteristics $(\alpha=.84)$. The researcher used the Personality Attributes Questionnaire (PAQ) to measure personality traits and measured the instrument on a 5-point bipolar scale. The researcher did not identify the scaled anchors. The dependent variables in the study were: career mobility/opportunity, recognition, security, and satisfaction. The researcher used the Job Diagnostic Survey developed by Hackman and Oldham (1980) and the Management Survey Audit developed by Kipnis and Schmidt (1980) to measure the dependent variables. The researcher measured both instruments on a 7-point Likert-type agreement scale. The researcher did not identify the scaled anchors. The coefficient alpha for the general satisfaction scale was .86 and .69 for the career opportunity/mobility scale. The coefficient alpha for the recognition scale, developed by Fagenson (1989b), was .77 and the coefficient alpha for the security scale was .87 .

Fagenson (1989) used a correlational design involving multivariate analysis of variance (MANOVA) to analyze the data. Study findings indicated that protégés rated themselves as having significantly more career mobility/opportunity, recognition, satisfaction, and promotions than non-protégés. High-level positioned individuals reported having more career 
mobility/opportunity and a greater degree of satisfaction than low-level positioned individuals.

Mobley, Jaret, Marsh, and Lim (1994) conducted a study to examine if having a mentor improves lawyers' job satisfaction and advancement opportunities and if so, does it differ for males and females. The participants in the study were lawyers $(N=589)$ working in the state of Georgia. The researchers used a survey to operationalize the independent variables: gender, race, and protégé status. To measure the dependent variables, the researchers created a scale ( $\alpha=.74)$ to measure mentoring benefits (advice and feedback on job performance, enhanced advancement prospects, personal camaraderie, increased prestige and job satisfaction). The researchers used a correlational design involving analysis of variance, linear multiple regression, and factor analysis to analyze the data. Study finding indicated lawyers with mentors reported greater job satisfaction than lawyers without mentors, $R^{2}=.11, \mathrm{p}<.001$. Heimann and Pittenger (1996) conducted a study to examine if a formal mentorship program could effectively socialize and enhance the commitment of new members of an organization. The participants in the study were faculty members $(N=44)$ from a Midwestern university participating in a formal mentoring program. Only the responses of the mentees were used to test the hypothesis.

The researchers used a questionnaire to operationalize the independent variable: formal mentorship. The dependent variables in the study were: organizational commitment, socialization, closeness of relationship ( $\alpha=.87)$, 
value of assigned mentorship program, and level of work interaction. To measure organizational commitment the researchers used the Porter, Steers, Mowday, and Boulian's (1974) Organizational Commitment Questionnaire and measured it on a 7-point Likert-type scale. The researchers did not identify the scaled anchors. To measure socialization, the researchers developed a 15-item questionnaire $(\alpha=.88)$. The researchers measured value of assigned mentorship program on a 5-point Likert-type value scale $(1=$ not at all valuable, $5=$ very valuable) and measured level of work interaction on a 5-point Likert-type scale (1 $=$ very little, $5=$ a great deal) .

The researchers used a correlational design involving hierarchical regression and path analysis to analyze the data. The results indicated there was a significant positive relationship between closeness of relationship and the mentee's perceived value of the mentorship program, there was a significant positive relationship between the level of the mentee's socialization and the closeness of the relationship, and there was a significant positive relationship between organizational commitment and closeness of relationship. Mentees reporting a higher quality of relationship, described themselves as benefiting more from the program, and reported higher levels of socialization and organizational commitment than those who did not have a close relationship with their mentors. Overall, the results indicated a significant positive relationship between closeness of relationship and socialization, commitment, and perceived value of the program. 
Baugh and Scandura (1999) conducted an investigation to examine the relationship between the number of mentors a protégé has and career-related attitudinal responses among protégés. The participants in the study were highranking managers and executives $(N=176)$ participating in a mentoring relationship. Baugh and Scandura used a questionnaire to operationalize the independent variables: demographic information, involvement in mentoring relationship (number of relationships, mentor currently), and organizational tenure. The dependent variables in the study were: organizational commitment, job satisfaction, career expectations, role conflict and role ambiguity, and perceived employment alternatives.

The researchers used the Organizational Commitment Questionnaire (Mowday, et al.,1979) to measure organizational commitment $(\alpha=.90)$, the Minnesota Satisfaction Questionnaire (Weis, Dawis, England, \& Lofquist, 1967) to measure job satisfaction $(\alpha=.90)$, an instrument developed by Scandura and Schriesheim (1991) to measure career expectations ( $\alpha=.80)$, an instrument developed by Rizzo, House, and Lirtzman (1970) to measure role conflict ( $\alpha=$ $.80)$ and role ambiguity ( $\alpha=.86)$, and an instrument developed by Katerberg and Green (1982) to measure perceived employment alternatives $(\alpha=.79)$. The researchers measured organizational commitment, role conflict and role ambiguity, and perceived employment alternatives on a 5-point type Likert-type agreement scale $(1=$ strongly disagree, $5=$ strongly agree $)$. The researchers measured career expectations on a 5-point Likert-type agreement scale $(1=$ 
strongly agree, 5 = strongly disagree) and job satisfaction on a 5-point Likert-type satisfaction scale $(1=$ very dissatisfied, $5=$ very satisfied $)$.

Baugh and Scandura (1999) used a quasi-experimental design involving multivariate analysis of covariance (MANCOVA) and discriminant analysis to analyze the data. Study findings indicated that having one or more mentoring relationships in the work place may result in greater commitment to the organization, greater job satisfaction, enhance career expectations, increase perceptions of alternative employment, and lower ambiguity about one's work role, Wilks' lambda $=.879, F(18,622)=1.61, p<.05,\left(\omega^{2}=.14\right)$.

Seibert (1999) used a longitudinal field experiment to examine the effectiveness of facilitated mentoring in terms of protégé's job satisfaction, organizational commitment, job stress, and self-esteem. The participants in the study were newly hired mechanical and electrical engineers $(N=109)$ working at a Fortune 100 company. Seibert used a survey to operationalize the independent variables: mentoring program participation (facilitated, not facilitated) and mentor behaviors (career, psychosocial). The researcher used a 21-item scale to measure career behaviors $(\alpha=.91)$ and psychosocial behaviors $(\alpha=.90)$. The researcher added a question to measure frequency of interaction and satisfaction of mentoring relationship ( $1=$ very dissatisfied, $5=$ very satisfied $)$. The dependent variables in the study were: job satisfaction, organizational commitment, work-role stress, and self-esteem at work.

Seibert (1999)used Smith, Balzer, Brannick, Chia, Eggleston, Gibson, Johnson, Josephson, Paul, Reilly, and Whalen's (1987a, 1987b) Job Descriptive 
Index (JDI) to measure job satisfaction $(\alpha=.95)$; Porter and Smith's (1970) Organizational Commitment Questionnaire (OCQ) to measure organizational commitment $(\alpha=.86)$; a 9-item scale developed by Kahn, Wolfe, Quinn, Snoek, and Rosental (1964) to measure role-stress ( $\alpha=.83$ ); and a scale developed by Quinn and Shepard (1974) to measure self-esteem at work. The researcher rated Quinn and Shepard's four bipolar adjectives on a 7-point continuum (successfulnot successfuI). The researchers measured the OCQ on a 7-point Likert-type agreement scale $(1=$ strongly disagree, $7=$ strongly agree $)$. The control variables in the study were: salary, relative salary, alternative employment opportunities, and hours worked per week.

Seibert (1999) used a quasi-experimental design involving one-way analysis of variance (ANOVA) and multiple regression to analyze the data. The study findings indicated individuals participating in the facilitated mentor program had higher job satisfaction than those not in the program. There was a positive relationship between the level of career mentoring received and job satisfaction for those participating in the facilitated mentor program. For individuals participating in the facilitated mentor program, there was a positive relationship between the level of psychosocial mentoring received and job satisfaction and a positive relationship between the level of psychosocial mentoring received and self-esteem at work.

Donaldson, Ensher, and Grant-Vallone (2000) conducted an investigation to examine the concurrent and somewhat longer-term relationships between mentoring, organizational commitment, and organizational citizenship behavior 
among ethnically diverse, non-professional protégés. The participants in the study were non-professional employees $(N=408)$ located in Southern California. Donaldon et al. (2000) used a questionnaire to operationalize the independent variables: instrumental and psychosocial support. The dependent variables in the study were: organizational commitment and organizational citizenship behavior.

The researchers measured organizational commitment with Mowday et al.'s (1979) Organizational Commitment Questionnaire and measured organizational citizenship behavior with Organ's (1988) Organizational Citizenship Behavior Questionnaire. The covariates in the study were: quality of mentoring relationships (low, medium, high) and contrasts (high versus moderate and low, low versus moderate and high). The researchers used an quasiexperimental design involving analysis of covariance (ANCOVA) and priori contrasts to analyze the data. The purpose of the priori contrast was to assess whether the protégés in high quality mentoring relationships had higher levels of organizational commitment and citizenship behavior than those in low or moderate quality mentoring and to asses if protégés in low quality mentoring relationships had significantly lower levels of organizational commitment and citizenship behavior than those in high or moderate level relationships. The study findings indicated that protégés with high quality mentoring relationships reported having higher levels of organizational commitment concurrently and over time than those in low or moderate quality mentoring relationships. Protégés in high quality mentoring relationships reported significantly more organizational 
citizenship behavior than those in low or moderate quality mentoring relationships.

Aremu and Adeyoju (2003) conducted a study to evaluate the effect of mentoring on commitment to job, job satisfaction, and gender in the Nigeria Police. The researchers used a cluster quota sampling to select the participants. The participants in the study were police $(N=592)$ working for the Nigeria Police. Aremu and Adeyoju (2003) used the Police Mentoring Scale $(\alpha=.69)$ to operationalize the independent variable: mentoring involvement. The researchers used the Police Job Commitment Scale $(\alpha=.73)$ and the Police Job Satisfaction Scale (.79) to measure the dependent variables: gender, job commitment, and job satisfaction. The respondents rated all scaled items on a 5-point Likert-type scale. The researchers used an ex-post facto design involving multiple regression analysis and descriptive statistics to analyze the data. The study findings indicated a positive significance with mentoring and job commitment $F(32,1297)=1.562, p<.05$ and mentoring and gender $F(32,1297)=1.560, p<$ .05. Findings also indicated there was a statistical significant difference between the mentored male and female in regard to job satisfaction with mentored females reporting more job satisfaction $(M=54.63, S D=2.31)$ than men $(M=$ 47.21, $S D=3.01)$.

Stallworth (2003) conducted an investigation to evaluate the usefulness of a multidimensional conceptualization of organizational commitment in the public accounting environment and to examine the influence of mentoring relationships on each dimension. The participants in the study were accountants $(N=107)$ 
who were members of the American Institute of Certified Public Accountants (AICPA). The researcher used a survey to operationalize the independent variables: role modeling and mentoring relationships. To measure the dependent variable, organizational commitment (affective, continuance, high sacrifice, low alternative, normal commitment) and intention to leave, the researcher used scales developed by Allen and Meyer (1990) and Meyer, Allen, and Smith (1993). The coefficient alpha for the organizational commitment scale was .81 and .87 for the intention to leave scale. The researcher did not specify the scaled anchors.

The researcher used a correlational design involving factor analysis and multiple regressions to analyze the data. Study findings indicated affective commitment is the most descriptive dimension of public accountants, antecedent variables for each dimension of commitment were significant, and role modeling was significant to affective, normative commitment, and the low alternative subdimension. There was a positive significant relationship between mentoring and affective commitment and the low alternative commitment sub-dimension. Affective commitment was the strongest predictor of intention to leave.

Joiner, Bartram, and Garreffa (2004) conducted a study to examine the relationships among formal mentoring, perceived career success, organizational commitment, and the effect on protégés turnover intentions. The participants in the study were managers participating in a formal mentoring program $(N=25)$ in a large recruitment and advertising industry. Joiner et al. (2004) used a survey to operationalize the independent variable: mentor functions (coaching, acceptance 
and confirmation, role modeling, counseling, protection, exposure and visibility, sponsorship, challenging assignments and friendship). The researchers used a modified version of Noe's (1998) 29-item scale to measure mentor functions. The dependent variables in the study were: organizational commitment, perceived career success, and intention to leave. The researchers used Mowday et al.'s (1979) 15-item scale to measure organizational commitment, Turban and Dougherty's (1994) 4-item scale to measure perceived career success, and Price and Mueller's (1981) one-item scale to measure intention to leave. The researchers measured organizational commitment and perceived career success on a 5-point Likert-type agreement scale (strongly agree, strongly disagree). The researchers did not specify the scaled anchors. The researchers measured intention to leave on a 5 -point Likert-type scale $(1=$ definitely will not, $5=$ definitely will). The researchers used an open-ended question ("What do you value in your mentor?") to gain insight to the benefits of mentoring perceived by the protégé.

Joiner, Bartram, and Garreffa (2004) used a correlational design involving descriptive statistics to analyze the quantitative data. The researchers did not identify the method used to analyze the qualitative data. Study findings indicated a negative association between mentoring and the protégés intention to leave their current organization. There was a positive association between mentoring and the protégés perceived career success, a positive relationship with perceived career success and organizational commitment, a negative relationship between organizational commitment and the protégés intention to leave, and a negative 
relationship between perceived career success and the employee's intention to leave. The qualitative analysis revealed that protégés valued mentors who were career oriented and provided psychosocial functions.

\section{Section Summary}

The quantitative articles in the above section involved the concept of mentoring related to job satisfaction and organizational commitment. Some of the particular outcomes of mentoring related to job satisfaction and organizational commitment were: there was a positive significance with mentoring and job commitment and gender, mentored men were more committed to their job than mentored women, mentored women showed more satisfaction with their job than mentored men, and mentoring predicted job commitment. Multiple mentors may result in greater commitment to the organization, greater job satisfaction, and enhanced career expectations. Protégés with high quality mentoring relationships reported having higher levels of organizational commitment concurrently and protégés rated themselves as having significantly more career mobility/opportunity, recognition, satisfaction and promotions than non-protégés. Mentored Nigerian police officers were more committed to their jobs and mentoring predicted Nigierian police officers commitment to their jobs.

Additional findings revealed a negative association between mentoring and the protégés intention to leave their current organization; a positive relationship with perceived career success and organizational commitment; and there was positive relationship between mentoring, perceived career success, and organizational commitment. Lawyers with mentors reported greater job 
satisfaction than lawyers without mentors. Individuals participating in a facilitated mentor program had higher job satisfaction than those not in a mentor program, there was a positive relationship between the level of career mentoring received and job satisfaction for those participating in a facilitated mentor program, there was a positive relationship between the level of psychosocial mentoring received and job satisfaction for individuals participating in a facilitated mentoring program, and there was a positive relationship between the level of psychosocial mentoring received and job satisfaction for individuals participating in a facilitated mentoring program. Protégés reported higher job satisfaction than non-protégés, there was a positive significance between mentoring and affective commitment, and there was a significant positive relationship between closeness of relationship (mentorship) and organizational commitment.

The overall findings indicated there is a significant relationship between mentoring, job satisfaction, and organizational commitment. Protégés reported they had more job satisfaction and more organizational commitment than nonmentored individuals. Additionally, multiple mentors positively impacted the protégés organizational commitment and job satisfaction. The follow review of articles examined mentoring as a construct in a variety of settings.

\section{Mentoring Constructs}

What makes a mentoring relationship successful? Do individuals receiving mentoring have more benefits than those who do not? Specific dynamics of the mentoring relationship may play an important role in the mentoring experience. Things such as (a) the length of the relationship, (b) formal or informal 
mentorships, (c) experience of the mentor, (d) particular phases of the mentoring relationship, and (e) quality of the relationship (Chao, 1997; Eby, McManus, Simon, \& Russell, 2000; Kram, 1988), for example, impact the mentoringship and mentoring outcomes. In mentorships, the success of the mentoring experience and costs and benefits falls not only on the mentor, but the protégé also. To provide breadth to the study and to examine mentoring at macro level that addresses some of the aforementioned conditions, the following review of articles provides an assortment of qualitative and quantitative studies that examine the mentoring construct in various organizational contexts.

Qualitative studies

Kram (1983) conducted a qualitative investigation to examine the successive phases of the developmental relationship of mentoring. The participants in the study were managers $(N=33)$ employed at a large northeastern public utility company. Kram used interviews to study the independent variables: management level (young, senior) and developmental relationship. The dependent variables in the study were career functions (sponsorship, exposure-and-visibility, coaching, protection, challenging assignments) and psychosocial functions (role modeling, acceptance-and confirmation, counseling, friendship). The researcher used a constant comparative method of analysis to analyze the data. Study findings indicated that the stages of the mentor relationship were: initiation (a period of six months to a year when the relationship is started), cultivation (two to five years during which time the range of functions provided expands), separation (six months to two 
years during which time the established nature of the relationship is altered by structural changes), and redefinition (an infinite period after the separation phase during which time the relationship evolves into a new form that is significantly different from the past or the relationship ends entirely).

Allen and Poteet (1999) conducted an investigation to examine the perceived characteristics of an ideal mentor and to investigate what mentors and protégés can do to facilitate the most effective mentoring relationship. The participants in the study were mentors $(N=27)$ from five different organizations in five different industries (municipal government, health-care, financial, communications, manufacturing). The researchers used semi-structured interviews to operationalize the independent variables: mentor and protégé experience. The dependent variables in the study were: ideal mentor characteristics (e.g. listening and communication skills, patience, honesty and trustworthy) and effective mentoring (set goals, allow mistakes, flexibility). The researchers used a three-step content-analytic procedure to analyze the qualitative data. Step one was to categorize similar comments, step two was to re-categorize comments using Cohen's Kappa, and step three was to collapse dimensions into similar themes.

Study findings indicated that ideal mentoring characteristics were: listening and communication skills, patience, knowledge of the company and industry, and the ability to understand others. These characteristics were followed by honesty, having a genuine interest in mentoring, being people oriented, and having structure and vision. The findings suggested that for mentoring to be effective, 
mentors and protégés should have open communication systems, set standards and goals, establish trust, care for and enjoy each other, allow mistakes, take training programs, participate in the mentorship, and be flexible.

Eby and McManus (2004) conducted a qualitative study to develop a continuum that maps the mentor's relational problems and negative experiences of protégés and to examine how both reported typicality of the overall negative experience with a protégé, as well as its perceived impact on the relationship as a whole. The participants in the study were mentors $(N=90)$ employed in a variety of organizations. Eby and McManus used a 360-degree feedback system to examine the independent variables: mentoring relationships (positive, negative, beneficial), number of protégés, gender of protégé, length of relationship, and on-going relationship. One purpose of 360-degree feedback is to heighten the manager's self-awareness of his/her skills to increase performance (Maurer, Barbeite, \& Mitchell, 2002). The dependent variables in the study were: perceptions of negative experiences, typicality, perceived impact, mentor relationship satisfaction, and relationship longevity. The researchers measured typicality on a 3-point Likert-type scale $(1=$ not at all typical, $3=$ very typical); perceived impact on a 3-point Likert-type scale $(1=$ not at all, $3=$ not very much); and mentor relationship satisfaction on a 5-point Likert-type satisfaction scale ( $1=$ very unsatisfactory, $5=$ very satisfactory $)$.

The researchers used content analysis and descriptive statistics to analyze the data. Study findings indicated marginally effective relationship experiences were the most frequently reported followed by ineffective 
relationship experiences, and dysfunctional experiences. Additionally, there was a negative association between greater impact and lower relationship satisfaction and a negative association between perceived impact and relationship satisfaction.

\section{Section Summary}

The qualitative articles in the above section involved an assortment of empirical research articles highlighting mentoring constructs. Some of the particular findings were: there are four stages of the mentoring relationship (initiation, cultivation, separation, redefinition); listening and communication skills, patience, knowledge of the company and industry, and the ability to understand others are the ideal mentoring characteristics; and marginally effective mentoring relationship experiences were the most frequently reported followed by ineffective relationship experiences, and dysfunctional experiences.

\section{Quantitative studies}

Burke (1984) conducted an investigation to examine mentoring relationships in organizations as experienced by protégés. The participants in the study were men and women participants in management development courses $(N=80)$. Burke used a questionnaire, comprised of qualitative and quantitative questions, to operationalize the independent variable: mentoring experience (prevalence of mentors, sex of mentors and protégés, age of mentors and protégés, career stage of mentor-protégé relationship, organizational relationship of mentor and protégé, emergence and duration of mentor relationship, and situational and organizational characteristics associated with mentors). The 
dependent variables in the study were: influence of mentor on the protégé and their career, perceived job performance, satisfaction and career satisfaction and success, what did they learn from their mentor, what was in it for the mentor, and functions served by mentors. The researcher used a quasi-experimental design and employed descriptive statistics to analyze the quantitative data. The researcher did not indicate the analysis of the qualitative data.

Older mentors were less likely to perform psychosocial functions or activities, $r=-.23, p<.01$. The larger the gap in ages between mentors and protégés, the less likely the mentor performed psychosocial functions, $r=-.29, p$ $<.05$, and role model functions, $r=-.18, p<.10$. The length of the relationship with one's mentor tended to be associated with greater performance of career development, $r=.23, p<.10$, and psychosocial functions, $r=20, p<.10$, by the mentor. Mentors performing career development, $r=.28, p<.05$; psychosocial, $r$ $=.42, p<.10$; and role model functions, $r=.55, p<.10$, had greater influences of a personal nature. Mentors performing more career development, $r=.44, p<$ .05; psychosocial, $r=.42, p<.05$; and role model functions, $r=.38, p<.05$, had greater influences of a career nature. Protégés whose mentors served more psychosocial, $r=.24, p<.05$, and role model functions, $r=.33, p<.01$, were more likely to report their mentors had an influence on their career aspirations. Protégés whose mentors served more career development, $r=.33, p<.01$, and psychosocial functions, $r=.28, p<.05$, reported their mentors had more influence on their career progress. Protégés who had greater career success tended to report their mentors provided more career development, $r=.18, p<$ 
.10 , and role model functions, $r=.18, p<.10$. Mentors who served greater role model function were more likely seen as more satisfied in their jobs, $r=.18, p<$ .10 ; as high performers, $r=.24, p<.05$; and more successful in their careers, $r=$ $.36, p<.05$

Additionally, $t$ tests indicated male protégés had more mentors, were older, and indicated their mentors had greater influence on their career choice. Female protégés indicated their mentors performed more psychosocial functions. Female mentors had a greater impact on career aspirations of their protégés and performed more psychosocial functions. Female protégés reported their male mentors had greater career influence on career progress and saw their male mentors as more satisfied with their job. Female mentors had greater influence on their protégé as female mentors engaged in more psychosocial activities.

Noe (1988) conducted an investigation to examine the influence of protégés' job and career attitudes, the gender composition of the mentoring dyad, the amount of time spent with the mentor, and the quality of the interaction with the mentor on the psychosocial and career benefits protégés gained from participating in assigned mentoring relationships. The participants in the study were mentors and protégés in the education field participating in a career developmental program $(N=182)$. Noe used a survey to operationalize the independent variables: locus of control (internal, external), job involvement, career planning, relationship importance, mentoring dyad gender composition, quality interaction, and time spent with mentor. The researcher measured job involvement and relationship importance on a 5-point Likert-type agreement 
scale (1 = strongly disagree, 5 = strongly agree $)$; measured locus of control and career planning on a 4-point Likert-type agreement scale $(1=$ strongly disagree, 4 = strongly agree); and measured quality interaction and time spent with on a 5point Likert-type extent scale ( 1 = a very slight extent, 5 = a very large extent $)$. The dependent variable in the study was: mentoring functions (career, psychosocial). The researcher measured these variables on a 5-point Likert-type scale ( $1=$ to a very slight extent, $5=$ to a very large extent). Noe used a correlational design involving exploratory factor analysis and hierarchical multiple regression to analyze the data. Psychosocial and career mentoring explained $82 \%$ of the variance. The study findings indicated that the more time a protégé spends with the mentor and the more effectively the protégé utilizes the mentor, the greater the psychosocial outcomes the protégé obtained from the mentorship.

Whitely, Dougherty, and Dreher (1991) conducted an investigation to examine the relationship of career mentoring to the promotions and compensation received by managers and professionals. The participants in the study were Master of Business Administration (MBA) graduates $(N=404)$ from the classes of 1980-1982 and were employed full-time. Whitely et al. (1991) used a survey to operationalize the independent variables: socioeconomic status (underclass, working poor, working class, mid-level, upper-level, social elite) and career mentoring practices (coaching, exposure and visibility, protection, personal support, sponsorship). The researchers used statements from Kram's (1985) scale to measure career-mentoring practices $(\alpha=.85)$ and measured it on 
a 5-point Likert-type scale. The researchers did not specify the scaled anchors. The dependent variables in the study were: number of promotions and current total compensation. The control variables in the study were: human capital investment, degree, work experiences, job source, continuous work history, staff positions, functional area, organization size, industry, average hours worked, expected future income, work centrality, gender, marital status, university attended, and years since graduation.

The researchers used a correlational design involving moderated regression analysis to analyze the data. Study findings indicated the standardized regression coefficient for promotion rate was .19 $(p<.01)$ and .13 $(p<.01)$ for total compensation. Socioeconomic origin moderated the relationship between career mentoring and promotion rates, $F(2,178)=5.23, p<$ .01 , with a change in $R^{2}=.023$. Career mentoring did predict the number of promotions for employees from upper-class backgrounds (change in $R^{2}=.293$ ) than employees from lower-class backgrounds (change in $R^{2}=.086$ )

Turban and Dougherty (1994) conducted an investigation to examine whether protégés' characteristics influenced the mentoring they received, whether mentoring received is related to career attainment and perceived career success, and whether protégé gender is related to attempts to initiate mentoring relationships and the receipt of mentoring. The participants in the study were graduates who obtained their bachelor's degree in management $(N=197)$ during the years of 1979 through 1988. Turban and Dougherty used a survey to operationalize the independent variables: protégés characteristics (locus of 
control, self-monitoring, emotional stability), initiation of mentoring, and mentoring received (psychosocial, career). The researchers used a scale developed by Spector (1988) to measure locus of control ( $\alpha=.79)$, a scale developed by Snyder (1987) to measure self-monitoring ( $\alpha=.81$ ), a scale developed by Rosenberg (1965) to measure self-esteem $(\alpha=.82)$, a scale developed by Levin and Stokes (1989) to measure negative affectivity $(\alpha=.87)$, and a scale developed by Dreher and Ash (1990) to measure psychosocial functions ( $\alpha=$ .93) and career functions $(\alpha=.88)$. The coefficient alpha for initiation of mentoring was .82. The researchers measured self-monitoring on a 7-point Likert-type agreement scale ( $1=$ strongly disagree, $7=$ strongly agree $)$. The dependent variables in the study were: career attainment (salary, promotions) and perceived career success $(\alpha=.87)$. The control variables in the study were: education level, work history, years since graduation, functional area, organization size, gender, and marital status. Turban and Dougherty used a correlational design involving a principal component analysis and confirmatory factor analysis to analyze the data.

Results of the study indicated that individuals who were internals in locus of control, high on self-monitoring, and high in emotional stability, initiated more mentoring relationships than individual who were externals of locus of control. Findings also indicated that initiation of mentoring influenced the type of mentoring received. There was a positive relationship between the type of mentoring received by an individual and his or her career attainment and 
perceived career success. There was a positive relationship between career attainment and career success.

Chao (1997) conducted a longitudinal investigation to examine the linkage of mentorship phases, functions, and outcomes to determine if mentorship phases are associated with different mentorship functions and outcomes. The participants in the study were engineering alumni from a Midwestern university in a small private institute $(N=428)$ participating in a mentorship within their organization. Chao used a survey to operationalize the independent variables: mentor condition (number of mentors) and mentoring phase (initial, learning, independence, redefinition). The dependent variables in the study were: mentor functions (psychosocial, career development), job satisfaction, career outcomes, organizational socialization (performance proficiency, people, politics, organizational goals, history), mentorship length, and income. Chao used the Minnesota Satisfaction Questionnaire to measure job satisfaction and measured it on a 5-point Likert-type satisfaction scale $(1=$ very dissatisfied, $5=$ very satisfied). The researcher used a 5-point Likert-type agreement scale to measure career outcomes $(1=$ strongly disagree, $5=$ strongly agree $)$. The researcher used a quasi-experimental design involving multivariate analysis of covariance (MANCOVA) to analyze the data. The study findings indicated that protégés in different phases of the mentorship perceived different levels of psychosocial and career-related support from their mentors, and except for first-year income, former and current protégés reported higher levels of job and career outcomes than their non-protégés. 
Fagenson-Eland, Marks, and Amendola (1997) conducted an investigation to examine the influence of the mentor-protégé relationship structure and experience factors on perceptions of mentoring. The participants in the study were mentors and protégés participating in formal and informal mentoring relationships $(N=81)$ in two intermediate size technology organizations. One company participated in a formal mentoring program and the other participated in an informal mentoring program. Fagenson-Eland et al. (1997) used a survey to operationalize the independent variables: gender, ethnic/racial background, organizational level, organizational tenure, age, education, number of years in the mentoring relationship, the total number of mentoring relationships, and whether the mentor was the protégé's boss. The dependent variables in the study were: career guidance, psychosocial support, role modeling, and frequency of communication. The researchers measured all dependent variables, except frequency of communication, with the Mentoring Functions Questionnaire developed by Scandura and Katterberg (1988). The researchers measured frequency of communication with an 11-item scale with anchors ranging from several times a week to never. The scaled anchors were not identified. The researchers used a correlational design involving two-step hierarchical regression to analyze the data.

Study findings indicated that more experienced mentors reported providing greater levels of career guidance, $r=.69, p<.001$, and those reporting a longer lasing current mentor-protégé relationship reported greater levels of career guidance, $r=.61, p<.001$, and role modeling, $r=.53, p<.01$. Formally 
assigned mentors reported communicating less frequently with protégés than informally assigned mentors $r=-.40, p<.05$. Mentors whose protégés were their subordinates reported providing more career guidance, $r=.49, p<.05$, and communicating more frequently with their protégés, $r=-.41, p<.05$, than mentors whose protégés were not their subordinates. Protégés in formal mentoring relationships reported receiving less psychosocial support than protégés in informal mentor relationships $r=-.41, p<.05$. Protégés who were their mentors' subordinates reported receiving more career guidance, $r=.71, p<$ .001 ; psychosocial, $r=.62, p<.001$; and communication, $r=-.47, p<.01$, than non-subordinate protégés. The hierarchical regression revealed the following: $R^{2}$ $=.647$ for career guidance, $R^{2}=.213$ for psychosocial support, $R^{2}=.351$ for role modeling, and $R^{2}=.338$ for frequency of communication.

Orpen (1997) conducted an investigation to examine the effects of a twoyear formal mentoring program in a medium-sized manufacturing company on work motivation, organizational commitment, and job performance of protégés. The participants in the study were senior managers who were mentors and first level managers or supervisors who were protégés $(N=78)$. Orpen used a questionnaire to operationalize the independent variables: opportunity to interact and closeness of the relationship. The researcher measured opportunity to interact on a 5-point Likert-type agreement scale $(1=$ strongly disagree, $5=$ strongly agree) and measured closeness of the relationship on a 5-point Likerttype scale $(1=$ very little, $5=$ very much $)$. The dependent variables in the study were: work motivation, organizational commitment, and job performance. 
The researcher used 6-items from Hackman and Oldham's (1998) Job Diagnostic Survey to measure work motivation and a scale developed by Allen and Meyer (1990) to measure organizational commitment. The researcher used a correlational design involving a stepwise multiple regression to analyze the data. Study findings indicated that there was a positive significant relationship between closeness of relationship, $r=.56, p<.001$; work motivation, $r=.39, p<$ .05 ; and organizational commitment, $r=.32, p<.001$. There was also a positive significant relationship between closeness of the relationship with work motivation, $r=.46, p<.01$, and organizational commitment, $r=.36, p<.05$. The beta coefficients for work motivation (.37) and organizational commitment (.30) were significant $(p<.05)$

Scandura (1997) conducted an investigation to examine mentorships that are built upon the assumption that organizational justice is an important consideration in the development of effective mentorships in the workplace. The participants in the study were employees $(N=197)$ working for Australian companies. Scandura used a survey to operationalize the independent variables: mentoring experience, career development ( $\alpha=.86)$, psychosocial support ( $\alpha=$ $.86)$, and role modeling $(\alpha=.83)$. The researcher measured the independent variables on a 5-point Likert-type agreement scale $(1=$ strongly disagree, $5=$ strongly agree). The dependent variable in the study was organizational justice (distributive, procedural). Scandura used scales developed by Moorman (1991) to measure distributive justice $(\alpha=.85)$ and procedural justice $(\alpha=.71)$. The researcher measured the scales on a 5-point Likert-type agreement scale $(1=$ 
strongly disagree, 5 = strongly agree). The control variables in the study were: career expectations, job satisfaction, and organization commitment. Scandura used Weis, Dawis, England, and Lofquist's, (1967) short form of the Minnesota Satisfaction Questionnaire (MSQ) to measure job satisfaction $(\alpha=.77)$ and measured the it on a 5-point Likert-type agreement scale $(1=$ strongly disagree, $5=$ strongly agree). The researcher used Mowday et al.'s (1979) OCQ to measure organizational commitment $(\alpha=.80)$ and measured career expectations $(\alpha=.77)$ on a 5-point Likert-type agreement scale $(1=$ strongly disagree, $5=$ strongly agree).

Scandura (1997) used a quasi-experimental design involving a one-way analysis of variance (ANOVA) to examine the differences between protégés and non-protégés scores on the distributive and procedural justice scales; partial correlations to examine career development, psychosocial and role modeling; and hierarchical multiple regression analysis to examine the variance of career development, psychosocial support, and role modeling related to career expectations of protégés, protégé job satisfaction, and protégé organizational commitment. Study findings indicated that protégés reported significantly higher levels of procedural justice $(M=21.18)$ than non-protégés $(M=19.04)$ controlling for organization type, $F(2,90)=.254, p<.05$. Career development mentoring correlated significantly and positively with distributive justice, $r=.31, p<.01$, and procedural justice, $r=.26, p<.01$. Psychosocial mentoring correlated significantly and positively with distributive justice, $r=.26, p<.01$, and procedural justice, $r=.18, p<.01$. Role modeling correlated significantly and 
positively with distributive justice, $r=.24, p<.01$, and procedural justice, $r=.25$, $p<.01$.

Career development mentoring accounted for significant variance in career expectations, $F(2,154)=4.28, p<.001$, and organizational commitment, $F(2,154)=12.87, p<.001$. For career expectation $R^{2}=.10$ and for organizational commitment $R^{2}=.25$. Psychosocial mentoring contributed significantly to career expectations, $F(2,154)=4.12, p<.01$; job satisfaction $F(2,154)=24.33, p<.001$ and organizational commitment $F(2,154)=12.44, p<.001$. For career expectations $R^{2}=.10$, for job satisfaction $R^{2}=.39$, for organizational commitment $R^{2}=.25$. Role modeling mentoring significantly contributed to job satisfaction, $F(2,154)=23.96, p<.001$, and organizational commitment, $F(2,154)=12.26, p$ $<.001$. For job satisfaction $R^{2}=.39$ and $R^{2}=.24$ for organizational commitment. Ragins and Scandura (1999) conducted an investigation to examine three specific mentoring concepts: (a) the specific costs and benefits of mentoring and the relationship of these expectations for future intentions to be a mentor; (b) to explore the relationship between experience as a mentor or a protégé and future intentions to mentor; (c) and to assess the complex dynamics among expected costs and benefits of mentoring relationship, prior experience in mentoring relationships, and future intentions to enter a mentoring relationship. The participants in the study were male and female executives $(N=275)$ working in predominately manufacturing and service organizations. Ragins and Scandura developed a survey instrument to operationalize the independent variables: mentoring costs (more trouble than worth, dysfunctional relationship, nepotism, 
bad reflection, energy drain) and benefits (rewarding experience, improved job performance, loyal base of support, recognition by others, generativity).

The researchers conducted a pretest for the cost scale $(\alpha=.83)$ and benefits $(\alpha=.89)$. The dependent variable in the study was intention to mentor and the researchers measured it on a 7-point Likert-type agreement scale $(1=$ strongly disagree, 7 = strongly agree). The researchers added two new items with two items from Ragins and Cotton's (1993) willingness to mentor scale ( $\alpha=$ .90). The researchers used a correlational design involving hierarchical multiple regression and multivariate analysis of covariance (MANCOVA) to test the relationship between experience in mentoring relationships and expected costs and benefits.

Study findings indicated that mentorship experience had a significant relationship with expected costs, Pillai's criterion $=0.37, F(3,122)=4.29, p<$ .0001 , and benefits, Pillai's criterion $=.44, F(3,122)=4.13, p<.0001$. The results of the hierarchical regression indicated that intention to mentor was significantly related to greater anticipated benefits, $\beta=.48, p<.001$, and fewer anticipated costs, $\beta=-.20, p<.001$. Additionally, participants with mentor and protégé experience reported greater future intentions to mentor than those lacking experience $\beta=.25, p<.001$.

Eby, McManus, Simon, and Russell (2000) conducted an investigation to examine what percentages of protégés report having at least one negative mentoring experience and what are the categories that best describe the negative mentoring experiences reported by protégés. The participants in the 
study were participants of two executive development programs $(N=277)$. Eby et al. (2000) used a survey to operationalize the independent variables: mentoring relationship involvement, perceived mentor background and attitude similarities (similar, dissimilar), and mentor type (supervisor mentor, nonsupervisor mentor). The dependent variable in the study was mentor relationship experience (positive, negative). The researchers used content analysis and coding to analyze the qualitative data and descriptive statistics to analyze the quantitative data. The study findings indicated protégés were more likely to report their mentor had dissimilar attitudes, values, and beliefs when describing their most negative mentoring experience compared to their most positive mentoring experience.

Ragins, Cotton, and Miller (2000) conducted an investigation to (a) compare career and job attitudes among individuals with formal mentors, informal mentors, and no mentors and (b) to examine the effects of the design and the quality of mentoring programs on career and work attitudes and on the satisfaction obtained from mentoring relationships. The participants in the study were male and female social workers, engineers, and journalists $(N=1,162)$ participating in formal and informal mentoring relationships. Ragins et al. (2000) used a survey to operationalize the independent variables: mentorship involvement, mentoring type (formal, informal) protégé relationship satisfaction, perceived effectiveness of formal mentoring program, and design of formal mentoring programs. The researchers used the Satisfaction with Mentor instrument $(\alpha=.83)$ developed by Ragins and Cotton (1999) to measure 
relationship satisfaction. The researchers measured the instrument on a 7-point Likert-type agreement scale ( $1=$ strongly disagree, $7=$ strongly agree $)$. The researchers measured perceived effectiveness of formal mentoring program ( $\alpha=$ .79) on a 7-point Likert-type agreement scale (1 = strongly disagree, $7=$ strongly agree). The dependent variables for the study were: career and job attitudes (career commitment, job satisfaction, satisfaction with opportunities for promotion, organizational commitment, procedural justice, organization-based self-esteem, and intentions to quit). The researchers used Blau's (1985) Career Commitment Scale ( $\alpha=.87$ ) to measure career commitment; a scale developed by Quinn and Staines (1979) to measure job satisfaction ( $\alpha=.83$ ); Smith, Kendall, and Hulin's (1969) Job Description Index to measure satisfaction with opportunities for promotion ( $\alpha=.88$ ); a scale developed by Mowday et al. (1979) to measure organizational commitment $(\alpha=.91)$; McFarlin and Sweeny's (1992) procedural justice scale $(\alpha=.89)$ to measure procedural justice; a scale developed by Pierce, Gardner, Cummings, and Dunham (1989) to measure organization-based self-esteem ( $\alpha=.91)$; and Nadler, Jenkins, Cammann, and Lawler's (1975) Michigan Organizational Assessment Questionnaire to measure intention to quit ( $\alpha=.77$ ). The control variables for the study were: protégé's' rank, protégés age, protégés' occupation, protégés' tenure in organization, the size of the organization, and the duration of the current mentoring relationship.

The researchers used a mixed design involving hierarchical multiple regression, multivariate analysis of covariance (MANCOVA), and analysis of covariance (ANCOVA) to analyze the data. Study findings indicated that protégés 
who reported highly satisfying informal or formal mentoring relationships reported greater job satisfaction, $r=.24, p<.01$; organizational commitment, $r=.19, p<$ .01 , satisfaction with opportunities for promotions, $r=.17, p<.01$; career commitment, $r=.24, p<.01$; organization-based self-esteem, $r=.16, p<.01$; procedural justice, $r=.21, p<.01$; and lower intentions to quit, $r=-.22, p<.01$. The adjusted means also indicated that nonmentored individuals reported less job satisfaction, satisfaction with opportunities for promotion, organizational commitment, career commitment, organization-based self-esteem, and procedural justice than protégés in highly satisfying informal mentoring relationships. The adjusted means indicated that protégés in highly effective informal relationships reported greater career commitment, job satisfaction, organizational commitment, organization-based self-esteem, and perceived opportunities for promotions than protégés in highly satisfying informal mentoring relationships. Protégés in effective formal mentoring programs reported more satisfying mentoring relationships than protégés in ineffective programs $F(1,79)=$ $18.67, \mathrm{p}<.001$.

The regression analysis indicated that satisfaction with the mentoring relationship was significantly related to all of the attitudinal variables (career commitment, job satisfaction, organizational commitment, organization-based self-esteem, promotion opportunities, intentions to quit, procedural justice). The changes in $R^{2}$ ranged from .01-.05. Additionally, the presence of a mentor was significantly related to job satisfaction (change in $R^{2}=.02$ ), career commitment (change in $R^{2}=.01$ ), and organization-based esteem (change in $R^{2}=.01$ ). 
Haynes (2003) conducted an investigation to examine the efficacy of formal and informal mentoring in socializing law faculty to their respective institutions. The participants were law professors on faculty at 44 of the 178 public and private American Bar Association Approved Law Schools $(N=298)$. Haynes created a mentoring questionnaire and demographics questionnaire to operationalize the independent variables: mentoring (formal, informal), gender, and position. Haynes used Chao et al.'s (1994) 34-item Likert-type agreement Organizational Socialization Questionnaire (1 = strongly disagree, 5 = strongly agree) to measure organizational socialization, the dependent variable. The six subscales are: history $(\alpha=.80)$, language $(\alpha=.76)$, politics $(\alpha=.78)$, people $(\alpha=$ $.81)$, organizational goals and values $(\alpha=.85)$, performance proficiency $(\alpha=.79)$.

The researcher used a causal-comparative design involving multiple regression analysis to test the null hypotheses', the Bonferroni procedure to protect against Type I error rate, and descriptive statistics to compare key variables within the sample population. Study findings indicated mentored faculty had higher mean scores than non-mentored faculty on people and organizational goals of the Organizational Socialization Questionnaire and senior level nonmentored faculty had higher mean scores on history, language, politics, and performance proficiency of the Organizational Socialization Questionnarie.

Raabe and Beehr (2003) conducted an investigation to examine the strength of the relationship between the formal mentor and the mentee's perceptions of their relationships with supervisor-subordinate relationships and the strength of the relationship with co-worker-co-worker relationships in relation 
to mentee outcomes. The participants in the study were mentors and mentees ( $N$ $=122)$ who were participating in a formal mentoring program in two different industries in two different locations in the United States. Raabe and Beehr used a 51-item questionnaire to operationalize the independent variables: formal mentor relationship (career development, psychosocial support, role modeling); supervisor relationship (affect, professional respect, loyalty, contribution); and coworker relationship (affect, professional respect, loyalty, contribution). The researchers measured the items a 7-point Likert-type agreement scale. The researchers did not specify the scaled anchors. The dependent variable in the study was career outcomes (job satisfaction, organizational commitment, turnover intent).

The researchers used the Minnesota Satisfaction Questionnaire to measure job satisfaction, the short form of the Porter, Mowday, Steers, and Boulian's (1974) scale to measure organizational commitment, and the Michigan Organizational Assessment Questionnaire to measure turnover intent. The researchers used a quasi-experimental design involving hierarchical multiple regression to analyze the data. Study findings indicated that mentors $(M=5.31$, $S D=.68$ ) believed they were giving a little more career development than mentees $(M=5.31, S D=.94)$ believed they were getting, $t(120)=-2.28, p<.05$. Mentees believed there was more mutual psychosocial support $(M=4.28, S D=$ .1.07) than the mentors $(M=3.85, S D=1.03)$ believed they were providing, $t=$ 2.12, $p<.05$. Mentees $(M=5.62, S D=.86)$ believed they were modeling their 
behaviors after the mentors $(M=4.98, S D=.80)$ more than the mentors believed, $t(120)=4.25, p<.001$.

Mentors and mentees shared similar perceptions of sharing personal problems, $r=.41, p<.01$; socializing after work, $r=.29, p<.05$; considering the other one to be a friend, $r=.48, p<.001$; and the protégé was placed in important assignments, $r=.37, p<.01$. There was a significant positive relationship between job satisfaction and the relationship with the protégé's supervisor in regard to affect, $r=.26, p<.05$; professional respect, $r=.53, p<$ .01 ; and loyalty, $r=.49, p<.01$. There was a significant positive relationship between organizational commitment and the relationship with the protégé's supervisor in regard to professional respect, $r=.27, p<.05$, and contribution, $r=$ $.29, p<.05$. There was a significant negative relationship between turnover intent and the relationship with the protégé's supervisor in regard to affect, $r=-.26, p<$ .05 ; professional respect, $r=-.44, p<.01$; and loyalty, $r=-.26, p<.05$.

There was a significant positive relationship between job satisfaction and the relationship with their protégés coworker in regard to professional respect, $r=$ $.43, p<.01$, and loyalty, $r=.28, p<.05$. There was a significant positive relationship between organizational commitment and the relationship with the protégés coworker in regard to affect, $r=.44, p<.05$; loyalty, $r=.33, p<.05$; and contribution, $r=.38, p<.01$. There was a significant negative relationship between turnover intent and the relationship with the protégé's coworker in regard to loyalty, $r=-.27, p<.05$. 
Supervisor relationships had a predicted incremental effect on job satisfaction, $R^{2}=.47, p<.01$, and turnover intention, $R^{2}=.25, p<.01$, than relationships with the protégé's mentor. Coworker relationships had a predicted incremental effect on job satisfaction, $R^{2}=.22, p<.05$, and organizational commitment, $R^{2}=.20, p<.05$, than relationships with the protégé's mentor.

Day and Allen (2004) conducted an investigation to examine career motivation and self-efficacy as mediators of the relationship between mentoring and measures of career success. The participants in the study were city employees who were supervisors, administrators, managers, or professionals ( $N$ $=125)$. Day and Allen used a questionnaire to operationalize the independent variables: demographics, protégé status, mentorship type (formal, informal), mentoring functions (career, psychosocial), and career motivation (feelings, attitude, behaviors). The researchers used the 27-item Career Motivation scale developed by Noe, Noe, and Bachhuber (1990) to measure behaviors and used the 17-item Career Motivation scale developed by London (1993) to measure feelings and attitudes. Day and Allen combined and modified the two scales for the study with a coefficient alpha of .84 for the 21 -item scale. The researchers did not identify the scaled anchors. The researchers used Noe's (1988) mentoring functions scale to measure career mentoring $(\alpha=.87)$ and psychosocial mentoring $(\alpha=.84)$. The dependent variables in the study were: career self-efficacy, subjective career success, objective career success, and performance effectiveness. 
Day and Allen (2004) used Kossek, Roberts, Fisher, and Demarr's (1998) 11-item Likert-type scale to measure career self-efficacy ( $\alpha=81)$. The researchers did not identify the scaled anchors. Day and Allen used Turban and Doughtery's (1994) 4-item Likert-type agreement scale ( 5 = strongly disagree, 1 $=$ strongly agree $)$ to measure subjective career success $(\alpha=.83)$. The researchers used Williams and Anderson's (1991) 7-item Likert-type effectiveness scale ( $1=$ ineffective, $5=$ highly effective) to measure performance effectiveness $(\alpha=.90)$. The control variables in the study were: mentor gender, participant age, participant gender, and education.

Day and Allen (2004) used a correlational design involving hierarchical multiple regression to analyze the data. Results of the study indicated that mentored individuals $(M=4.24, S D=.37)$ had a higher level of career motivation than non-mentored individuals $(M=4.02, S D=.40)$. The independent samples $t$ test was significant $t(123)=3.16, p<.01$. There was a positive relationship between psychosocial mentoring and career motivation, $r=.31, p<.05$. Career mentoring was significantly related to career motivation, $r=.28, p<.05$. There was a positive significance between career motivation and current salary $r=.46$, $p<.001$; subjective career success, $r=.39, p<.001$; and performance effectiveness, $r=.42, p<.001$. There was a positive relationship between career mentoring and self-efficacy, $r=.29, p<.05$. There was a positive significant relationship between self-efficacy and current salary, $r=.30, p<.001$; career success, $r=.42, p<.001 ;$ and performance effectiveness, $r=.40, p<.001$. Career motivation mediated the relationship between career mentoring and 
performance effectiveness, $r=.28, p<.05$. When performance effectiveness was regressed on self-efficacy and career mentoring was added, the change in $R^{2}=.04$ and was not significant. When performance effectiveness was regressed on career mentoring and self-efficacy was added, the change in $R^{2}=.04$ and was not significant.

Smith and Ingersoll (2004) conducted a study to examine whether firstyear teachers who participated in or received induction activities and supports (such as mentoring), collaborative activities with other teachers, and additional resources, were more or less likely to stay with their teaching jobs the following year. The participants in the study were first year teachers $(N=3,235)$ and were selected from the National Center for Education Statistics' Schools and Staffing Survey. Smith and Ingersol used a survey to operationalize the independent variables: mentoring activities and induction activities. The dependent variable in the study was turnover. The control variables in the study were: age, race, gender, subject taught, full-time or part-time, and earnings.

The researchers used a quasi-experimental design involving multinomial logistic regression to analyze the data. Study findings indicated beginning teachers reported they were less likely to move to other schools and less likely to leave the teaching occupation after their first year of teaching when they were provided with mentors and participated in collective induction activities.

Andrews and Quinn (2005) conducted an investigation to examine the difference in the perceptions of the amount of support received among first-year school teachers that were: (a) assigned a mentor through the school district's 
mentor teacher program, (b) assigned a mentor by their principals, or (c) not assigned a mentor. The participants in the study were first-year school teachers $(N=135)$. Andrews and Quinn used a questionnaire to operationalize the independent variable: mentor assignment (principal, program, none). The dependent variable in the study was perceived support (assistance with and ideas about instruction and curriculum, personal and/or emotional support, obtaining materials, supplies and resources, information about school and school district procedures and policies, help with and ideas about classroom management and discipline, ideas for dealing with parents or parent conferences). The researchers used a 6-point Likert-type agreement scale $(1=$ very strongly disagree, 6 = very strongly agree) to measure the dependent variable. Andrews and Quinn used a quasi-experimental design involving analysis of variance (ANOVA), descriptive statistics, and the Tukey HSD post hoc test to analyze the data. The results show there was a significant difference, $F(2,132)=3.39, p=.04)$, in the amount of support first-year teachers perceived they received among first-year teachers with (a) a mentor assigned by the school district, (b) a mentor assigned by their principal, and (c) no assigned mentor. The Tukey HSD indicated that first-year teachers with a mentor assigned by the school district's mentor teacher program perceived they received significantly more support than teachers with no assigned mentor, $p=.049$.

Pellegrini and Scandura (2005) conducted an investigation to examine whether the mentoring construct is comparable across satisfied and unsatisfied protégés. The participants in the study were employed Master of Business 
Administration (MBA) graduates $(N=374)$ from two different universities. To measure satisfaction or non-satisfaction of the mentoring relationship, the dependent variable, Pellegrini and Scandura used a questionnaire. The researchers used Ragins and Cotton's (1999) scale to measure protégé satisfaction (satisfied, dissatisfied) and measured it on a 7-point type Likert-type agreement scale $(1=$ strongly disagree, $5=$ strongly agree $)$. The dependent variable in the study was mentoring functions (career support, psychosocial support, and role modeling). The researchers used the Mentoring Functions Questionnaire (MFQ-9) developed by Castro and Scandura (2004), to measure the dependent variables. The participants rated the MFQ-9 on a 5-point Likerttype agreement scale $(1=$ strongly disagree, $5=$ strongly agree $)$. The researchers used a multiple group confirmatory factor analysis involving LISREL 8 to analyze the data. Study findings indicated that the confirmatory factor analysis supported the mentoring functions of career support, psychosocial support, and role modeling. Also, the MFQ-9 met the psychometric properties (validity, reliability) with unsatisfied protégés.

\section{Section Summary}

The quantitative articles in the above section involved an assortment of empirical research articles highlighting mentoring constructs. The following highlights some of the findings from the articles. There was a positive relationship between the type of mentoring received by an individual and his or her career attainment and perceived career success, there was a positive relationship between career attainment and career success, protégés reported higher levels 
of procedural justice than non-protégés, there was a positive relationship between career development mentoring and distributive justice and procedural justice, first-year teachers with a mentor assigned by the schools district's mentor teacher program perceived they received significantly more support than those not assigned a mentor, and mentored individuals had a higher level of career motivation than non-mentored individuals.

Mentored individuals indicated a positive relationship between psychosocial mentoring and career motivation and a positive relationship with career mentoring and career motivation. There was a statistical significance difference between mentored law faculty and non-mentored law faculty on organizational socialization. The more experience mentors had in a mentoring relationship, the more willing they were to become a mentor in the future and protégés indicated a positive relationship with career mentoring and career selfefficacy.

Protégés in positive mentorships were more satisfied than those in negative mentorships; protégés in positive mentorships reported their mentors as being similar in values and beliefs; protégés in different phases of the mentorship perceived different levels of psychosocial and career-related support from their mentors; dissimilar attitudes, values, and beliefs between the protégé and mentor where characteristics of negative mentorships; and the more time a protégé spends with the mentor, the protégé received greater psychosocial outcomes.

Findings also suggested that when mentors and protégés are in close proximity, it may lead to a positive mentorship and formal mentorships may 
benefit from frequent meetings. Additionally, protégés rated themselves as having significantly more career mobility/opportunity, recognition, satisfaction and promotions than non-protégés. Mentors and protégés participating in mentoring relationships were more likely to participate in future mentoring relationships than those not involved in mentoring relationship. This latter appears to be a positive finding for the future of mentoring.

\section{Chapter Summary}

The sections above included qualitative and quantitative empirical research articles examining mentoring involving race and gender, empirical research articles examining mentoring involving organizational commitment and job satisfaction, and empirical research articles highlighting the constructs of mentoring. Each section included a section summary providing significant findings of some of the articles. The next chapter is the methodology section that provides information on how the study was conducted. 


\section{CHAPTER III \\ METHODOLOGY}

Introduction

This study examined the relationship between mentoring, job satisfaction, and organizational commitment. Specifically the study examined mentoring African American men and their level of job satisfaction and organizational commitment. This chapter reveals the population and sample, research instruments, the pilot study, research design, and a chapter summary. To reiterate, this study answered the following three questions:

1. What is the relationship between mentoring and job satisfaction?

2. What is the relationship between mentoring and organizational commitment?

3. After controlling for select demographic variables, what is the relationship between mentoring, job satisfaction, and organizational commitment?

$$
\text { Population and Sample }
$$

Because the study examined mentoring African American men, the participants in the study were African American men who currently work in various industries and/or are chapter members the National Black Masters of 
Business Administration Association (NMBAA). This study used purposive sampling methods to select the participants. Purposive sampling is characterized by the use of judgment and a deliberate effort to include presumably typical groups in the sample (Kerlinger, 1986). Because the literature review revealed a lack of mentoring research conducted on African American men, purposive sampling appeared most appropriate for this study. The researcher collected data from chapter members of the NBMBAA.

The NBMBAA's website (http://www.nbmbaa.org/membership_demographics.cfm.) indicates the organization has over 6000 financial (due paying) members and 40 chapters. The gender breakdown for the national membership is $49 \%$ males and $50 \%$ females. The organization does not have the breakdown for each chapter's gender makeup.

The researcher selected this organization because of the potential large sample size (3000) of African American men and the potential to gather data from various areas of the United States. The 40 chapters are located in five regions. The regions are: East region with nine chapters, West region with seven chapters, Mideast region with seven chapters, Midwest region with seven chapters, and South region with ten chapters.

Prior to sending out the questionnaire, the researcher contacted the chapter president of one of the Mideast's region chapter to present a draft of the questionnaire to the presidents at the national conference in the fall of 2006. (The chapter presidents hold a meeting during each annual conference and no 
surveys were completed). The purpose for this activity was to make an initial contact, to provide the presidents with a prototype of what the participants may be asked to complete, gain chapter president support, and for the presidents to have knowledge about the study so when they received the questionnaire they will be familiar with the request. In a second pre-contact effort, the researcher spoke with and/or left a voicemail with each chapter's president seeking support for the study prior to sending out the questionnaire. Dillman, Christenson, Carpenter, and Brooks, 1974; Goyder, 1985; and Heberlein and Bumgartner, 1978, indicated that the most powerful determinant of the response rates is the number of attempts made to contact the sample unit. Therefore, to help increase the response rate, these activities were conducted.

This study used Dillman's (2000) online survey protocol to administer the survey. A pre-notification e-mail with an explanation of the research study was sent to all chapter presidents. The e-mail informed and requested that each president forward the preamble and Web-link to the potential participants once they received the link. Two days after the pre-notification e-mail was sent, the researcher sent an e-mail containing the Web-link and a request to forward the Web-link and preamble to the potential participants. Three days later, a reminder e-mail was sent to the presidents with the same protocol as the second e-mailing to increase the response rate. Lastly, two days later, a thank you/reminder e-mail was sent to the presidents with an additional request to remind the participants to complete the survey if the participants have not already done so. Throughout this study, the researcher did not have access to participant's e-mail addresses or 
any participant information that would jeopardize the outcomes of the study. Again, the researcher relied on a mediator (chapter presidents) to forward the Web-link to the appropriate participants.

While Dillman $(1978,2000)$ emphasized the importance of sending surveys directly to participants rather than to a person in an organization, sending the surveys to the president, in this study, appeared the most appropriate because gaining access to a database of all members was not allowed by the national organization. Therefore, using the presidents as a mediator to send all correspondences to the participants appeared appropriate. Even though the respondents themselves were not involved in the initial contacts, it is presumed that contacting the leaders of the chapters by these activities assisted in gaining support to enhance the response rate.

\section{Quantitative Research}

This quantitative research study used a survey for collecting data. According to Stainback and Stainback (1988), the distinguishing difference between qualitative research and quantitative research is that qualitative research "calls for the investigator to enter into the lives of the persons being studied as fully and naturally as possible" (p. 1). Isaac and Michael (1995) suggested that surveys are "a means of gathering information that describes the nature and extent of a specified set of data ranging from physical counts and frequencies to attitudes and opinions" (p. 128). In contrast, to gather data, qualitative researchers use: (a) participation in the setting, (b) direct observation, (c) in-depth interviewing, and (d) document review (Marshall \& Rossman, 1995). 
Because this study investigated job satisfaction and organizational commitment and not an observable phenomenon where a qualitative study would be appropriate, qualitative data collection approaches were not used.

\section{Data Collection}

\section{Web Survey}

This study used an electronic software (Zoomerang ${ }^{\mathrm{TM}}$ ) instead of direct mailing to collect data. Mehta and Sivadas (1995) suggested the Web is attractive to many researchers for a variety of reasons, including cost and speed. Comley (1997) and Mehta and Sivadas (1995) found that electronic mail responses generally occurred within the first three days versus direct mail responses, which took up to three weeks. Shannon and Bradshaw (2002) suggested that participants are more likely to respond to a Web-based survey if all they have to do is click on the provided Web-link. Because Web-based research includes the ability for real time interactions with geographically diverse respondents (Kannan, Chang, \& Winston, 2000) and the previously mentioned advantages, the researcher choose to use an electronic software to collect data. Additional advantages of Web-based surveys include: design flexibility and interactivity, ability to reach large numbers of people, anonymity, more economical, less time-consuming than mail and telephone surveys, minimized interviewer error, and minimized interviewer bias (Sheehan \& Hoy, 1999; Simsek \& Veiga, 2001).

One disadvantage for using electronic surveys is the variability of response rates. According to Schonlau, Fricker and Elliott (2002), Web-based 
survey response rates range from $6 \%$ to $68 \%$. While there is a wide range for response rates, Shannon and Bradshaw (2002) reported that it takes an average of 9.13 days to receive a survey response by mail compared to 3.21 days for Web-based surveys. Dillman (2000) notes multiple contacts will protect low response rates. According to Simsek \& Veiga (2001) Web-based surveys can include the following methods: (1) sending an e-mail message with the survey as part of the message text; (2) sending the survey as an attachment to an e-mail message that the respondent must open in order to respond; and (3) sending an e-mail message with a Uniform Resource Locator-embedded (URL) message in the text that the respondent is directed to click on a hypertext link that allows the recipient to view and respond to a Web-based survey. For this study the researcher choose method three.

\section{Response Rate}

Because the researcher did not have direct access to potential participants and did not know the exact or estimated number of members per chapter, an exact survey response rate could not be calculated. The inability to ascertain an exact response rate is a limitation reported in studies by Koresdoski (2002) and Mungania (2004). In both studies, the researchers relied on third parties to forward survey requests and Web-links to the target population. However, in comparison to response rates conducted via the Web or via mailing, Kaplowitz, Hadlock, and Levine (2004) found that a Web-based survey application achieved a comparable response rate to a mailed hard copy questionnaire when an advance notification was sent. 


\section{Research Instruments}

\section{Demographic data}

To gather data on the demographics of the participants, the survey included items to capture gender, race, organizational tenure, job tenure, organization size, industry, and advance degree attainment. To gather data pertaining to the participant's mentoring experiences, included in the mentoring section were items for participants to indicate the race and gender of their mentors and whether the mentoring relationships developed naturally (informal) or through the organization (formal). Examples of the demographic questions are: (please place a check mark beside the industry that best matches the industry you currently work, indicate the approximate number of years you have worked in your current organization, and indicate the size of your organization).

\section{Mentoring}

The mentoring portion of the survey included seven items to explore mentoring. At the beginning of this section of the questionnaire, to help the participants understand mentoring, the participants were given a definition of informal mentoring, formal mentoring, and non-mentoring as defined by Haynes (2003). The first question of the study operationalized mentoring by asking participants to report if their mentoring experience was through a formal mentoring program, an informal mentoring program, or never had a mentoring experience (non-mentoring). The specific item was: "As a protégé I was/am involved with" (1 = informal mentoring, 2 = formal mentoring, 3 = non-mentoring). If participants choose non-mentoring, they were instructed to proceed to the next 
section of the questionnaire (organizational commitment). Haynes defined mentoring as follows: informal mentoring as a naturally occurring relationship based on attributes, attraction and similar interests, where an experienced organizational member provided career and psychosocial support to a lesserexperienced organizational member; formal mentoring as a program designed and developed by the organization to facilitate structured mentoring relationships where an experienced organizational member provided career and psychosocial development to a lesser-experienced organizational member; and non-mentoring as never having any involvement in a formal or informal mentoring relationship where an experienced organizational member provided career and psychosocial development to a lesser-experienced organizational member.

The remaining items of the scale explored mentoring effectiveness, mentor race, mentor gender, mentor age, and frequency of mentoring meetings. To explore the effectiveness of formal or informal mentoring the items were: "The formal mentoring I receive (d) is/was effective" and "The informal mentoring I receive (d) is/was effective". The researcher measured these two items on a 5point Likert-type agreement scale $(1=$ strongly disagree, $5=$ strongly agree $)$. The participants were able to select N/A if one of the two items did not apply. To explore the mentor's gender, the item was: "The gender of my mentor was/is" (1 $=$ male, $2=$ female). To explore the mentor's race, the item was: "The race of my mentor was/is," (1 = Black, 2 = White, $3=$ Neither Black nor White $)$. To explore the age difference between the protégé and mentor the item was: "My mentor is/was," ( $1=$ Older, $2=$ Younger, $3=$ Similar in age $)$. To explore the frequency of 
mentoring meetings, the item was: "My mentor and I met" ( 1 = Once a month, 2 = Twice a month, $3=$ Three times a month, $4=$ more than three times a month).

For the purpose of the multiple regression analyses that addressed the research questions, the following reveals how the researcher operationally defined mentoring. Participants who answered they were informally mentored and/or formally mentored were coded 1 , meaning they received at least some type of mentoring. Those who answer they were not mentored were coded 0 , meaning they received no type of mentoring.

The operational definition above assumed that a sufficient number of participants will be coded 0 (received no type of mentoring) that the dichotomous version of the mentoring variable will be meaningful. If only a small proportion of cases were not mentored, the variable mentoring was defined in terms of the strength of the mentoring experience: $0=$ received no type of mentoring, $1=$ informal mentoring, 2 = formal mentoring.

\section{Organizational Commitment Questionnaire}

To measure organizational commitment, the researcher used Mowday et al.'s (1979) Organizational Commitment Questionnaire. According to Mowday et al. organizational commitment involves: (a) a psychological orientation measuring the employee's strong belief in and acceptance of the organization's goals and values (also known as affective commitment), (b) the behavioral orientation measuring the employee's willingness to exert considerable effort on behalf of the organization (also known as continuance commitment), and (c) the behavioral orientation measuring the employee's strong desire to remain within 
the organization (also known as normative commitment). Mowday et al. reported internal consistencies (coefficient alpha) ranging from .82 to .93. Previous mentoring studies that used the scale to examine organizational commitment reported internal consistency scores ranging from .80 to .91 (Baugh \& Scandura, 1999; Ragins, Cotton, \& Miller, 1999; Scandura, 1997). Other notable mentoring studies that used the questionnaire are: Donaldson, Ensher, and Grant-Vallone, 2000; Joiner, Bartram, and Garreffa, 2004; Ragins and Cotton, 2002.

The researcher measured the 15-item scale on a 7-point type Likert-type agreement scale $(1$ = strongly disagree, 2 = moderately disagree, 3 = slightly disagree, $4=$ neutral, $5=$ slightly agree, $6=$ moderately agree, $7=$ strongly agree). Sample questions are: (a) "I am willing to put a great deal of effort beyond what is normally expected in order to help this organization be successful," (b) "I feel very little loyalty to this organization," (c) "I could just as well be working for a different organization as long as the type of work was similar," (d) "I am extremely glad I chose this organization to work for over others I was considering at the time I joined," and (e) "The decision to work for this organization was a definite mistake on my part." The originator of the scale gave permission to use the questionnaire.

\section{Job Satisfaction Scale}

The researcher used Spector's (1998) Job Satisfaction Scale (JSS) to measure job satisfaction. Spector granted permission to use the scale for the study with the requirement of providing the results of the scale (validity and reliability) from the study. The JSS is a 36 -item scale and the researcher 
measured the scale on a 6-point Likert-type agreement scale to measure employee attitudes about their job and aspects of their job $(1=$ disagree very much, 2= disagree moderately, $3=$ disagree slightly, $4=$ agree slightly, $5=$ agree moderately, $6=$ agree very much). The nine facets of the scale are pay, promotion, supervision, fringe benefits, contingent rewards (performance based rewards), operating procedures (required rules and procedures), coworkers, nature of work, and communication. Sample questions are: (a) "I feel I am being paid a fair amount for the work I do;" (b) "There is really too little chance for promotion on my job;" (c) "When I do a good job, I receive the recognition for it that I should receive;" (d) "My supervisor is unfair to me;" (e) "I often feel that I do not know what is going on with the organization;" and (f) "There are benefits we do not have which we should have."

\section{Pilot Study Survey}

Dillman (2000) indicated that pilot studies provide an opportunity to assure that the procedures outlined to administer the survey will achieve the desired response. Five individuals participated in the pilot study for this purpose. The specific purposes for this study are: (a) clarity (for instructions), (b) time (to take the questionnaire), and (c) formatting issues. The researcher made appropriate adjustments based on the pilot participant's comments. The researcher ensured the adjustments did not jeopardize the integrity of the questionnaire.

\section{Research Design}

For this quantitative research study the researcher used a correlational design. A correlational designed study is one where the variables are allowed to 
vary and the researcher records the extent to which changes are related to each other (Crano \& Brewer, 2002). In a correlational design, change in one variable is not necessarily caused by the other. Crano and Brewer (2002) stated, "The major advantage of correlational research is that it permits the free variation of both variables of interest so that the degree of relationship between them can be determined without the loss of information inherent in the experimental design" (p. 127).

\section{Statistical Analysis}

To address the research questions in the study, the researcher used multiple linear regression. This statistical procedure allowed a test of the relationships among predictor variables and the dependent variables. The multiple regression analysis also allowed a mediation analysis to test if job satisfaction mediates the effect of mentoring on organizational commitment or that mentoring directly affects organizational commitment without any mediation by job satisfaction.

The table below shows the relationship among the variables. 
Table 1

Types of Variables Used in the Study

\begin{tabular}{lll}
\multicolumn{2}{l}{ General Name of Variable } & Specific Variable in This Study \\
Independent $(X)$ & Mentoring \\
Mediator & (M) & Job Satisfaction \\
Outcome & (Y) & Organizational Commitment
\end{tabular}

\section{Research Question 1}

What is the relationship between mentoring and job satisfaction? The researcher performed a regression with mentoring as the predictor variable and job satisfaction the dependent variable. A statistically significantly positive regression coefficient was evidence that mentoring has a direct positive effect on the mediator job satisfaction.

Research Question 2

What is the relationship between mentoring and organizational commitment?

The researcher performed a hierarchical regression with mentoring entered as the first predictor variable and organizational commitment the dependent variable. A statistically significant regression coefficient was evidence that mentoring is positively associated with job satisfaction. This is the total effect of the independent variable (mentoring) on the outcome variable (organizational commitment) ignoring the mediator (job satisfaction). 
In the second step of the hierarchical regression, the researcher entered the mediator variable, job satisfaction, into the equation. This resulted in two partial regression coefficients, estimating the effects of: (a) mentoring on organizational commitment, controlling for job satisfaction and (b) job satisfaction on organizational commitment, controlling for mentoring.

\section{Mediation analysis}

The regression analyses used to answer research questions 1 and 2 produced the information needed to perform a mediation analysis. The mediation analysis addressed the question: are the effects of mentoring on organizational commitment all direct effects, or are some or all of the effects indirect, through the variable job satisfaction?

The researcher used procedures described by Berger (2004) to perform the mediation analysis. Table 2 shows the regression coefficients that were used for the analysis. 
Table 2

Source of Regression Coefficients for Mediation Analysis

Regression Number of regression equation and coefficient effect of predictor variable on dependent variable

a $\quad$ 1. Mentoring predicting Job satisfaction

Step of

1. Mentoring predicting Job salis aclion

C

2. Mentoring predicting Org. Commitment

equation

$c^{\prime}$

2. Mentoring predicting Org. Commitment, controlling for Job satisfaction

b

2. Job satisfaction predicting Org. Commitment, controlling for Mentoring

Note. Notation for regression coefficients derived from Berger (2004).

If the regression analyses indicate that regression coefficients $a$ and $b$ shown in Table 2 are statistically significant, this is evidence that mediation is occurring. If only regression coefficient $\mathrm{c}$ is significant, then the effect of mentoring on organizational commitment is a direct effect, i.e., the effect of mentoring is not mediated by job satisfaction. These patterns of results are hypothetical, because the study may reveal no significant effects of any kind. Research question 3

After controlling for select demographic variables, what is the relationship between mentoring, job satisfaction, and organizational commitment?

The researcher performed hierarchical regression. Select demographic variables were entered in step 1. In step 2, mentoring and job satisfaction were entered. This allowed a test of whether, after demographic variables were 
controlled, mentoring and job satisfaction significantly predict the outcome variable organizational commitment.

Independent and Dependent Variables

The dependent variables in this study were organizational commitment and job satisfaction. The independent variable in the study was mentoring. Therefore, because the study predicted the outcome of mentoring on job satisfaction and organizational commitment, hierarchical multiple regression was appropriate for this correlational designed study. Prior mentoring studies that used multiple regression to analyze the data are: Aremu and Adeyoju, 2003; Heimann and Pittenger, 1996; Mobley, Jaret, Marsh, and Lim, 1994; Noe, 1988; Ragins, Cotton, and Miller, 2000; Raabe and Beehr, 2003; Seibert, 1999; and Stallworth, 2003.

\section{Chapter Summary}

This methodology chapter highlighted the design of study that pertained to the procedure of data gathering. Included in this chapter, the researcher provided detailed information about the questionnaires used in the study and a description of the participants and data analysis. The results of the study are presented in chapter 4. 


\section{CHAPTER IV}

\section{RESULTS}

Introduction

This chapter presents the quantitative data obtained through a Web-based survey (Zoomerang ${ }^{\mathrm{TM}}$ ), which the researcher analyzed the data by hierarchical multiple regression and mediational analysis. This correlational study examined the strength and direction of the relationship between mentoring and job satisfaction and mentoring and organizational commitment among African American men in a business setting. Additionally, this study examined the unique relationship between mentoring, job satisfaction, and organizational commitment. The specific research questions of the study were:

1. What is the relationship between mentoring and job satisfaction?

2. What is the relationship between mentoring and organizational commitment?

3. After controlling for select demographic variables, what is the relationship between mentoring, job satisfaction, and organizational commitment?

Included in the following section are the descriptive statistics of the sample (e.g., age, gender, education attainment, mentoring experience), the results of the hierarchical multiple regression analysis, and results of the mediational analysis, which answered the research questions. The discussion and implications of the results are presented in chapter 5 . 


\section{Population and Sample}

As indicated in chapter 3 , the participants in the study were intended to be African American men who were members of the NBMBAA. Table 3 provides a summary of demographic variables measured in the survey. The number of subjects in this study was 364 . However, there were missing data on some variables. As a consequence, the $n$ used for some statistical analyses is less than 364. As indicated in Table 3, there were participants who were not members of the NBMBAA and those who were females. (After question one of the survey, the directions instructed the participant to discontinue taking the survey if the participant selected female). Additionally, since the researcher did not have a database of members of the NBMBAA, the researcher could not control who participated in the survey.

\section{Demographic Variables}

Gender, Ethnicity, NBMBAA affiliation, and Age of Participants

Table 3 displays the gender, ethnicity, NBMBAA affiliation, and age of the participants. Results from the survey indicate 98.6 percent of the participants identified themselves as male $(n=359)$ and $1.4 \%$ identified themselves as female $(n=5)$. Approximately $96.2 \%$ of the respondents were African American and $56.6 \%$ of the respondents $(n=206)$ were members of the NBMBAA.

The age ranges of the participants were: $38.2 \%$ reported being in the age range of $30-39$ and $34.9 \%$ reported being in the age range of $40-49$. These age ranges accounted for $73.1 \%$ of the population. Additional demographic information can be found in Appendix E. 
Table 3

Gender, Membership, Ethnicity and Age of Respondents ( $N=364)$

\begin{tabular}{lll}
\hline & $\underline{n}$ & $\underline{\%}$ \\
\hline $\begin{array}{l}\text { Gender } \\
\text { Male }\end{array}$ & \\
$\quad$ Female & 359 & 98.6 \\
Membership in NBMBAA & 5 & 1.4 \\
Yes & & \\
No & 206 & 56.6 \\
Ethnicity & 158 & 43.4 \\
African American & & \\
Other & 350 & 96.2 \\
Age & 14 & 3.8 \\
21-29 & & \\
30-39 & & \\
$40-49$ & 30 & 8.2 \\
$50-59$ & 139 & 38.2 \\
$60+$ & 127 & 34.9 \\
& 61 & 16.8 \\
\hline
\end{tabular}

Job Title, Position Tenure, and Organization Tenure

Table 4 presents the demographic variables of the participants job title, position tenure, and organizational tenure. The most frequently reported job title reported was non-management $(n=97)$. However, the variables of nonmanagement and manager accounted for $51.6 \%$ sample $(n=188)$. The majority of the respondents $(n=193)$ were employed by their organization for 0-3 years with 4-7 years being the second highest reported $(n=82)$. The majority of the respondents $(n=170)$ worked for their current organization for 0-3 years with 4-7 
years being the second highest reported $(n=90)$. Additional demographic information can be found in Appendix E.

Table 4

Job Title, Position Tenure, and Organization Tenure $(N=364)$

\begin{tabular}{lll}
\hline & $\underline{n}$ & $\underline{\%}$ \\
\hline Job Title & & \\
President & 33 & 9.1 \\
Vice-President & 21 & 5.8 \\
Director & 46 & 12.6 \\
Manager & 91 & 25.0 \\
Supervisor & 20 & 5.5 \\
Non-Management & 97 & 26.6 \\
Other & 56 & 15.4 \\
& & \\
Position Tenure & & \\
$17+$ & 37 & 10.2 \\
$14-16$ & 9 & 2.5 \\
$11-13$ & 17 & 4.7 \\
$8-10$ & 26 & 7.1 \\
$4-7$ & 82 & 22.5 \\
$0-3$ & 193 & 53.0 \\
& & \\
Organization Tenure & & 11.0 \\
$17+$ & 40 & 3.3 \\
$14-16$ & 12 & 5.5 \\
$11-13$ & 20 & 8.8 \\
$8-10$ & 32 & 24.7 \\
$4-7$ & 90 & 46.7 \\
$0-3$ & 170 & \\
\hline
\end{tabular}

Organization Size, Industry, Area of Specialty

Table 5 presents the demographic variables of the participant's organization size, the industry in which they are currently working, and their 
specialty area. Table 5 indicates that $61 \%$ of the participants worked in an organization with more than 1000 employees, 53.3\% reported working in an industry other than what was specified in the survey, and $37.4 \%$ reported working in a specialty area other than what was specified in the survey. Banking $(n=39)$ and healthcare $(n=38)$ were the second and third most reported industries. The specialty area of finance was second most reported, which accounted for $13.7 \%$ of the sample. Additional demographic information can be found in Appendix E. 
Table 5

Organization Size, Industry, Area of Specialty $(N=364)$

\begin{tabular}{|c|c|c|}
\hline & $\underline{n}$ & $\underline{\%}$ \\
\hline \multicolumn{3}{|l|}{ Organization Size } \\
\hline Fewer than 1000 & 142 & 39.0 \\
\hline Greater then 1000 & 222 & 61.0 \\
\hline \multicolumn{3}{|l|}{ Industry } \\
\hline Banking & 39 & 10.7 \\
\hline Education & 30 & 8.2 \\
\hline Healthcare & 38 & 10.4 \\
\hline Computer Services & 15 & 4.1 \\
\hline Consumer Products & 32 & 8.8 \\
\hline Telecommunications & 16 & 4.4 \\
\hline Other & 194 & 53.3 \\
\hline \multicolumn{3}{|l|}{ Specialty Area } \\
\hline Marketing & 34 & 9.3 \\
\hline Finance & 50 & 13.7 \\
\hline Accounting & 12 & 3.3 \\
\hline Operations & 37 & 10.2 \\
\hline Law & 5 & 1.4 \\
\hline Engineering & 25 & 6.9 \\
\hline Human Resources & 22 & 6.0 \\
\hline Information Systems & 35 & 9.6 \\
\hline Public Relations & 8 & 2.2 \\
\hline Other & 136 & 37.4 \\
\hline
\end{tabular}

Education, Type of Mentoring Received, Mentoring Effectiveness

Table 6 presents the demographic variables of the participant's education level, the type of mentoring received (informal, formal), and the effectiveness of the mentoring received. The majority of respondents, $53.8 \%$, possessed an MBA, with $42.3 \%$ of the respondents reporting possessing a bachelor's degree. 
Informal mentoring was the most frequent reported type of mentoring received by the respondents $(n=147)$ with non-mentoring as the second highest reported ( $n$ $=101)$. For the participants reporting they received informal mentoring, $29.6 \%$ agreed and $21 \%$ strongly agreed $(n=51)$ that the informal mentoring they received was effective. For the participants reporting they received formal mentoring, 37\% agreed and $35.8 \%$ strongly agreed that the formal mentoring they received was effective. Additional demographic information can be found in Appendix E. 
Table 6

Type of Mentoring, Mentoring Effectiveness ( $N=364)$

\begin{tabular}{|c|c|c|}
\hline & $\underline{n}$ & $\underline{\%}$ \\
\hline \multicolumn{3}{|l|}{ Education Level ${ }^{a}$} \\
\hline Bachelors & 154 & 42.3 \\
\hline MA & 10 & 2.7 \\
\hline MAT & 3 & 0.8 \\
\hline MBA & 196 & 53.8 \\
\hline MEd & 6 & 1.6 \\
\hline MFA & ---- & ---- \\
\hline MPA & 3 & 0.8 \\
\hline $\mathrm{MPH}$ & 1 & 0.3 \\
\hline MS & 20 & 5.5 \\
\hline MUP & 1 & 0.3 \\
\hline Doctorate & 14 & 3.8 \\
\hline Other & 41 & 9.0 \\
\hline \multicolumn{3}{|l|}{ Type of Mentoring } \\
\hline Informal (IM) & 147 & 45.0 \\
\hline Formal (FM) & 79 & 24.2 \\
\hline Non-mentoring & 101 & 30.9 \\
\hline \multicolumn{3}{|l|}{ Effectiveness of IM } \\
\hline Strongly Disagree & 8 & 3.3 \\
\hline Disagree & 10 & 4.1 \\
\hline Undecided & 20 & 8.2 \\
\hline Agree & 72 & 29.6 \\
\hline Strongly Agree & 51 & 21.0 \\
\hline Not Applicable & 82 & 33.7 \\
\hline \multicolumn{3}{|l|}{ Effectiveness of FM } \\
\hline Strongly Disagree & 8 & 3.1 \\
\hline Disagree & 7 & 2.8 \\
\hline Undecided & 12 & 4.7 \\
\hline Agree & 94 & 37.0 \\
\hline Strongly Agree & 91 & 35.8 \\
\hline Not Applicable & 42 & 16.5 \\
\hline
\end{tabular}

Note. Participants could choose multiple degrees. 
Mentor's Gender, Race, and Age, and Meeting Frequency

Table 7 presents the demographic variables of the mentor's gender, race, and age, and meeting frequency between the participants and their mentors. Eighty-seven percent of the participants reported that the gender of their mentor was male $(n=220), 47.4 \%$ reported that the race of their mentor was Black, 85.3\% reported their mentors were older, and 52\% reported they met with their mentors at least once per month. Additional demographic information can be found in Appendix E.

Table 7

Mentor's Gender, Race, Age, and Meeting Frequency $(N=364)$

\begin{tabular}{lll}
\hline & $\underline{n}$ & $\underline{\%}$ \\
\hline $\begin{array}{ll}\text { Gender } \\
\text { Male }\end{array}$ & \\
Female & 220 & 87.0 \\
Race & 33 & 13.0 \\
$\quad$ Black & & \\
$\quad$ White & 155 & 47.4 \\
$\quad$ Neither Black nor White & 95 & 29.1 \\
Age & 77 & 23.5 \\
$\quad$ Older & 214 & 85.3 \\
Younger & 6 & 2.4 \\
Similar in age & 31 & 12.4 \\
Frequency & & \\
One & & \\
$\quad$ Two & 129 & 52.0 \\
Three & 56 & 22.6 \\
More than three & 11 & 4.4 \\
& 52 & 21.0 \\
\hline
\end{tabular}




\section{Data Analysis}

Reliability analysis

Cronbach's alpha internal consistency reliability coefficients were calculated for the two scales (JSS and Organizational Commitment). For the 15item Organizational Commitment scale Cronbach's alpha was .90. For the 36item Job Satisfaction scale Cronbach's alpha was .94. These exceeded the criterion of .70 that is often used by researchers (Nunnally \& Bernstein, 1994). Thus, it was justified to use scaled means as variables in further analyses. See Appendices $F$ and $G$ for complete means and standard deviation scores for the scales.

\section{Research Question 1}

Research question 1 dealt with the relationship between being mentored and job satisfaction. Prior to performing a regression analysis, the researcher calculated a frequency distribution to determine how many subjects were mentored. It was found that 101 subjects were not mentored, 79 were formally mentored, and 147 were informally mentored. The researcher combined the two categories of formally mentored and informally mentored. This allowed the data for the variable to be dichotomized into two categories: mentored (coded 1) and not mentored (coded 0).

The researcher performed a hierarchical regression with job satisfaction, the dependent variable, and mentoring (Yes, or No) the independent variable. This is summarized in Table 8. It was found that being mentored was significantly related to job satisfaction $(B=.337, p<.01)$. The variance accounted for in job 
satisfaction by mentoring was $R^{2}=.032$ (adjusted $R^{2}=.028$ ) indicating a small effect size.

Table 8

Summary of Hierarchical Regression Analysis for Job Satisfaction Predicted by Mentoring $(N=256)$

Variable

Mentored
B

SEB

116 $\beta$

$.179 * *$

Note. Total variance accounted for by the predictor is: $R^{2}=.032\left(\right.$ adjusted $R^{2}=$ $.028)$.

${ }^{\star *} p<.01$

Research Question 2

Research question 2 dealt with the relationship between the two predictor variables, mentoring and job satisfaction, and the dependent variable, organizational commitment. The researcher performed a hierarchical regression with organizational commitment as the dependent variable and mentoring (Yes or No) and job satisfaction as the independent variables. This is summarized in Table 9. 
Table 9

Summary of Hierarchical Regression Analysis for Organizational Commitment

Predicted by Mentored and Job Satisfaction $(N=256)$

$\begin{array}{llll}\text { Variable } & \text { B } & \text { SEB } & \beta\end{array}$

Step 1

Mentored

.508

.166

$.188^{\star \star}$

Step 2

Mentored

.134

.107

.050

Job Satisfaction

1.108

.057

$.772^{\star \star}$

Note. Total variance accounted for: In Step 1 is $R^{2}=.035$ (adjusted $R^{2}=.032$ ),

In Step 2 is $R^{2}=.613$ (adjusted $R^{2}=.609$ ).

${ }^{\star \star} p<.01$

In step 1 of the analysis, it was found that being mentored was significantly related to organizational commitment $(B=.508, p<.01)$. The variance accounted for in organizational commitment by mentoring was $R^{2}=.035$ (adjusted $R^{2}=.032$ ) indicating a small effect size.

In step 2 of the analysis, it was found that, controlling for job satisfaction, being mentored was not significantly related to organizational commitment $(B=$ $.134, N S)$. It was also found that controlling for being mentored, job satisfaction was significantly related to organizational commitment $(B=1.108, p<.01)$. 


\section{Mediation analysis}

Results of the regression analyses performed for research questions 1 and 2 allowed a mediation analysis to be performed. This analysis showed that job satisfaction is a mediator of the effect of mentoring on organizational commitment. Being mentored has a direct effect on organizational commitment (from regression 2 , step $1, B=.508, p<.01$ ). If a participant was mentored, the person had higher organizational commitment. However, when job satisfaction was controlled, the regression coefficient for being mentored on organizational commitment became non-significant (from regression step 2 , $B=.134, p>.05$ ). In other words, the effect of mentoring worked through job satisfaction. If someone was mentored, he or she was more satisfied with his or her job, and this in turn was associated with greater organizational commitment.

\section{Research Question 3}

Research question 3 dealt with the relationship between the two predictor variables, mentored and job satisfaction, and the dependent variable organizational commitment, when controlling for the demographic variables. The researcher performed a hierarchical regression with organizational commitment as the dependent variable, three demographic variables entered in step 1, and mentoring and job satisfaction entered in step 2. This is summarized in Table 10.

In step 1 of the analysis, of the three variables that were entered (membership, age, years in position), it was found that age was significantly related to organizational commitment $(B=.285, p<.01)$. This suggests that the older the participant is the more likely he or she will be committed to the 
organization. The variance accounted for in organizational commitment by age was $R^{2}=.043$ (adjusted $R^{2}=.032$ ) indicating a small effect size.

In step 2 of the analysis, while controlling for three demographic variables (membership, position tenure, age) and mentoring, it was found that job satisfaction was a significant predictor of organizational commitment $(B=.059, p$ $<.01)$. The variance accounted for in organizational commitment by job satisfaction was $R^{2}=.616$ (adjusted $R^{2}=.608$ ) indicating a large effect size. Job satisfaction was the only significant predictor variable in step 2 . 
Table 10

Summary of Hierarchical Regression Analysis for Organizational Commitment Controlling for Demographic Variables $(N=256)$

Variable

Step 1

Membership

Age

Position Tenure

Step 2

Membership

Age

Position Tenure

Mentoring

Job Satisfaction
B SEB

$-.116$

.153

$-.047$

.285

.087

$.214^{\star *}$

$-.067$

.051

$-.086$

$-.098$

.009

$-.040$

.044

.057

.033

$-.033$

.033

$-.042$

.158

.109

.058

1.095

.059

$.763^{\star \star}$

Note. Total variance accounted for: In Step 1 is $R^{2}=.043$ (adjusted $R^{2}=.032$ ), In Step 2 is $R^{2}=.616$ (adjusted $R^{2}=.608$ ).

$\star * p<.01$.

\section{Summary}

This chapter presented: (a) descriptive statistics on the sample, (b) reliability coefficients on the job satisfaction and organizational commitment scales, and (c) the findings of the statistical tests conducted to answer the three 
research questions. This section also provided the descriptive statistics, results of the hierarchical regression analysis, and results of the mediational analysis. In this study the internal consistencies for the scales were: .90 for the 15item Organizational Commitment scale and .94 for the 36-item Job Satisfaction scale. Ninety-six percent of the participants were males, $56.6 \%$ were members of the NBMBAA, and $96.2 \%$ were African Americans. Forty-five percent of the participants reported receiving informal mentoring and $24.2 \%$ reported receiving formal mentoring.

In answering the three research questions, the results indicate that mentoring is a significant predictor of job satisfaction and organizational commitment, and that job satisfaction is a mediator of mentoring's effect on organizational commitment. These intriguing findings clearly show some of the organizational benefits of mentoring and will be influential to the mentoring literature. An enhanced discussion of the results is presented in chapter 5. 


\section{CHAPTER V \\ DISCUSSION AND CONCLUSIONS}

Introduction

The purpose of this chapter is to discuss the findings and implications of the study related to mentoring, job satisfaction, and organizational commitment among African American men, and draw conclusions for future mentoring research. This chapter presents the study's rationale, summary of the findings, theoretical contributions, implications of the findings, practical implications, limitations of the findings, future research recommendations, and conclusion.

Rationale for the Study

The purpose of the study was to examine the strength and direction of relationship between mentoring, job satisfaction, and organizational commitment among African American men exclusively in a business setting. Due to a lack of empirical mentoring research conducted on African American men, this study attempted to fill this gap. As noted in chapters 1 and 2, researchers indicated that historically people of color and women have been overlooked in most mentoring research (Ensher \& Murphy, 1997; Graham, 1992; Sue, 1999). Ensher and Murphy (1997) specifically suggested:

While mentoring has been shown to be very helpful for the career development of White males, upon whom most of the research has 
focused, only in the last few years have researchers begun to examine the importance of mentoring for women and people of color. (p. 461)

This study attempted to inform researchers interested in mentoring as it relates to minority research.

When it comes to mentoring African Americans, there are various programs where mentoring African American youth is a major component of its curriculum and/or mission. Organizations such as the Young Men Christian Association's (YMCA) Black Achievers program, 100 Black Men, NBMBAA, and Black Greek fraternities and sororities fall into this category. Ironically, while collecting data for this study, Alpha Phi Alpha Fraternity Incorporated was conducting a survey on mentoring African American males (youth). Even though these are examples of youth mentoring programs, the mentoring function received seems more aligned with the psychosocial rather than the career development function of mentoring. In these programs there is a keen focus of keeping the youth on the right track and exposing them to role models. Therefore, while there are many mentoring services offered to African American youth, we have little information about the type of mentoring experiences African American adults have once they begin working at the organizational level. The literature suggests a mentoring gap between adolescence and adulthood of African Americans; this study attempted to fill this gap.

\section{Summary of Findings}

This study was designed to answer the following research questions:

1. What is the relationship between mentoring and job satisfaction? 
2. What is the relationship between mentoring and organizational commitment?

3. After controlling for select demographic variables, what is the relationship between mentoring, job satisfaction, and organizational commitment? In answering research question 1, the survey results indicated that mentoring was a statistically significant predictor of job satisfaction among the African American men in this study $(B=.337, p<.01)$. The variance accounted for in job satisfaction by mentoring was $R^{2}=.032$ (adjusted $R^{2}=.028$ ), indicating a small effect size. Overall, this finding suggests mentored individuals were more likely to be satisfied with their job than those who were not.

In answering research question 2 , the survey results revealed that mentoring is a statistically significant predictor of organizational commitment among this study's African American men $(B=.508, p<.01)$. The variance accounted for in organizational commitment by mentoring was $R^{2}=.035$ (adjusted $R^{2}=.032$ ), indicating a small effect size. On the whole, this result demonstrates that mentored individuals were more likely to be committed to their organization than those who were not mentored.

In further analysis associated with answering research question 2, the mediational analysis results demonstrated that job satisfaction was a mediator of the relationship between mentoring and organizational commitment. Therefore, when job satisfaction was statistically controlled, the regression coefficient for being mentored on organizational commitment became non-significant (from regression 2 , step 2 , B $=.134, p>.05$ ). In other words, the evidence suggested 
that the effect of mentoring on organizational commitment worked through the job satisfaction variable. Thus, when someone was mentored in this study, there was likely to be greater job satisfaction, which in turn was associated with greater organizational commitment.

In answering research question 3, step 2 of the analysis indicated that, while statistically controlling for three demographic variables (e.g., membership, position tenure, age) in the first step of the hierarchical regression equation, and mentoring in the second step, job satisfaction was a statistically significant positive predictor of organizational commitment $(B=.059, p<.01)$. The unique variance accounted for in organizational commitment by job satisfaction was $R^{2}=$ .616 (adjusted $R^{2}=.608$ ), illustrating a large effect size. Additionally, the survey suggested that of the demographic variables (membership, age, position tenure), age was the sole variable making a unique statistically significant contribution to organizational commitment $(B=.285, p<.01)$. This result suggested that the older the participant was, the more likely they were committed to the organization. The variance accounted for in organizational commitment by age was $R^{2}=.043$ (adjusted $R^{2}=.032$ ), indicating a small effect size.

\section{Theoretical Contributions}

The theoretical framework that guided this research study was Bandura's (1977) social learning theory, which suggests that engaging in observations and direct experiences can be powerful means to job-related learning. The career component of mentoring involves a number of functions likely to be strongly influenced by social learning experiences, including sponsorship, protection, 
coaching, exposure and visibility, and challenging assignments (Kram, 1983). This career component involves specific developmental tasks to assist in the employee's career advancement (e.g., promotions, salary increases, greater job responsibilities) where the protégé may observe the mentor and/or gain experience through various assignments. For example, Dreher and Chargois (1998) found that graduates participating in a mentorship received $\$ 10,000$ more in annual compensation than those not in a mentorship. Additionally, the psychosocial function of mentoring includes role modeling, by which the mentor provides a standard to be measured. This role modeling function can impact the protégés performance and likelihood to remain in an organization. For example, Burke (1984) found that mentors performing the role model function had greater influences of a career nature. Thus, through a social learning theory lens, both the career and psychosocial functions of mentoring lend themselves to providing protégés (mentors can benefit as well) in particular significant opportunities to learn through a process of engaging in amble observational and experiential activities related to adapting to one's job, work group, and organization. This study's findings support the utility of social learning as a theoretical lens in guiding and interpreting the results of mentoring-related research. Further, the findings extend social learning theory by presenting evidence that social learning activity (i.e., mentoring) is a salient contributor to an important organizational outcome (i.e., organizational commitment) among non-majority research populations. 


\section{Mentoring and Job Satisfaction Findings}

Locke (1976) defined job satisfaction as “...a pleasurable or positive emotional state resulting from the appraisal of one's job and job experiences" ( $p$. 1307). The research results indicated that mentoring was a positive predictor of job satisfaction. This finding complements other mentoring studies that examined the relationship between mentoring and job satisfaction (e.g., Aremu \& Adeyoju, 2003; Baugh \& Scandura, 1999; Seibert, 1999).

The finding that mentoring is related to greater job satisfaction in this study supports Aremu and Adeyoju's (2003) work with a large group of Nigerian police officers where they found that mentoring influenced both job commitment and job satisfaction for the male and female officers. This study's findings also mirror Baugh and Scandura's research results (1999) where workplace mentoring relationships increased the likelihood of managerial and executive organizational commitment and job satisfaction. Further, the researcher's findings that mentoring influences job satisfaction also supports Seibert's (1999) field experiment results where engineering newhire mentoring facilitated higher job satisfaction. In that study, there was a positive relationship between the level of career and psychosocial mentoring received and job satisfaction for those participating in the facilitated mentor program.

A possible explanation for the significant relationship between mentoring and job satisfaction could be related to the functions of mentoring (psychosocial, career). When an employee develops personal and/or professional organizational links that assists their socialization into the organization, possible 
advancement opportunities, and networking, one plausibly becomes more satisfied with their job. This satisfaction may not necessarily indicate the individual is satisfied with the functions, tasks, or responsibilities of their job, but may indicate satisfaction with other more global aspects of the job (e.g., specialty, industry, co-workers, and culture).

Job Satisfaction and Organizational Commitment Findings Meyer and Allen (1991) defined organizational commitment as, “...the view that commitment is a psychological state that (a) characterizes the employee's relationship with the organization and (b) has implications for the decision to continue membership in the organization" (p. 67). The findings of this study support the notion that mentoring is a positive predictor of organizational commitment (e.g., Donaldson, Ensher, \& Grant-Vallone; Heiman \& Pittenger, 1996; Joiner, Bartram, \& Garreffa, 2004).

Like Donaldson, Ensher, and Grant-Vallone (2000), who found that mentoring was related strongly to organizational commitment among a sample of ethnically diverse, non-professional protégés $(N=408)$, this study's results demonstrated that job satisfaction had a strong influence on the organizational commitment of this study's African American male participants. This study's findings also support Heimann and Pittenger's (1996) faculty mentoring program research where protégés reporting a higher quality of relationship described themselves as benefiting more from the program, and reported higher levels of socialization and organizational commitment. Finally, this researcher's findings are concordant with Joiner et al.'s (2004) research where there was a positive 
association between mentoring and organizational commitment with managers participating in a formal mentoring program $(N=25)$.

An explanation for the relationship between mentoring and organizational commitment may again be related to the functions of mentoring (psychosocial, career), specifically the career function. If an employee perceives there is an advancement opportunity within the organization or is receiving challenging assignments where they are being exposed to senior executives with the potential for mobility, the relationship between mentoring and organizational commitment might increase.

An additional finding was that job satisfaction was a mediator of the relationship between mentoring and organizational commitment. This finding appears logical, as it would be less likely an employee would stay with an organization where he or she was not satisfied with their job, and is an extension of the aforementioned research. Moreover, age uniquely predicted organizational commitment, suggesting that the older employees were more likely to be committed to the organization.

\section{Practical Implications}

The results indicate that, as an African American man, having access to a mentor, whether formal or informal, can influence positively their job satisfaction and organizational commitment. In particular, finding ways to improve mentoring relationships might increase job satisfaction, which in turn would strongly influence commitment to the organization. Thus, it might be useful for managers 
to more clearly identify job-related tasks, activities, and goals that would foster better job satisfaction for the purpose of increasing organizational commitment.

\section{Limitations}

There are several limitations to this study that pertain to the generalizability of the findings. The first is that $43.4 \%$ of the respondents were not members of the NBMBAA. While the correspondences that were sent to the presidents specifically instructed the surveys to be sent to members of their chapters, there were a sizeable percentage of non-members who participated in the study. Because the survey Weblink could be forwarded to others, this result could be due to the participants forwarding the link to friends and colleagues. The second limitation to the study has to do with reporting the response rate. As there was not a database/directory available of all African American men in the chapters, the response rate could not be reported. However, 510 individuals visited the Weblink. These visits may include: (a) individuals who completed surveys, (b) individuals who partially completed surveys and did not return to complete the survey, (c) individuals who partially completed surveys and did not return to complete the survey because it did not pertain to them (e.g. females), and (d) individuals who previewed the survey but for some reason did not participate.

Because the study retrieved its data from questionnaires exclusively, the final limitation is associated with common method variance (Doty \& Glick, 1998). Using the survey called for participants to answer questions by self-reporting. Past studies have questioned self-reports for primarily two reasons: self-reports 
are prone to many kinds of response bias (Campbell \& Fiske, 1959; Donaldson, Thomas, \& Graham, 2002; Graham, Collins, Donaldson \& Hansen, 1993;

Schwartz, 1999; Stone, Turkkan, Bachrach, Jobe, Kurtzman, \& Cain, 2000) and inferences about correlational and causal relationships may be inflated by the problem of common method variance (Borman, 1991; Donaldson, Thomas, Graham, Au, \& Hansen, 2000; Spector, 1994). Notwithstanding, the strength and direction of the findings of the study are consistent with previous mentoring, job satisfaction, and organizational commitment research.

Future Research Suggestions

Based on the findings of the study, there is evidence that continuing research on minorities, specifically African American men, may be beneficial to extending the mentoring literature. The following provides the researcher's suggestions for future research.

Because the findings of the study indicated mentoring is a predictor of job satisfaction and organizational commitment of African American men, more mentoring research should be conducted on other minorities (e.g., Hispanic men and women, Asian men and women, African American women) to test the model presented in this study further. As proportional minority representation in the United States increases, it would be very useful for researchers to focus more of their efforts on these populations.

A second suggestion pertains to formal and informal mentoring. As indicated by Haynes (2003), "Prevailing trends suggests that formal mentoring and informal mentoring programs will continue to be used by organizations..." ( $p$. 
119). The demographic portion of the survey used for this study asked participants to identify whether their mentoring experience was formal, informal, or non-mentoring. For the purpose of analyzing the data, formal mentoring and informal mentoring were combined. This allowed the data to be dichotomized into two categories: mentored and non-mentored. The results indicated that mentoring, whether formal or informal, was a significant predictor of job satisfaction and organizational commitment. Additional studies should be designed specifically to collect data from far more participants to afford informal and formal mentoring experience comparisons among African American men, and to examine its impact on job satisfaction and organization.

A third suggestion pertains to the job performance of the protégé in the mentorship. The career function of mentoring involves: sponsorship, protection, coaching, exposure and visibility, and challenging assignments (Kram, 1983). As this career component specifically involves challenging assignments and coaching, do these functions lead to greater job performance of the protégé? Examining how mentoring, specifically the career function of mentoring, impacts the job performance of African Americans and other non-majority participants would be a productive extension of the job performance literature.

The mentoring literature consists largely of quantitative research. Thus, the mentoring literature could benefit from additional qualitative research that might identity, heretofore, unexamined variables related to mentoring in the research literature. For example, a researcher might ask what mentoring actually means to members of specific groups (e.g., women, men, minorities), which 
could be used in future mentoring studies when operationally defining mentoring for survey development purposes.

The final suggestion involves examining the psychosocial and career functions of mentoring more extensively. Because several studies investigating the impact of race in mentoring relationships found mixed results related to race and mentoring (e.g., Dreher \& Cox, 1996; Dreher \& Chargois, 1998; Ensher \& Murphy, 1997; Thomas, 1990; Viator, 2001), it would be interesting to conduct a quasi-experimental study to systematically investigate the mentoring outcomes of African American protégés when paired with same-race and different race mentors.

\section{Significance of Study}

Glatthorn (1998) indicated that certain criteria need to be present to determine the significance of a study, which includes: (a) extending existing knowledge; (b) changing prevailing beliefs; (c) suggesting relationships between phenomena; (d) extending a research methodology or instrument; and (e) providing greater depth of knowledge about previously studied phenomena. Below is an explanation of how this study met each of the criteria.

First, this study adds to previously conducted mentoring studies in that it examined mentoring for a specific population, which has received little emphasis in the mentoring literature, African American men. While there are mentoring studies that examined mentoring and its relationship with job satisfaction and organizational commitment (involving both genders and various ethnicities), this is the first study of its kind to examine the mentoring experiences of African 
American men and the outcomes of job satisfaction and organizational commitment. An important note about the findings is this study's findings complements previous mentoring studies examining job satisfaction and organizational commitment.

Graham (1992) indicated that 3.9\% of empirical research articles were conducted specifically with African Americans. Sue (1999) suggested that the lack of empirical research on minority groups may be because few researchers were interested in the topic and that there was little understanding about the implications of generalizing research findings to disparate populations. Thus, if a study was not designed with a certain minority in mind, researchers should be far more cautious about generalizing their findings to minorities. Because there is a lack of empirical research involving African American men in general, this study may encourage future research with African American males, and other minorities.

The findings of this study indicated that mentoring is a positive significant predictor of African American male job satisfaction and organizational commitment. These interesting findings can be beneficial to many organizations that are in need of retaining top talent who happen to be African American men. It is important to note that while mentoring was found to be a significant predictor, it is not suggested that it is the only means to employee job satisfaction and organizational commitment.

This study also extended the research by employing a rigorous research methodology which employed hierarchical regression and mediational analyses 
to analyze the data. The hierarchical regression model indicated that mentoring is a significant predictor of job satisfaction and organizational commitment. However, in step 2 of the mediational analysis, it was found that, controlling for job satisfaction, being mentored was not significantly related to organizational commitment. The mediational analysis also found that controlling for being mentored; job satisfaction was significantly related to organizational commitment. Therefore, the mediational analysis allowed an explanation that the impact of mentoring on organizational commitment was through the job satisfaction variable.

Lastly, according to Holton and O'Neill (2002), these variables (job satisfaction and organizational commitment) are important because organizations incur costs associated with recruiting, socializing, and training new hires. Therefore, instead of using monies to recruit, train, and socialize new employees, these monies may be useful in recruitment and retention interventions, such as mentoring, as a means to retain current employees.

\section{Conclusion}

The findings of the study indicate that mentoring is a statistically significant predictor of job satisfaction, mentoring is a statistically significant predictor of organizational commitment, and job satisfaction is a statistically significant and strong predictor of organizational commitment. These findings are salient to the mentoring literature, as it suggests that mentoring is one avenue to job satisfaction and organizational commitment. This implies that if organizations are seeking how to facilitate African American men's commitment to the organization, 
based on this study, human resource professionals and managers should explore creative means to increase both positive mentoring activities and job satisfaction. 


\section{REFERENCES}

Allen, N., \& Meyer, J. P. (1990). The measurement and antecedents of affective, normative and continuance commitment to the organization. Journal of Occupational Psychology, 63, 1-18.

Allen, T. D., Day, R., \& Lentz, E. (2002). Interpersonal comfort in mentorships: A mediation mechanism. Paper presented at the $17^{\text {th }}$ Annual Conference of the Society of Industrial and Organizational Psychology, Toronto, ON.

Allen, T. D., Eby, L. T., Poteet, M. L., Lentz, E., \& Lima, L. (2004). Career benefits associated with mentoring for protégés: A meta-analysis. Journal of Applied Psychology, 89, 127-136.

Allen, T. D., \& Poteet, M. L. (1999). Developing effective mentoring relationships: Strategies from the mentors' viewpoint. Career Development Quarterly, 48, 59-73.

Allen, T. D., Poteet, M. L., \& Burroughs, S. M. (1997). The mentor's perspective: A qualitative inquiry and future research agenda. Journal of Vocational behavior, 51, 70-89.

Andrews, B. D., \& Quinn, R. J. (2005). The effects of mentoring on first-year teachers' perceptions of support received. The Clearing House, 78, 110116.

Aremu, A. O., \& Adeyoju, C. A. (2003). Job commitment, job satisfaction and gender as predictors of mentoring in the Nigeria Police. An International Journal of Police Strategies \& Management, 26, 377-385.

Atkinson, D. R., Casas, A., \& Neville, H. (1994). Ethnic minority psychologists: Whom they mentor and benefits they derive from the process. Journal of Multicultural Counseling \& Development, 22, 37-49.

Bandura, A. (1982). Self-efficacy mechanism in human agency. American Psychologist, 37, 122-147. 
Bandura, A. (1994). Self-efficacy. In V. S. Ramachaudran (Ed.), Encyclopedia of human behavior (Vol. 4 ,pp. 71-81). New York: Academic Press.

Baugh, S. G., \& Scandura, T. A. (1999). The effects of multiple mentors on protégé attitudes toward the work setting. Journal of Social Behavior \& Personality, 14, 503-521.

Berger, D. E. (2004). Using regression analysis. In J. S. Wholey, \& H. P. Hatry (Eds.), Handbook of Practical Program Evaluation (pp. 479-505). San Francisco: Jossey-Bass.

Blackwell, J. E. (1989). Mentoring: An action strategy for increasing minority faculty. Academe, 75, 8-14.

Blake-Beard, S. D. (1999). The costs of living as an outsider within: An analysis of the mentoring relationships and career success of black and white women in the corporate sector. Journal of Career Development, 26, 21-36.

Blau, G. (1985). The measurement and prediction of career commitment. Journal of Occupational Psychology, 58, 277-288.

Borman, W. C. (1991). Job behavior, performance, and effectiveness. In M. D. Dunnette \& L. M. (Eds.), Handbook of industrial and organizational psychology (p. 271-326). Newbury Park, CA: Sage.

Bradley, D. E., \& Roberts, J. A. (2004). Self-employment and job satisfaction: Investigating the role of self-efficacy, depression, and seniority. Journal of Small Business Management, 42, 37-58.

Brief, A. P., \& Roberson, L. (1987). Job attitude organization: An exploratory study. Paper presented at the meeting of the Academy of Management, New Orleans.

Burke, R. J. (1984). Mentors in organizations. Group and Organization Studies, 9, 353-372.

Burke, R. J. (1991). Early work and career experiences of female and male managers and professionals: Reasons for optimism? Canadian Journal of Administrative Sciences, 8, 224-230.

Burke, R. J., \& McKeen, C. A. (1996). Gender effects in mentoring relationships. Journal of Social Behavior \& Personality, 11, 91-104.

Butler, S. (1944). The odyssey of Homer. Roslyn, New York: Walter J. Black. 
Cameron, W. W., \& Blackburn, R. T. (1981). Sponsorship and academic career success. Journal of Higher Education, 52, 369-377.

Campbell, D. T., \& Fiske, D. W. (1959) Convergent and discriminant validation by multi-trait-multimethod matrix. Psychological Bulletin, 56, 81-105.

Campbell-Whately, G. D., \& Allgozzine, B. (1997). Using mentoring to improve academic programming for African American male youths with mild disabilities. School Counselor, 44, 362-367.

Carmin, C. N. (1988). Issues in research on mentoring: Definitional and methodological. International Journal of Mentoring, 2, 9-13.

Castro, S. L., \& Scandura, T. A. (2004). The tale of two measures: Evaluation and comparison of Scandura's (1992) and Ragins and McFarlin's (1990) mentoring measures. Paper presented at the Southern Management Association Meeting, San Antonio, TX.

Chao, G. T., Walz, P. M., \& Gardner, P. D. (1992). Formal and informal mentorships: A comparison on mentoring functions and contrast with nonmentored counterparts. Personnel Psychology, 45, 619-636.

Chao, G. T. (1997). Mentoring phases and outcomes. Journal of Vocational Behavior, 51, 15-28.

Clark, S. M., \& Corcoran, M. (1986). Perspectives in the professional socialization of women faculty: A case of accumulative disadvantage? Journal of Higher Education, 57, 20-43.

Collins, L. M., \& Killough, L. N. (1992). An empirical example of stress in public accounting. Accounting, Organizations and Society, 17, 535-547.

Collins, P. M., Kamya, H. A., \& Trouse, R. W. (1997). Questions of racial diversity and mentoringship: An empirical exploration. Social Work, 42, 145-152.

Cook, J. D., Hepworth, S. J., Wall, T. D., \& Warr, P. B. (1981). The experience of work: A compendium and review of 249 measures and their use. San Diego: Academic Press.

Crano, W. D., \& Brewer, M. B. (2002). Principles and Methods of Social Research $\left(2^{\text {nd }}\right.$ ed.). Mahwah, NJ: Lawrence Erlbaum Associates.

Crawford, K., \& Smith, D. (2005). The we and the us: Mentoring African American women. Journal of Black Studies, 36, 52-67. 
Day, R., \& Allen, T. D. (2004). The relationship between career motivation and self-efficacy with protégé career success. Journal of Vocational Behavior, $64,72-91$.

Dillman, D. A., Christenson, J. A., Carpenter, E. H., \& Brooks, R. (1974). Increasing mail questionnaire response: A four-state comparison. American Sociological Review, 39, 744-756.

Donaldson, S. I., Ensher, E. A., \& Grant-Vallone, E. J. (2000). Longitudinal examination of mentoring relationships on organizational commitment and citizenship behavior. Journal of Career Development, 26, 233-249.

Donaldson, S. I., Thomas, C. W., \& Graham, J. W. (2002) Understanding selfreport bias in prevention research. Manuscript under review.

Donaldson, S. I., Thomas, C. W., Graham, Au, J., \& Hansen, W. B. (2000). Verifying drug prevention program effects using reciprocal best friend reports. Journal of Behavioral Medicine, 23, 221-234.

Douglas, C. A. (1997). Formal mentoring programs in organizations: An annotated bibliography. Greensboro, NC: Center for Creative Leadership.

Doty, D. H., \& Glick, W. H. (1998). Common method bias: Does common methods variance really bias results? Organizational Research Methods, $1,374-406$.

Dreher, G. F., \& Ash, R. A. (1990). A comparative study of mentoring among men and women in managerial, professional, and technical positions. Journal of Applied Psychology, 75, 539-546.

Dreher, G. F., \& Chargois, J. A. (1998). Gender, mentoring experiences, and salary attainment among graduates of an historically black university. Journal of Vocational Behavior, 53, 401-416.

Dreher, G. F., \& Cox, T. H., Jr. (1996). Race, gender, and opportunity: A study of compensation attainment and the establishment of mentoring relationships. Journal of Applied Psychology, 81, 297-308.

Eby, L. T., \& Lockwood, A. (2004). Protégés and mentors' reactions to participating in formal mentoring programs: A qualitative investigation. Journal of Vocational Behavior, 67, 441-458.

Eby, L. T., \& McManus, S. E. (2002). The protégé's role in negative mentoring experiences. Journal of Vocational Behavior, 65, 255-275. 
Eby, L. T., McManus, S. E., Simon, S. A., \& Russell, J. E. (2000). The protégés perspective regarding negative mentoring experiences: The development of a taxonomy. Journal of Vocational Behavior, 57, 1-21.

Ensher, E. A., \& Murphy, S. E. (1997). Effects of race, gender, perceived similarity, and contact on mentor relationships. Journal of Vocational Behavior, 50, 460-481.

Erikson, E. H. (1963). Childhood and society. New York: W. W. Norton.

Fagenson, E. A. (1989a). The mentor advantage: Perceived career/job experiences of protégés versus non-protégés. Journal of Organizational Behavior, 10, 309-320.

Fagenson, E. A. (1986b). The mentor advantage: Career and job experiences considered. Paper presented at the Academy of Management Conference, New Orleans.

Fagenson-Eland, E. A., Marks, M. A., \& Amendola, K. L. (1997). Perceptions of mentoring relationships. Journal of Vocational Behavior, 51, 29-42.

Farmer, H. S. (1985). Model of career and achievement motivation for women and men. Journal of Counseling Psychology, 32, 363-390.

Ford, D. L. \& Wells, L. (1985). Upward mobility factors among black public administrators: The role of mentors. Centerboard: Journal of the Center for Human Relations, 3, 33-48.

Gaskill, L. R. (1993). A conceptual framework for the development, implementation, and evaluation of formal mentoring programs. Journal of Career Development, 20, 147-160.

Glatthorn, A. (1998). Writing the winning dissertation: A step-by-step guide. Thousand Oaks, CA: Corwin Press, Inc.

Goyder, J. C. (1985). Face-to-face interviews and mail questionnaires: The net difference in response rate. Public Opinion Quarterly, 49, 234-252.

Graham, J. W., Collins, N. L., Dondaldson, S. I., \& Hansen, W. B. (1993). Understanding and controlling for response bias: Confirmatory factor analysis of multitratit-multimethod data. In R. Steyer, K. F. Wender, \& K. F. Widamen (Eds.), Psychometric Methodology (p. 585-590). Stuttgart and New York: Gustav Fisher Verlag. 
Greenhaus, J. H., Parasuraman, S., \& Wormley, W. M. (1990). Effects of race on organizational experiences, job performance evaluations, and career outcomes. Academy of Management Journal, 33, 64-86.

Hackman, R., \& Oldham, G. (1980). Work Redesign. Menlo Park, CA: Addison Wesley Publishing Company.

Haynes, R. (2003). A comparative analysis of mentoring as a socialization strategy among law faculty. Unpublished doctoral dissertation, University of Louisville.

Heimann, B., \& Pittenger, K. (1996). The impact of formal mentorship on socialization and commitment of newcomers. Journal of Managerial Issues, 3, 108-117.

Heneman, H. G., \& Schwab, D. P. (1985). Pay satisfaction: Its multidimensional nature and measurement. Journal of Psychology, 20, 129-141.

Holton, B. C., \& O'Neill, B. S. (2002). Job embeddedness: A theoretical foundation for developing a comprehensive nurse retention plan. Journal of Nursing Administration, 34, 216-227.

Hopkins-Thompson, P. A. (2000). Colleagues helping colleagues: Mentoring and coaching. National Association of Secondary School Principals. NASSP Bulletin, 84, 29-36.

Heberlein, T. A., \& Baumgartner, R. (1978). Factors affecting response rates to mailed questionnaires: A quantitative analysis of the published literature. American Sociological Review, 43, 447-462.

Joiner, T.A., Bartram, T., \& Garreffa, T. (2004). The effects of mentoring on perceived career success, commitment and turnover. Journal of American Academy of Business, 5, 164-170.

Kahn, R. L., Wolfe, D. M., Quinn, R. P., Snoek, J. D., \& Rosenthal, R. (1964). Organizational stress: Studies in role conflict and ambiguity. New York: Basic Books.

Kaplowitz, M. D., Hadlock, T. D., \& Levine, R. (2004). A comparison of web and mail survey response rates. Public Opinion Quarterly, 68, 94-101.

Katerberg, R., \& Green, S. G. (1982). Unpublished survey. University of Cincinnati.

Kelinger, F. N. (1986). Foundations of Behavioral Research, $3^{\text {rd }}$ ed. CBS Publishing Limited: Japan. 
Kipnis, D., \& Schmidt, S. (1980). Management Survey Audit. Temple University.

Kopelman, R. E., Greenhaus, J. H., \& Connolly, T. F. (1983). A model of work, family, and interrole conflict: A construct validation study. Organizational Behavior and Human Performance, 32, 198-215.

Koresdoski, A. E. (2002). The value of distance learning MBA programs to employers and employees. Unpublished doctoral dissertation, Nova Southeastern University.

Kossek, E. E., Roberts, K., Fisher, S., \& Demarr, B. (1998). Career selfmanagement: A quasi-experimental assessment of the effects of a training intervention. Personnel Psychology, 51 935-962.

Kram, K. E. (1983). Phases of the mentoring relationship. Academy of Management Journal, 26, 608-625.

LaVant, B. D., Anderson, J. L., and Tiggs, J. W. (1997). Retaining African American men through mentoring initiatives. New Directions for Student Services, 80, 43-53.

Levin, I., \& Stokes, J. P. (1989). Dispositional approach to job satisfaction: Role of negative affectivity. Journal of Applied Psychology, 74, 752-758.

Liden, C., Wayne, S. J., \& Stillwell, D. (1993). A longitudinal study on the early development of leader-member exchanges. Journal of Applied Psychology, 78, 622-674.

Linnehan, F. (2001). The relation of a work-based mentoring program to the academic performance and behavior of African American students. Journal of Vocational Behavior, 59, 310-325.

Locke, E. A., 1976. The nature and causes of job satisfaction. Handbook of industrial and organizational psychology, 1297-1349. Chicago: Rand McNally.

Lodahl, T., \& Kejner, N. (1965). The definition and measurement of job involvement. Journal of Applied Psychology, 49, 24-33.

London, M. (1993). Relationships between career motivation, empowerment, and support for career development. Journal of Occupational and Organizational Psychology, 66, 55-69. 
Lu, K. Y., Lin, P. L., Wu, C. M., Hsieh, Y. L., and Chang, Y. Y. (2002). The relationships among turnover intentions, professional commitment, and job satisfaction of hospital nurses. Journal of Professional Nursing, 18, 214219.

Malone, B. (1981). Relationship of black female administrators mentoring experiences and career satisfaction. Unpublished doctoral dissertation, University of Cincinnati.

Marshall, C., \& Rossman, G. B. (1995). Designing Qualitative Research (2 ${ }^{\text {nd }}$ ed.). Thousand Oaks, CA: Sage.

Maurer, T. J., Barbeite, F. G., \& Mitchell, D. R. (2002). Predictors of attitudes towards a 360-degree feedback system and involvement in post-feedback development activity. Journal of Occupational \& Organizational Psychology, 75, 87-107.

McFarlin, D. B., \& Sweeney, P. D. (1992). Distributive and procedural justice as predictors of satisfaction with personal and organization outcomes. Academy of Management Journal, 35, 626-637.

Mehta, R., \& Sivadas, E. (1995). Comparing response rates and response content in mail vursus electronic mail surveys. Journal of the Market Research Society, 37, 429-439.

Meyer, J. P. \& Allen, N. J. (1991). Testing the "side bet theory" of organizational commitment: Some methodological considerations. Journal of Applied Psychology, 69, 372-378.

Meyer, J. P., \& Allen, N. J. (1991). A three-component conceptualization of organizational commitment. Human Resource Management Review, 1, 61-89.

Meyer, J. P., Allen, N. J. \& Smith, C.A. (1993). Commitment to organizations and occupations: Extension and test of a three-component conceptualization. Journal of Applied Psychology, 78, 538-531.

Mobley, G. M., Jaret, C., Marsh, K., \& Lim, Y. Y. (1994). Mentoring, job satisfaction, gender, and the legal profession. Sex Roles, 31, 79-98.

Moorman, R. H. (1991). Relationship between organizational justice and organizational citizenship behavior: Do fairness perceptions influence employee citizenship? Journal of Applied Psychology, 76, 845-855.

Mowday, R., Steers, R. M., \& Porter, L. W. (1979). The measurement of organizational commitment. Journal of Vocational Behavior, 14, 224-247. 
Mueller, C. W., \& Wallace, J. E. (1996). Justice and the paradox of contented female worker. Social Psychology Quarterly, 59, 338-349.

Mungania, P. (2004). Employee's perceptions of barriers in e-learning: The relationship among barriers, demographics, and e-learning self-efficacy. Unpublished doctoral dissertation, University of Louisville.

Murray, M. (1991). Beyond the myths and magic of mentoring: How to facilitate an effective mentoring program. San Francisco: Jossey-Bass.

Nadler, D. A., Jenkins, G. D., Cummings, L. L., \& Dunham, R. B. (1989). The Michigan organizational assessment package: Progress report II. Ann Arbor, MI: Institute for Social Research.

Newton, R. R., \& Rudestam, K. E. (1999). Your statistical consultant: Answers to your data analysis questions. Thousand Oaks, CA: Sage

Noller, R. B. (1982). Mentoring: A voice scarf. New York: Bearly Limited.

Noe, R. A. (1988). An investigation of the determinants of successful assigned mentoring relationships. Personnel Psychology, 41, 457-479.

Noe, R. A., Noe, A. W., \& Bachhuber, J. A. (1990). An investigation of correlates of career motivation. Journal of vocational Behavior, 37, 340-356.

Nunnally, J. C., \& Bernstein, I. H. (1994). Psychometric theory ( $3^{\text {rd }}$ ed.). New York; McGraw-Hill.

Organ, D. W. (1988). Organizational Citizenship Behavior. Lexington, MA: Lexington Books.

O'Reilly, C., III, \& Chatman, J. (1986). Organizational commitment and psychological attachment: The effects of compliance, identification, and internalization on prosocial behavior. Journal of Applied Psychology, 71, 492-499.

Orpen, C, (1997). The effects of formal mentoring on employee work motivation, organizational commitment and job performance. The Learning Organization, 4, 53-60.

Ortiz-Walters, R. \& Gilson, L. L. (2005). Mentoring in academia: An examination of the experiences of protégés of color. Journal of Vocational Behavior, $67,459-475$. 
Packard, B. W., Walsh, L., and Seidenberg, S. (2004). Will that be one mentor or two? A cross-sectional study of women's mentoring during college. Mentoring and Tutoring, 12, 71-85.

Pearlin, L, I., Liberman, M. A., Menaghan, E. G., and Mullan, J. T. (1981). The stress process. Journal of Health and Social Behavior, 22, 337-356.

Pellegrini, E. K., \& Scandura, T. A. (2005). Construct equivalence across groups: An unexplored issue in mentoring research. Educational and Psychological Measurement, 65, 323-335.

Pierce, J. L., Gardner, D. G., Cummings, L. L., \& Dunham, R. B. (1989). Organization-based self-esteem: Construct definition, measurement, and validation. Academy of Management Journal, 32, 622-648.

Pollack, M. (1990). An in-depth analysis of mentoring and non mentoring work relationships. Unpublished doctoral dissertation, University of Manitoba, Winnipeg.

Price, J. L. (1990). Wilford Hall Medical Center Retention Survey. Lackland Air Force Base, TX.

Price. J. L., \& Mueller, C. W. (1986). Absenteeism and turnover of hospital employees. Greenwich, CT: JAI Press.

Porter, L., Steers, R. M., Mowday, R. T., \& Boulian, P. V. (1974). Organizational commitment, job satisfaction, and turnover amongst psychiatric technicians. Journal of Applied Psychology, 59, 603-609.

Quinn, R. P., \& Shepard, L. J. (1974). The 1972-1973 Quality of Employment Survey. Institute for Social Research, University of Michigan, Ann Arbor, MI.

Quinn. R. P., \& Staines, G. L. (1979). The 1977 Quality of Employment Survey. Ann Arbor, MI: Institute for Social Research.

Raabe, B., \& Beehr, T. A. (2003). Formal mentoring versus supervisor and coworker relationships: Differences in perceptions and impact. Journal of Organizational Behavior, 24, 271-293.

Ragins, B. R., \& Cotton, J. L. (1993). Gender and willingness to mentor in organizations. Journal of Management, 19, 97-111.

Ragins, B. R., \& Cotton, J. L. (1999). Mentor functions and outcomes: A comparison of men and women in formal and informal mentoring relationships. Journal of Applied Psychology, 84, 529-550. 
Ragins, B. R., Cotton, J. L., \& Miller, J. S. (2000). Marginal mentoring: The effects of type of mentor, quality of relationship, and program design on work and career attitudes. Academy of Management Journal, 43, 11771194.

Ragins, B. R. and McFarland, D (1990). Perception of mentor roles in crossgender mentoring relationships. Journal of Vocational Behavior, 37, 321339.

Ragins, B. R., \& Scandura, T, A. (1999). Burden or blessing? Expected costs and benefits for being a mentor. Journal of Organizational Behavior, 20, 493-509.

Russo, A. (Producer), \& Landis, J. (Director/Screenwriter). (1983). Trading Places [Motion picture]. United States: Cinema Group Ventures and Paramount Pictures.

Rusbult, C. E. Martz, J. M., \& Agnew, C. R. (1999). The investment model scale: Measuring commitment level, satisfaction level, quality of alternatives, and investment size. Personal Relationships, 5, 357-392.

Sacket, P. R., \& Larson, J. R. (1990). Research strategies and tactics in industrial and organizational psychology. In M. D. Dunnette 7 L. M. Hough (Eds.), Handbook of industrial and organizational psychology (p. 419-489). Palo Alto, CA: Consulting Psychologists Press.

Scandura, T. A. (1997). Mentoring and organizational justice: An empirical investigation. Journal of Vocational Behavior, 51, 58-69.

Scandura, T. A., \& Katterberg, R. J. (1988). Much ado about mentors and little ado about measurement. Development of an instrument. Paper presented at the meeting of the National Academy Management. Anaheim.

Scandura, T. A., \& Schriesheim, C. A. (1991). Effects of structural characteristics of mentoring dyads on protégé career outcomes. In D. F. Ray and M. E. Schnake (Eds.), Proceedings of the southern Management Association, 306-208.

Schonlau M., Fricker R., \& Elliott M. (2002). Conducting research surveys via email and the Web. Santa Monica, CA: Rand.

Schwartz, N. (1999). Self-reports: How the questions shape the answers. American Psychologist, 54, 93-105. 
Seibert, S. (1999). The effectiveness of facilitated mentoring: A longitudinal quasi-experiment. Journal of Vocational Behavior, 54, 483-502.

Shannon, D. M., \& Bradshaw, C. C. (2002). A comparison of response rate, response times, and costs of mail and electronic surveys. The Journal of Experimental Education, 70, 179-192.

Sheehan, K. B. \& Hoy, M. G. (1999). Using e-mail to survey Internet users in the United States: Methodology and Assessment. Journal of Computer Mediated Communication, 4(3). Retrieved January 12, 2007 from http://jcmc.indiana.edu/vol4/issue3/sheehan.html

Simsek, Z., \& Veiga, J. F. (2001). A primer on Internet organizational surveys. Organizational Research Methods, 4, 218-235.

Smith, P. C., Balzar, W., Brannick, M., Chia, W., Eggleston, S., Gibson, W., Johnson, B., Josephson, J., Paul, K., Reilly, C., \& Walen, M. (1987a). The revised JDI: A facelift for an old friend. The Industrial Psychologist, 24, 31-33.

Smith, P. C., Balzer, W., Brannick, M., Eggleston, S., Gibson, W., Johnson, G., Josephson, H., Paul, K., Reilly, C., \& Whalen, M. (1987b). Manual for the revised JDI and Job in General scales. Bowling Green State University.i

Smith, P. C., Kendall, L. M., \& Hulin, C. L. (1969). The measurement of satisfaction in work and retirement. Chicago: Rand McNally.

Smith, J. W., Smith, W. J., \& Markham, S. E. (2000). Diversity issues in mentoring academic faculty. Journal of career Development, 26, 251-262.

Smith, T. M., \& Ingersoll, R. M. (2004). What are the effects of induction and mentoring on beginning teacher turnover? American Educational Research Journal, 41, 681-715.

Snyder, M. (1987). Public appearance/private realities. New York: Freeman.

Sosik, J. J., \& Godshalk, V. M. (2000). The role of gender in mentoring: Implications for diversified and homogenous mentoring relationships. Journal of Vocational Behavior, 57, 102-122.

Spector, P. E. (1985). Measurement of human service staff satisfaction: Development of the Job Satisfaction Survey. American Journal of Community Psychology 13, 693-713.

Stallworth, H. L. (2003). Mentoring, organizational commitment and intentions to leave public accounting. Managerial Auditing Journal, 18, 405-418. 
Stainback, S., \& Stainback, W. (1988). Understanding and conducting qualitative research. Reston, VA: The Council for Exceptional Children.

Stevens, J. P. (2002). Applied multivariate statistics for the social sciences ( $4^{\text {th }}$ ed.). Lawerence Erlbaum Associates, Inc.: Mahwah, New Jersey.

Stone, A. A., Turkkan, J. S., Bachrach, C. A., Jobe, J. B., Kurtzman, H. S., \& Cain, V. S. (2000). The science of self-report: Implications for research and practice. Mahwah, NJ: Lawerence Erlbaum Assoicates.

Sue, S. (1999). Science, ethnicity, and bias: Where have we gone wrong? American Psychologist, 54, 1070-1077.

Tenenbaum, H. R., Crosby, F. J., \& Gilner, M. D. (2001). Mentoring relationships in graduate school. Journal of Vocational Behavior, 59, 326-341.

Tharenou, P. (2005). Does mentor support increase women's career advancement more than men's? The differential effects of career and psychosocial support. Australian Journal of Management, 30, 77-109.

Thies-Sprinthall, L. (1986). A collaborative approach for mentor training: A working model. Journal of Teacher Education, 37, 13-20.

Thomas, D. A. (1990). The impact of race on managers' experiences of developmental relationships (mentoring and sponsorship): An intraorganizational study. Journal of Organizational Development, 11, 479-492.

Tillman, L. C. (2001). Mentoring African American faculty in predominately White institutions. Research in Higher Education, 42, 295-325.

Turban, D. B., \& Dougherty, T. W. (1994). Role of protégé personality in receipt of mentoring and career success. Academy of Management Journal, 37, 688-702.

Turban, D. B., \& Jones, A. P. (1988). Supervisor-subordinate similarity: Types, effects and mechanisms. Journal of Applied Psychology, 73, 228-234.

United States Census Bureau (2000). The Black population: 2000. Census 2000 brief. Retrieved May 12, 2006 from http://www.census.gov/population/www/cen2000/briefs.html

Utsey, S. O, Howard, A, \& Williams III, O. (2003). Therapeutic group mentoring with African American male adolescents. Journal of Mental Health Counseling, 25, 126-139. 
Viator, R. E. (2001). An examination of African Americans' access to public accounting mentors: Perceived barriers and intentions to leave. Accounting, Organizations, and Society, 26, 541-561.

Wallace, J. E. (2001). The benefits of mentoring for female lawyers. Journal of Vocational Behavior, 58, 366-391.

Wayne, S. J., \& Ferris, G. R. (1990). Influence tactics, affect, and exchange quality in supervisor-subordinate interactions: A laboratory experiment and field study. Journal of Applied Psychology, 75, 487-499.

Watson, D., \& Tellegen, A. (1985). Toward a consensual structure of mood. Psychological Bulletin, 98, 219-235.

Weiss, D. J., Dawis, R. V., England, G. W., \& Lofquist, L. H. (1967). Manual for the Minnesota Satisfaction Questionnaire. University of Minnesota: Industrial Relations Center.

Whitely, W., Dougherty, T. W., \& Dreher, G. F. (1991). Relationship of career mentoring and socioeconomic origin to managers and professionals' early career progress. Academy of Management Journal, 34, 331-351.

Williams, L. J., \& Anderson, S. E. (1991). Job satisfaction and organizational commitment as predictors of organizational citizenship and in-role behaviors. Journal of Management, 17, 601-617.

Young, B. S., \& Worchel, Stephen (1998). Organizational commitment among public service employees. Public Personnel Management, 27, 339-348. 
APPENDICES 


\section{APPENDIX A}

Internal Review Board Approval Letter 


\section{APPENDIX B \\ Letter of request for permission to use the Organizational Commitment Questionnaire}


From: Davis Robinson [mailto:Davisro@ulh.org]

Sent: Monday, August 28, 2006 10:51 AM

To: Pike, Mary Alice

Cc: Davis Robinson

Subject: Organizational Commitment Questionnaire Importance: High

Good afternoon Ms. Pike,

I am a doctoral candidate at the University of Louisville and I am pursuing a Ph.D. in Organizational Development. My dissertation is a study of Job Satisfaction and Organizational Commitment. To assist my study I would like to use Mowday, Steers, and Porter's Organizational Commitment Questionnaire. I am aware that Dr. Porter is a professor in the Graduate School of Management and would like find how Dr. Porter proceeds with requests such as mine. So that I may use this questionnaire, I am writing to find out what type of permission is needed to acquire the questionnaire, the best way to obtain a copy, and what stipulations are associated with using the questionnaire. You guidance would be most appreciated.

Sincerely,

Davis M. Robinson, M.Ed.

Attached please find a scanned copy. Per Prof. Porter, you do not need permission to use this, so feel free. Good luck to you.

mary alice 


\section{APPENDIX C}

Stipulations for using the Job Satisfaction Scale 
The Job Satisfaction Survey, JSS is a copyrighted scale. You are welcome to use the JSS for free under two conditions.

1. The use is for noncommercial educational or research purposes. This means no one is charging anyone a fee.

2. You agree to share results with me. This is how I continue to update the norms and bibliography.

\section{What Results Do I Need?}

1. Means per subscale and total score

2. Sample size

3. Brief description of sample, e.g., 220 hospital nurses. I don't need to know the organization name if it is sensitive.

4. Name of country where collected, and if outside of the U.S., the language used. I am especially interested in nonAmerican samples.

5. Standard deviations per subscale and total score (optional)

6. Coefficient alpha per subscale and total score (optional)

I would love to see copies of research reports (thesis, dissertation, conference paper, journal article, etc.) in which you used the JSS. Summaries are fine for long documents (e.g., dissertation), and e-mailed documents are preferred if possible (saves copy and mail costs). Be sure to indicate how you want the work cited in the bibliography.

You can send the material to me via e-mail: spector@chuma.cas.usf.edu or via regular mail: Paul Spector, Department of Psychology, University of South Florida, Tampa, FL 33620 USA.

Copyright Paul E. Spector, All rights reserved, Last modified November 2, 1998. http://shell.cas.usf.edu/ spector/scales/jssshare.html 


\section{APPENDIX D}

Questionnaire 


\section{PART I}

DEMOGRAPHICS

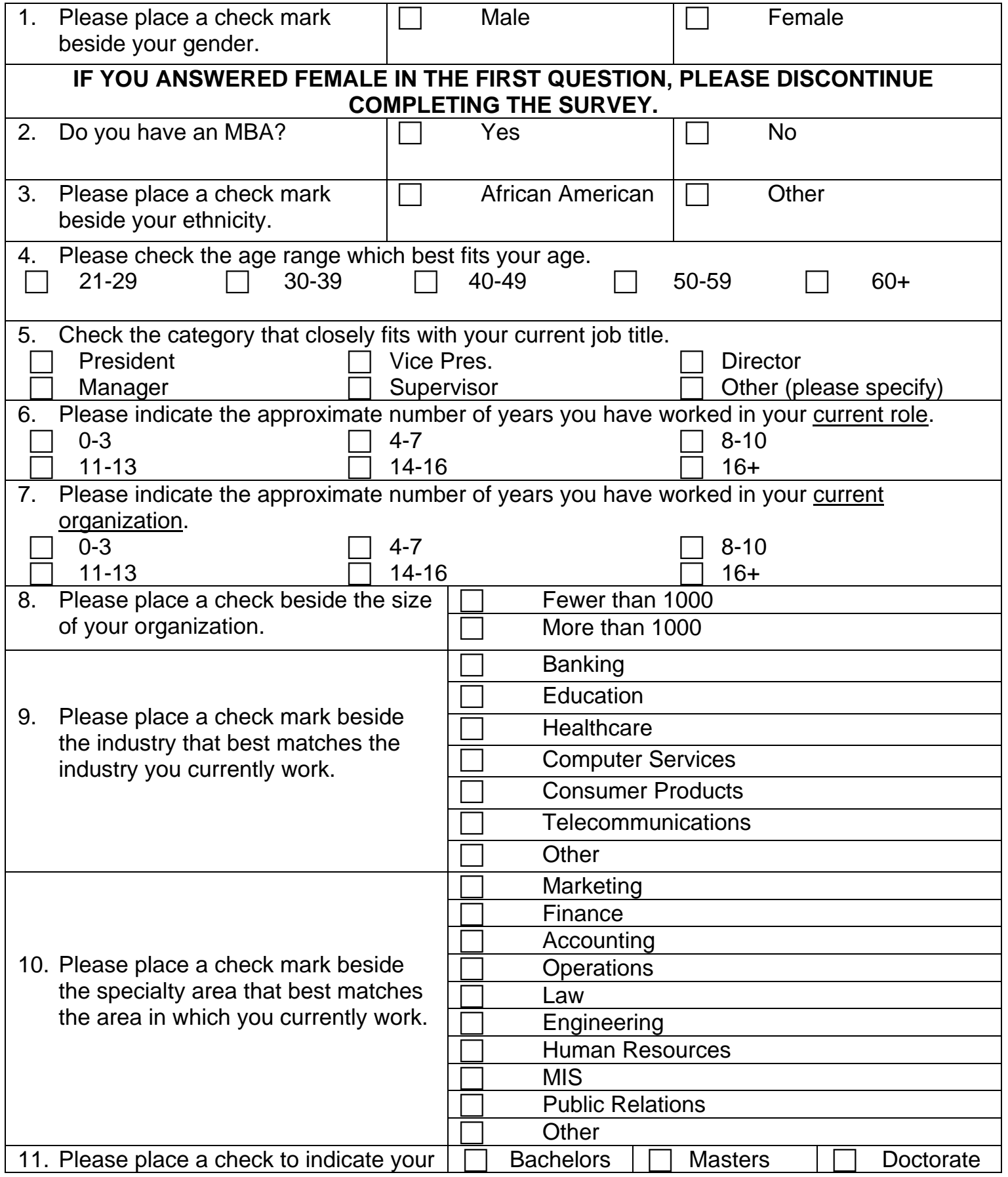




\begin{tabular}{|l|c|c|c|}
\hline $\begin{array}{l}\text { educational level. (Please check all } \\
\text { that apply). }\end{array}$ & $\square$ & MA & \\
& & MAT & \\
& & MBA & \\
& & MED & MFA \\
& & MPH & \\
& & MPA & \\
& & MPH & \\
& & MS & MUP \\
& & $\square$ & MUP \\
\hline
\end{tabular}




\section{PART II}

\section{MENTORING QUESTIONNAIRE}

\section{Mentoring Operationally Defined}

Informal Mentoring: A naturally occurring relationship based on attributes, attraction and similar interests, where an experienced organizational member provided career and psychosocial support to you as a lesser-experienced organizational member.

Formal Mentoring: A program designed and developed by the organization to facilitate structured mentoring relationships where an experienced organizational member provided career and psychosocial development to you as a lesser-experienced organizational member.

Non-Mentoring: Never having any involvement in a formal or informal mentoring relationship where an experienced organizational member provided career and psychosocial development to you as a lesser-experienced organizational member.

Please indicate the type of mentoring you received at your current or former organization by selecting the appropriate number listed. IF YOU SELECT NON-MENTORING IN QUESTION 1, PLEASE PROCEED TO THE NEXT SECTION (PART III).

\begin{tabular}{|l|c|c|c|}
\hline \multicolumn{1}{|c|}{ Item } & Informal Mentoring & Formal Mentoring & Non-Mentoring \\
\hline $\begin{array}{l}\text { 1. As a protégé I } \\
\text { was/am involved } \\
\text { with }\end{array}$ & 1 & 2 & 3 \\
\hline
\end{tabular}

For the next two items please indicate your level of agreement with each statement by selecting the appropriate number listed.

\begin{tabular}{|l|c|c|c|c|c|c|}
\hline \multicolumn{1}{|c|}{ Items } & $\begin{array}{c}\text { Strongly } \\
\text { Disagree }\end{array}$ & Disagree & Undecided & Agree & $\begin{array}{c}\text { Strongly } \\
\text { Agree }\end{array}$ & N/A \\
\hline $\begin{array}{l}\text { 2. The formal } \\
\text { mentoring I receive } \\
\text { (d) is/was effective. }\end{array}$ & 1 & 2 & 3 & 4 & 5 & 6 \\
\hline $\begin{array}{l}\text { 3. The informal } \\
\text { mentoring I } \\
\text { receive(d) is/was } \\
\text { effective }\end{array}$ & 1 & 2 & 3 & 4 & 5 & 6 \\
\hline
\end{tabular}

Please indicate the gender of your mentor by selecting the appropriate number listed.

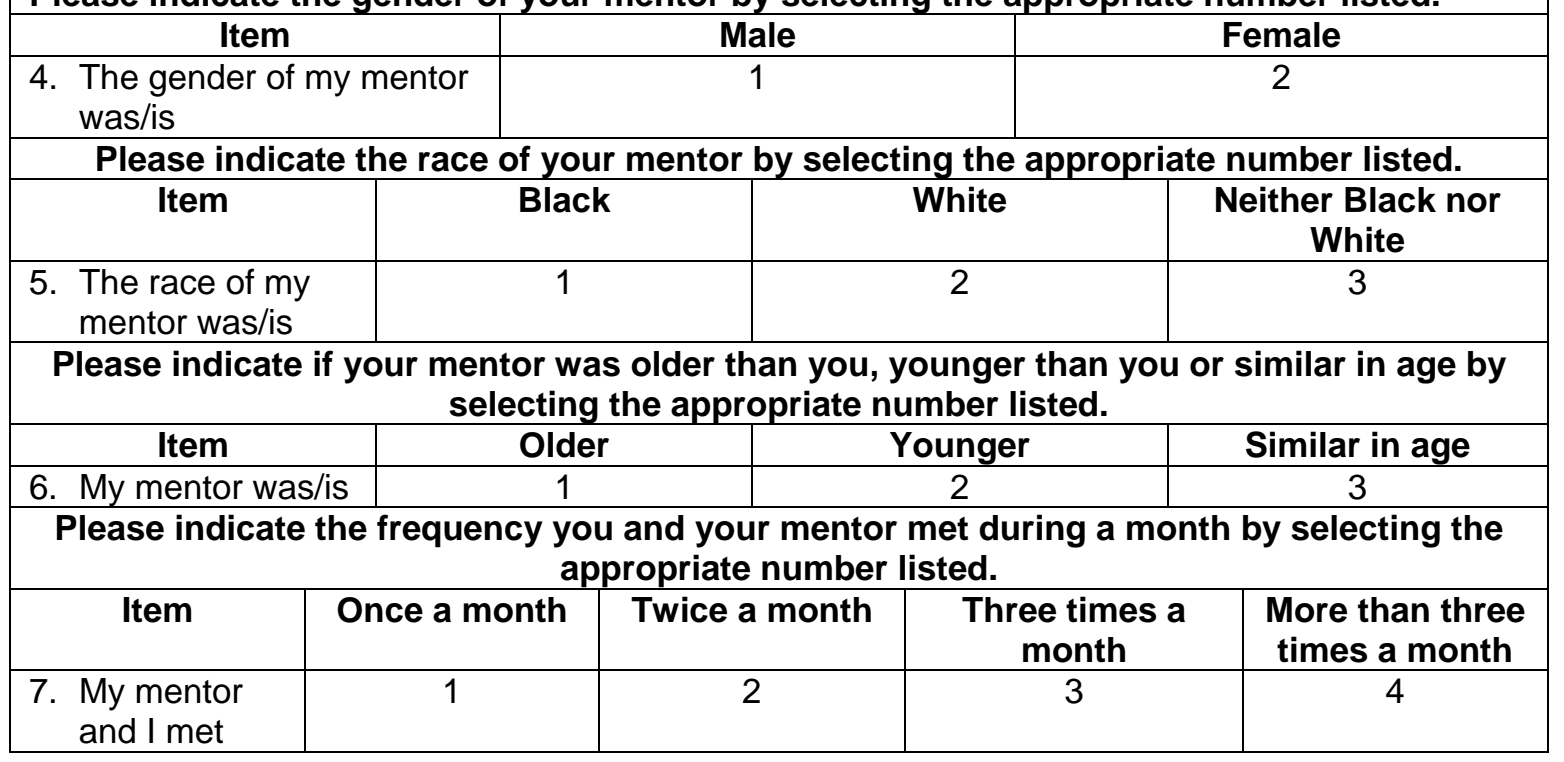




\section{PART III}

ORGANIZATIONAL COMMITMENT

\begin{tabular}{|c|c|c|c|c|c|c|c|}
\hline $\begin{array}{l}\text { Listed below are } 15 \text { statements that represent } \\
\text { possible feelings individuals might have about } \\
\text { the organization for which they work. With } \\
\text { respect to your own feelings about the } \\
\text { organization in which you currently work, } \\
\text { please indicate the level of your agreement or } \\
\text { disagreement with each statement by circling } \\
\text { one number in the appropriate column. }\end{array}$ & 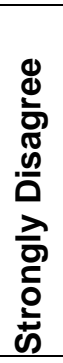 & 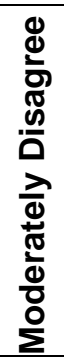 & 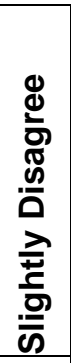 & 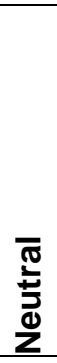 & 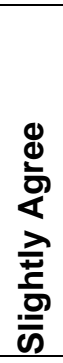 & 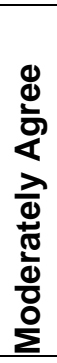 & 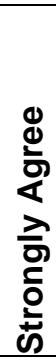 \\
\hline $\begin{array}{l}\text { 1. I am willing to put a great deal of effort beyond } \\
\text { what is normally expected in order to help this } \\
\text { organization be successful. }\end{array}$ & 1 & 2 & 3 & 4 & 5 & 6 & 7 \\
\hline $\begin{array}{l}\text { 2. I talk up this organization to my friends as a } \\
\text { great organization to work for. }\end{array}$ & 1 & 2 & 3 & 4 & 5 & 6 & 7 \\
\hline 3. I feel very little loyalty to this organization. & 1 & 2 & 3 & 4 & 5 & 6 & 7 \\
\hline $\begin{array}{l}\text { 4. I would accept almost any type of job } \\
\text { assignment in order to keep working for this } \\
\text { organization. }\end{array}$ & 1 & 2 & 3 & 4 & 5 & 6 & 7 \\
\hline $\begin{array}{l}\text { 5. I find my values and the organization's values } \\
\text { are very similar. }\end{array}$ & 1 & 2 & 3 & 4 & 5 & 6 & 7 \\
\hline $\begin{array}{l}\text { 6. I am proud to tell others I am part of this } \\
\text { organization. }\end{array}$ & 1 & 2 & 3 & 4 & 5 & 6 & 7 \\
\hline $\begin{array}{l}\text { 7. I could just as well be working for a different } \\
\text { organization as long as the type of work was } \\
\text { similar. }\end{array}$ & 1 & 2 & 3 & 4 & 5 & 6 & 7 \\
\hline $\begin{array}{l}\text { 8. This organization really inspires my best job } \\
\text { performance. }\end{array}$ & 1 & 2 & 3 & 4 & 5 & 6 & 7 \\
\hline $\begin{array}{l}\text { 9. It would take very little change in my present } \\
\text { circumstances to cause me to leave this } \\
\text { organization. }\end{array}$ & 1 & 2 & 3 & 4 & 5 & 6 & 7 \\
\hline $\begin{array}{l}\text { 10. I am extremely glad I chose this organization } \\
\text { to work for over others I was considering at } \\
\text { the time I joined. }\end{array}$ & 1 & 2 & 3 & 4 & 5 & 6 & 7 \\
\hline $\begin{array}{l}\text { 11. There is not too much to be gained by sticking } \\
\text { with the organization indefinitely. }\end{array}$ & 1 & 2 & 3 & 4 & 5 & 6 & 7 \\
\hline $\begin{array}{l}\text { 12. Often, I find it difficult to agree with this } \\
\text { organization's policies on important matters } \\
\text { relating to its employees. }\end{array}$ & 1 & 2 & 3 & 4 & 5 & 6 & 7 \\
\hline 13. I really care about the fate of this organization. & 1 & 2 & 3 & 4 & 5 & 6 & 7 \\
\hline $\begin{array}{l}\text { 14. For me, this is best of all possible } \\
\text { organizations for which to work. }\end{array}$ & 1 & 2 & 3 & 4 & 5 & 6 & 7 \\
\hline $\begin{array}{l}\text { 15. Decision to work for this organization was a } \\
\text { definite mistake on my part. }\end{array}$ & 1 & 2 & 3 & 4 & 5 & 6 & 7 \\
\hline
\end{tabular}


JOB SATISFACTION

\begin{tabular}{|c|c|c|c|c|c|c|}
\hline $\begin{array}{l}\text { In the following } 36 \text { statements, please circle one } \\
\text { number in the column that comes closest to } \\
\text { reflecting your level of agreement or disagreement. }\end{array}$ & 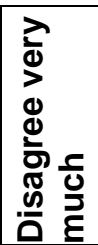 & 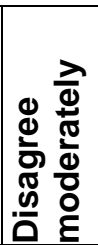 & 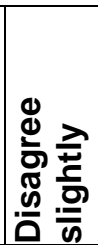 & 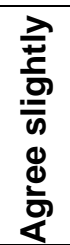 & 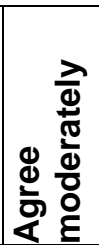 & 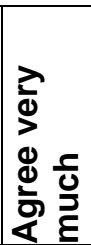 \\
\hline $\begin{array}{l}\text { 1. I feel I am being paid a fair amount for the work I } \\
\text { do. }\end{array}$ & 1 & 2 & 3 & 4 & 5 & 6 \\
\hline $\begin{array}{l}\text { 2. There is really too little chance for promotion on my } \\
\text { job. }\end{array}$ & 1 & 2 & 3 & 4 & 5 & 6 \\
\hline $\begin{array}{l}\text { 3. My supervisor is quite competent in doing his/her } \\
\text { work. }\end{array}$ & 1 & 2 & 3 & 4 & 5 & 6 \\
\hline 4. I am not satisfied with the benefits I receive. & 1 & 2 & 3 & 4 & 5 & 6 \\
\hline $\begin{array}{l}\text { 5. When I do a good job, I receive the recognition for it } \\
\text { that I should receive. }\end{array}$ & 1 & 2 & 3 & 4 & 5 & 6 \\
\hline $\begin{array}{l}\text { 6. Many of our rules and procedures make doing a } \\
\text { good job difficult. }\end{array}$ & 1 & 2 & 3 & 4 & 5 & 6 \\
\hline 7. I like the people I work with. & 1 & 2 & 3 & 4 & 5 & 6 \\
\hline 8. I sometimes feel my job is meaningless. & 1 & 2 & 3 & 4 & 5 & 6 \\
\hline $\begin{array}{l}\text { 9. Communications seem good within this } \\
\text { organization. }\end{array}$ & 1 & 2 & 3 & 4 & 5 & 6 \\
\hline 10. Raises are too few and far between. & 1 & 2 & 3 & 4 & 5 & 6 \\
\hline $\begin{array}{l}\text { 11. Those who do well on the job stand a fair chance of } \\
\text { being promoted. }\end{array}$ & 1 & 2 & 3 & 4 & 5 & 6 \\
\hline 12. My supervisor is unfair to me. & 1 & 2 & 3 & 4 & 5 & 6 \\
\hline $\begin{array}{l}\text { 13. The benefits we receive are as good as most other } \\
\text { organizations offer. }\end{array}$ & 1 & 2 & 3 & 4 & 5 & 6 \\
\hline 14. I do not feel that the work I do is appreciated. & 1 & 2 & 3 & 4 & 5 & 6 \\
\hline $\begin{array}{l}\text { 15. My efforts to do a good job are seldom blocked by } \\
\text { red tape. }\end{array}$ & 1 & 2 & 3 & 4 & 5 & 6 \\
\hline $\begin{array}{l}\text { 16. I find I have to work harder at my job because of } \\
\text { the incompetence of people I work with. }\end{array}$ & 1 & 2 & 3 & 4 & 5 & 6 \\
\hline 17. I like doing the things I do at work. & 1 & 2 & 3 & 4 & 5 & 6 \\
\hline 18. The goals of this organization are not clear to me. & 1 & 2 & 3 & 4 & 5 & 6 \\
\hline $\begin{array}{l}\text { 19. I feel unappreciated by the organization when I } \\
\text { think about what they pay me. }\end{array}$ & 1 & 2 & 3 & 4 & 5 & 6 \\
\hline $\begin{array}{l}\text { 20. People get ahead as fast here as they do in other } \\
\text { places. }\end{array}$ & 1 & 2 & 3 & 4 & 5 & 6 \\
\hline $\begin{array}{l}\text { 21. My supervisor shows too little interest in the } \\
\text { feelings of subordinates. }\end{array}$ & 1 & 2 & 3 & 4 & 5 & 6 \\
\hline 22. The benefits package we have is equit & 1 & 2 & 3 & 4 & 5 & 6 \\
\hline
\end{tabular}




\section{PART IV}

JOB SATISFACTION (con't)

\begin{tabular}{|c|c|c|c|c|c|c|}
\hline $\begin{array}{l}\text { In the following statements, please circle one } \\
\text { number in the column that comes closest to } \\
\text { reflecting your level of agreement or disagreement. }\end{array}$ & 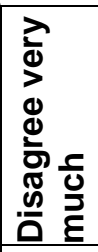 & 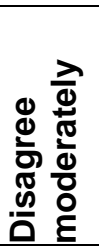 & 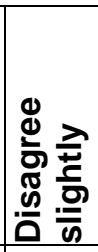 & 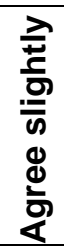 & 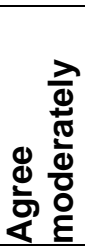 & 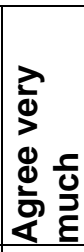 \\
\hline 23. There are few rewards for those who work here. & 1 & 2 & 3 & 4 & 5 & 6 \\
\hline 24. I have too much to do at work. & 1 & 2 & 3 & 4 & 5 & 6 \\
\hline 25. I enjoy my co-workers. & 1 & 2 & 3 & 4 & 5 & 6 \\
\hline $\begin{array}{l}\text { 26. I often feel that I do not know what is going on with } \\
\text { the organization. }\end{array}$ & 1 & 2 & 3 & 4 & 5 & 6 \\
\hline 27. I feel a sense of pride in doing my job. & 1 & 2 & 3 & 4 & 5 & 6 \\
\hline $\begin{array}{l}\text { 28. I feel satisfied with my chances for salary } \\
\text { increases. }\end{array}$ & 1 & 2 & 3 & 4 & 5 & 6 \\
\hline $\begin{array}{l}\text { 29. There are benefits we do not have which we should } \\
\text { have. }\end{array}$ & 1 & 2 & 3 & 4 & 5 & 6 \\
\hline 30. I like my supervisor. & 1 & 2 & 3 & 4 & 5 & 6 \\
\hline 31. I have too much paperwork. & 1 & 2 & 3 & 4 & 5 & 6 \\
\hline $\begin{array}{l}\text { 32. I don't feel my efforts are rewarded the way they } \\
\text { should be. }\end{array}$ & 1 & 2 & 3 & 4 & 5 & 6 \\
\hline 33. I am satisfied with my chances for promotion. & 1 & 2 & 3 & 4 & 5 & 6 \\
\hline 34. There is too much bickering and fighting at work. & 1 & 2 & 3 & 4 & 5 & 6 \\
\hline 35. My job is enjoyable. & 1 & 2 & 3 & 4 & 5 & 6 \\
\hline 36. Work assignments are not fully explained. & 1 & 2 & 3 & 4 & 5 & 6 \\
\hline
\end{tabular}




\section{APPENDIX D}

\section{Letters and e-mails sent to NBMBAA Presidents and Participants}


Dear President:

My name is Dr. Thomas G. Reio and I am the principle investigator and Davis M. Robinson is the sub-investigator for a dissertation research and I am seeking support from you and your chapter to take part in a national study pertaining to African American men. You may recall Davis' name from a phone conversation, a voice mail, conference call, or during the president's meeting at the national conference (through Crawford Owens; president of the Louisville Chapter) regarding the study. The name of the study is Mentoring African American men: A study of job satisfaction and organizational commitment.

During the month of February 2007 correspondences will be sent to all NBMBAA chapter presidents with a Web-link to forward to all African American male members of their chapter and other professional African American men. Again, this is a national survey involving African American men in all chapters of NBMBAA and other professional African American men and is for a doctoral dissertation that is being conducted at the University of Louisville.

The survey will take approximately 7-10 minutes to complete and is designed to study the relationship of mentoring and organizational commitment and job satisfaction of African American men. In addition, it is desired to reveal the results from the study at the next national NBMBAA conference.

Again, only African American men are being asked to participate in the study and your chapter's participation is most important to the success of this study. Your support is appreciated.

Respectfully,

Dr. Thomas G. Reio, P.I. Assistant Professor University of Louisville
Davis M. Robinson, S.I. Doctoral Candidate University of Louisville 
Dear President,

The purpose of this e-mail is to request your assistance in completing a research study on Mentoring African American men. As a doctoral student at the University of Louisville, I am conducting a research to determine the relationship of mentoring and job satisfaction and organizational commitment of African American men. The results of this study may assist organizations who are in need of retaining African American men and seeking to diversify the management pool. I will be collecting data from African American men who are members of their local NBMBAA chapter throughout the United States and other professional African American men during the month of February 2007.

Your willingness to forward the attached document to African American men and encouragement to participate in this study will help facilitate understanding if mentoring plays a role in the job satisfaction and organizational commitment of African American men. In three days, another email will be sent requesting participation, along with Weblink to the online survey. You will be asked to forward this e-mail as well. This survey does not contain any identifying questions; therefore, members can be sure that their identities will remain anonymous.

Please contact me atdmr30@yahoo.com if you have any questions or concerns. Thank you for your consideration in forwarding this e-mail to the African American men in your chapter.

Best Regards,

Davis M. Robinson

Doctoral Student

University of Louisville 
Dear NBMBAA member,

I am a doctoral student at the University of Louisville and am collecting data for my dissertation on Mentoring African American men. This is an introductory email to inform you of the upcoming study that will take place in the month of February 2007. In three days, you will receive another e-mail with a request for participation, along with the Weblink to the online survey. Your participation is voluntary and would consist of completing the Web-based survey, which will take about 7-10 minutes of your time. The survey does not contain any identifying questions; therefore, your identity will remain anonymous.

Thank you for considering my invitation to participate in this study. Your contribution may help other African American men who are currently in a mentoring relationship or considering a future mentoring experience.

Regards,

Davis M. Robinson

Doctoral Student

University of Louisville 


\section{Request for Participation E-mail to NBMBAA Presidents}

\section{Dear President,}

The research study you were notified about three days ago is about to begin. I kindly ask that you forward the request below to all African American men of your chapter. In one week, you will receive a thank you/reminder e-mail to be sent to the participants thanking them for participating and reminding them of the study if they have not already completed the survey. You will be asked to forward this e-mail as well.

Thank you for your consideration and forwarding the notice and Weblink to the African American men in your chapter.

Best Regards,

Davis M. Robinson

Doctoral Student

University of Louisville 
Dear NBMBAA member,

As an African American man, you are being invited to participate in a research study sponsored by Dr. Thomas G. Reio, at the University of Louisville and conducted by Davis M. Robinson. The purpose of this study is to determine if mentoring is related to the job satisfaction and organizational commitment of African American men.

Your participation is voluntary and would consist of completing the Web-based survey, which will take about 7-10 minutes of your time. As mentioned in the previous e-mail, your identity will remain anonymous. You can access the survey by clicking on the following link:

Thank you for considering my invitation to participate in this study. Your contribution may help other African American men who are currently in a mentoring relationship or considering a future mentoring experience.

Best Regards,

Davis M. Robinson

Doctoral Student

University of Louisville 


\section{Dear President,}

This is a second reminder regarding a doctoral research study on Mentoring African American men. In order for this research study to be a success, we will need between 200-300 respondents. At this point, I have received $(X)$ responses. Please forward the attachment as reminder e-mail below to African American men of your chapter and other professional African American men, as well as encourage those who haven't yet filled out the survey to please do so.

Your assistance has been greatly appreciated.

Best Regards,

Davis M. Robinson

Doctoral Student

University of Louisville 


\section{Reminder E-mail to NBMBAA Members}

\section{Dear Member,}

For those of you who have not yet completed the Web-based survey regarding mentoring African American men you can access the survey by clicking on the following link:

At this point, I have received $(\mathbf{X})$ responses. In order for this study to be a success, 200-300 respondents are needed. Your responses are very valuable to this study and greatly appreciated.

I would like to thank each of you who have already completed the survey. Your contribution may help other African American men who are currently in a mentoring relationship or considering a future mentoring experience.

Best Regards,

Davis M. Robinson

Doctoral Student

University of Louisville 


\section{Reminder/Thank You Email to NBMBAA Presidents}

\section{Dear President,}

This is the final email regarding a doctoral research study on mentoring African American men. In order for this research study to be a success, we will need between 200-300 respondents. At this point, I have received (X) responses. Therefore, I am asking that you please forward the attachment to African American men of your chapter and other professional African American men, as well as encourage those who haven't yet filled out the survey to please do so.

Your assistance has been greatly appreciated.

Best Regards,

Davis M. Robinson

Doctoral Student

University of Louisville 


\section{Dear Participant,}

For those of you who have not yet completed the Web-based survey regarding Mentoring African American men you can access the survey by clicking on the following link:

At this point, I have received $(X)$ completed surveys. In order for this study to be a success, 200-300 completed surveys are needed. Therefore, I am asking that you please take time to complete the survey, which will take about 7-10 minutes. Your responses are very valuable to the success of this study and greatly appreciated.

I would like to thank each of you who have already completed the survey. Your contribution may help other African American men who are currently in a mentoring relationship or considering a future mentoring experience.

Best Regards,

Davis M. Robinson

Doctoral Student

University of Louisville 
APPENDIX E

$\underline{\text { Race, Positions, Industries, Specialties, of Participants }}$ 
Race

African

Frequency

Bi-Racial

1

Black American

1

Hispanic

1

Jamaican

2

Panamanian

1

Position

Administrator

Frequency

Analyst

1

Business Owner

1

Case Manager

1

CEO

1

Clerical

Computer Programmer Analyst

Consultant

Doctor

Elected Union Official

Electrical Engineer

Energy Consultant

Engineer

Entrepreneur

Executive Assistant

Executive Director

File Clerk IAP/IRS

Financial Advisor

Full Time Student

Government Disaster Preparedness Planner

Independent Realtor/Investor

1

Intern

Jr. Accountant

Network administrator 
$\begin{array}{ll}\text { Physician } & 1\end{array}$

Professional 1

Professor 1

Relationship Manager 1

Retired 1

Retired surgeon 1

Self-employed Financial Services 1

Specialist/Consultant 1

Student 1

Teacher 1

unemployed 2

Industry $\quad$ Frequency

Advertising 1

Aerospace 2

Aerospace Defense 1

Business Consulting 1

Business Travel 1

Cheerleading Gym Owner/Instructor 1

Chemical 1

$\begin{array}{ll}\text { Chemical Dependency } & 1\end{array}$

Community Development / Real Estate Development 1

Construction - Real Estate 1

Consulting 1

Consulting Engineering 1

Corporation Finance 1

Customer Services 1

Defense Electronics 1

Economic Development 1

Electric and Gas Utility 1

Electric Utility 1

Energy 4

Engineering 5 
Entertainment \& Media

Factory 1

Fashion Retail 1

Federal Government - Legislative Branch 1

Finance, Tax Strategies 1

Financial Services $\quad 6$

Financial Services and Insurance 1

Fire Service 1

Foodservice 1

Foodservice Distribution 1

Government 3

Government/Public Health 1

Hospitality 3

Industrial Distribution 1

Industrial rubber 1

Industrial sector/manufacturing 1

Insurance $\quad 6$

Insurance and Financial Services 1

Insurance/Risk Mgmt.

Investments 1

IRS 2

Major League Baseball 1

$\begin{array}{ll}\text { Manufacturing } & 7\end{array}$

Marketing 1

Membership Organization 1

MFG: Food Service 1

Military, Government 1

Ministry 1

Molding 1

Non-Profit 3

Oil and Gas 1

Outsourcing and Financial Services 1 
Pharmaceutical 1

Postal Service $\quad 2$

Previously Employed in Automotive Manufacturing 1

Print Services 1

Printing/Duplication 1

Public Accounting 1

Public Utility 1

QSR-Franchising 1

Quick Serve Restaurant 1

Real Estate $\quad 5$

Recreation 1

Research and Development 1

Retail 4

Retired 1

Service 3

Social Service, Entertainment, Hospitality, IT 1

Specialty Chemicals 1

State Government 1

Supply and Logistics 1

Technology (Web Applications) 1

Transportation 3

Unemployed 1

$\begin{array}{ll}\text { Utilities } & 7\end{array}$

Venue Industry 1

Waste Management 1

Water Transport 1

Youth Service 1

Specialty

Accountability 1

Administration 2

All of the above 1

All Star Cheerleading 1 
Analysis 1

Auditing 1

$\begin{array}{ll}\text { Budgeting/financial management } & 1\end{array}$

Business Development 5

Case Management 1

CEO 2

College Administration 1

Compliance 2

Contract Administration/Management 1

Corporate Operations 1

Corporate Real Estate 1

Credit Administration 1

Customer Service 5

Distribution Maintenance 1

Economic Development 1

Education 2

Energy 1

Entertainment 1

Factory 1

Federal Government - Legislative Branch 1

File clerk 1

Financial Consulting/Financial Services 1

Financial Planning 1

Financial Services 1

Fire Fighter 1

Fire Service 1

Fitness 1

General Management 1

Healthcare 1

HIM/COMPLIANCE

Hybrid - Marketing, Finance, Insurance, Banking 1

Instructor, Life skills delivery 1 
Learning \& Development 1

Management 3

Medical Equipment Repair Tech. 1

Medicine 2

Merchandise Planning 1

Ministry 1

Mortgage Broker Consultant 1

Music 1

$\begin{array}{ll}\text { Nursing } & 1\end{array}$

Operations, Sales, and Marketing 1

Pharmaceutical Sales 1

Podiatry 1

President \& CEO 1

Previously in Supervision 1

Privacy \& Data Protection (law related) 1

Product Management 1

Purchasing/Supply Chain Management 3

Regulatory 1

Relationship Management 1

Research \& Development 1

Retired 1

Risk Management 1

Sales/ Business Development $\quad 8$

Service 1

Supply 3

$\begin{array}{ll}\text { Tax } & 1\end{array}$

$\begin{array}{ll}\text { Teaching } & 1\end{array}$

Unemployed 1

Degree

Associates Degree

Frequency

3

B.S., M.S., MD. Surgery 1

Completing MBA in 2007 
High School Graduate $\quad 1$

Juris Doctor 2

Master of Divinity 1

Master of Liberal Arts 1

Master of Social Work 2

Masters of Health Services Management 1

MD 3

MPA Studies 1

Some College 3

Working on Bachelors 1 


\section{APPENDIX F}

\section{Descriptive Statistics of the Organizational Commitment Scale}


I am willing to put a great deal of effort beyond what is normally expected in order to help this organization be successful.

I talk up this organization to my friends as a great organization to work for.

I feel very little loyalty to this organization. ${ }^{a}$

$4.3 \quad 2.1$

I would accept almost any type of job assignment in order to keep working for this organization.

I find my values and the organization's values are very similar.

I am proud to tell others I am part of this organization.

I could just as well be working for a different organization as long as the type of work was similar. ${ }^{a}$

This organization really inspires my best job performance.

It would take very little change in my present circumstances to cause me to leave this organization. ${ }^{a}$

I am extremely glad I chose this organization to work for over others I was considering at the time I joined.

There is not too much to be gained by sticking with the organization indefinitely. ${ }^{a}$

Often, I find it difficult to agree with this organization's policies on important matters relating to its employees. ${ }^{a}$ 
Descriptive Statistics for Organization Commitment Scale $(N=256)$

M

SD

Decision to work for this organization was a definite mistake on my part. ${ }^{a}$

5.7

1.6

Note. Items were rated on a 7-point Likert-type agreement scale.

${ }^{a}$ These questions were reverse scored. 


\section{APPENDIX G}

\section{Descriptive Statistics of the Job Satisfaction Scale}


Descriptive Statistics for Job Satisfaction Scale $(N=256)$

M

SD

I feel I am being paid a fair amount for the work I do.

3.82

1.55

There is really too little chance for promotion on my job. ${ }^{a}$

3.30

1.62

My supervisor is quite competent in doing his/her work.

4.60

1.43

I am not satisfied with the benefits I receive. ${ }^{a}$

4.11

1.57

When I do a good job, I receive the recognition for it that I should receive.

Many of our rules and procedures make doing a good job difficult. $^{\text {a }}$

I like the people I work with.

I sometimes feel my job is meaningless. ${ }^{a}$

Communications seem good within this organization.

Raises are too few and far between. ${ }^{a}$

Those who do well on the job stand a fair chance of being promoted.

My supervisor is unfair to me. ${ }^{a}$

The benefits we receive are as good as most other organizations offer.

I do not feel that the work I do is appreciated. ${ }^{a}$

My efforts to do a good job are seldom blocked by red tape.

I find I have to work harder at my job because of the incompetence of people I work with. ${ }^{a}$

I like doing the things I do at work.

The goals of this organization are not clear to me. ${ }^{a}$ 
Descriptive Statistics for Organization Commitment Scale $(N=256)$

$\mathrm{M}$

SD

I feel unappreciated by the organization when I think about what they pay me. ${ }^{a}$

People get ahead as fast here as they do in other places.

3.29

My supervisor shows too little interest in the feelings of subordinates. ${ }^{a}$

The benefits package we have is equitable.

There are few rewards for those who work here. ${ }^{a}$

I have too much to do at work. ${ }^{a}$

I enjoy my co-workers.

I often feel that I do not know what is going on with the organization. $^{\text {a }}$

I feel a sense of pride in doing my job.

I feel satisfied with my chances for salary increases.

There are benefits we do not have which we should have. ${ }^{a}$

I like my supervisor.

$4.81 \quad 1.26$

I have too much paperwork. ${ }^{a}$

I don't feel my efforts are rewarded the way they should be. ${ }^{a}$

I am satisfied with my chances for promotion.

There is too much bickering and fighting at work. ${ }^{a}$

My job is enjoyable.

Work assignments are not fully explained. ${ }^{a}$

Note. Items were rated on a 6-point Likert-type agreement scale.

${ }^{\mathrm{a}}$ These questions were reverse scored. 


\section{VITAE}

\section{DAVIS M. ROBINSON}

7312 Brook Meadow Drive, Louisville, KY 40228

(502) 290-4504 (h) (502)345-2787(h)

E-mail: dmr30yahoo.com

\section{EDUCATION}

Organizational Development/Educational Leadership, Ph.D., 2007 University of Louisville, Louisville, KY

Human Resource Education (OTD), M.Ed., 1996

University of Louisville, Louisville, KY

Psychology and Communications, B.S., 1990

Western Kentucky University, Bowling Green, KY

\section{PROFESSIONAL EXPERIENCE}

Staff Performance and Development Coordinator

2005-present University of Louisville Hospital

This position reports to the Director of Staff Performance and Development and applies performance improvement concepts to create and implement interventions that increase the ability of the organization's performers to improve individual, departmental, and organizational results and efficiencies in the delivery of products and services to customers. The position also provides training for targeted employee populations.

\section{Accomplishments:}

- Internal consultant for University Physicians Group

- Lead focus groups to assess individual development needs for Leadership Development program: Project G.R.O.W.,

- Synthesized data and presented recommendations to Human Resources for Project G.R.O.W.

- Designed and implemented first phase of Leadership Development Program: Project G.R.O.W. (Time Management and Coaching for Performance)

- Project leader for Customer Service initiative, created and submitted an Organizational Change Plan for Customer Service 
- Researched and synthesized data to guide the development of the organization's customer service SPIRIT standards

- Leader for Customer Service Training for new scheduling department

- Created alliances with VP of Nursing and nursing managers to revise Charge Nurse selection tool

- Facilitator for Practice Development Unit accreditation

- Facilitator for Customer Service Committee retreat

- Facilitator for Pharmacy Take Home Medication Process Improvement

- Facilitator for Radiology CT Process Improvement

- Developed and interviewed/surveyed physicians and nursing staff on the organization's Computerized Physician Order Entry system for implementation purposes

\section{Committee/Organizational Activities}

- Customer Satisfaction Committee

- Access One Advisory Committee

- Educational Affinity Committee

- Computerized Physician Order Entry Committee

- Intranet (UHCNet) committee

- Making Connections Louisville Advisory Committee

This position reported directly to the Manager of Organizational Development. The primary responsibilities of the position were: Designing, developing, implementing and maintaining curriculum for training programs (computer/soft skills) through KHC University. Provide facilitation, consultation and training for process improvement. Advise, assist staff at all corporate levels with special projects, training needs; perform training needs assessments, evaluate internal/external training programs. Work closely with Organizational Development and Human Resources.

\section{Accomplishments}

- Enhanced the Corporate University's mentoring program and created an internal networking program

- Researched and assisted with the implementation of the corporate Telecommuting Policy

- Submitted an "on-boarding" proposal to Human Resources

- Assisted Human Resources Department in Workforce Planning examination

\section{Committee/Organizational Activities}

- Cultural Diversity Chair

- Process Improvement Committees

OD Director/Leadership Development 2002 Eastern Kentucky University

The position reported directly to the Training Branch Manager. Managed 
programmatic areas of Cultural Diversity, Internal Consultant, and Informational Technology. Responsibilities included supervision, training and development, and leadership development.

Training Specialist

1996-2002

Eastern Kentucky University

Provided training to department staff, including foster parents, based on

assessed needs. Provided technical assistance to Family Services staff regarding education and training. Planned and developed training based on assessed needs, using in-house resources experts in field and private contractors.

\section{Accomplishments}

- Lead Trainer/Facilitator for Cabinet for Families and Children Change Management initiative

- Developed and managed Adolescent Curriculum

\section{Committees/Organizational Activities}

- Curriculum Development Committee

Part-time Adult Basic Education Instructor

1999 Jefferson County Public School System Louisville, KY Assisted with Adult and Continuing Education program by providing instruction to persons age 16 and over. Provided comprehensive evaluation and instructional program to meet needs of students; planned and coordinated classroom programs in compliance with state, federal and local directives. Explained purpose of specific programs to interested persons.

Family Service Worker Clinician 1991-1996 Cabinet for Families and Children Louisville, $\mathrm{KY}$ Responsible for counseling and casework management for probated, status, and delinquent juvenile offenders. Human Services Consultant for development and implementation of offender treatment and intervention plans. Client interest representative in the court system. Developed and supervised implementation of short and long-term re-assimilation goals.

\section{Accomplishments}

- Promoted two grade levels

Committee and Organizational Activities

- Facilitator, Working with African American Families Seminar

- Mgt. Representative Cultural Diversity Panel

Compliance Enforcement Officer

1994-1995

Kentucky Commission on Human Rights Louisville, KY Investigative Specialist in areas of Employment, Housing, Public Accommodations, and Credit. Managed collection, analysis, and interpretation of compiled data. Developed and presented 'Fact Profiles' with recommendation for resolution of alleged complaints.

Accomplishments 
- Presenter at the EEO Governors Conference

Home School Support Worker Spring Hill Elementary School

Spring 1991

Managed youth needs analysis/assessment and intervention program

development and implementation. Developed and supervised academic and career enrichment programs for Junior High "at risk" youth. Facilitated mentor/mentee program for youth clients.

Assistant Store Manager/Sales Associate

$1984-1991$

Walgreen's Drug Company

Louisville, KY

Supervised ten sales associates. Managed inventory planning, forecasting, and procurement processes. Assisted in sales budget, forecast preparation and reporting, and customer merchandise selection.

Kentucky Book Fair

PRO BONO EXPERIENCE

Independent Consultant

2005-2006

Facilitated the 5-year strategic plan for 25 year-old non-profit organization.

Thornton's Inc.

2004 Independent Consultant Louisville, KY Co-facilitated 4 Focus Groups to assist company in identifying corporate climate and cultural change (brand marketing).

\section{ENTREPRENURIAL EXPERIENCE}

Horizon Consulting Incorporated

2001-2003

Personal and OD Consultant, Louisville, KY

Provide consulting services for personal and organizational development.

Accomplishments

- Eti-K.I.D.D.S youth enrichment program

- Kentuckiana American Society for Training and Development (2002). The Ladder of Inference. Louisville, KY.

- Alpha Phi Alpha State Convention (2002). The Etiquette of Dining. Frankfort, KY.

- Alpha Phi Alpha State Convention (2002). Let's communicate: Talk less, listen more. Frankfort, $\mathrm{KY}$.

- First Gethsemane Baptist Church (2002). Christian Leadership.

Louisville, KY.

- Fayette County Housing Authority (2001). Career Development.

Lexington, $\mathrm{KY}$.

- Cabinet for Families and Children Tuberculosis Seminar (2001). Developing a Casework Relationship. Cumberland, KY.

- Jefferson County Public School System 2000-2002. Resume Writing. Louisville, KY

- Kentuckiana College Access Center (2000). Resume Writing. Louisville, 
$\mathrm{KY}$.

- Jefferson Community College (2000). Cultural Diversity and Prejudice

Reduction.

College Success Inc.

2000

Independent Contractor (Making College Count) Cincinnati, OH

Presented to over 3,600 high school seniors in Kentucky, Indiana and St. Louis

on how to succeed in college and best prepare themselves to maximize

graduation opportunities. Tailored each presentation to meet informational

needs of specific audiences based upon their progression in the college process.

\section{PROFESSIONAL CERTIFICATIONSIQUALIFICATIONS}

Qualified Practitioner

2003

Myers-Briggs Type Indicator

Louisville, KY

Obtained professional qualifications to administer the MBTI in assessing preferences of the 16 types to organizations and teams to increase performance.

Certified Consultant

2001-2003

Franklin Covey Seven Habits

Park City, UT

Certified facilitator/trainer for the international leadership program. Lead trainer/facilitator for Cabinet for Families and Children's leadership development program. Facilitated leadership skills in Public and Private Victory of Franklin Covey Seven Habits.

\section{PROFESSIONAL ORGANIZATIONS}

Kentuckiana American Society for Training and Development 1994-97, 2006-07 - Event Planning Committee

Louisville SHRM

2006

National Association of Healthcare Service Executives

2006

- Education Advisory Committee

National Black MBA Association

2006

American Society for Training and Development

2002-2004

\section{COMMUNITYIVOLUNTEER ACTIVITIES}

Community Health fair

2006

Project One: Professional Presenter

2006

Black Achievers Educational Cluster Leader

1999,2001

Clothe-A-Child Fundraiser Volunteer

1999-2000

WHAS Crusade for Children Volunteer

1998

Cystic Fibrosis Fundraiser Volunteer

Governors Drug Summit Cluster Facilitator

EEO Governors Conference, Facilitator

NAACP Annual Scholarship Award Committee

Jefferson County District Court "Teen Court", Facilitator

1995-1996

College Practicum Student mentor for CHR

1995-1996 
Metroversity Higher Education Symposium, Presenter

Manhood Enrichment/Life Skills Program Facilitator

Cabinet for Human Resources Cultural Diversity Competency Panel 1993-1996

Cabinet for Human Resource Cultural Diversity Committee

Governors Minority Student College Preparation Program

1988-1989

\section{BOARD APPOINTMENT \& HONORS}

March of Dimes Board of Trustees

Gold Key International Honor Society

Saint Xavier High School Alumni Association Board of Directors

- Alumni of the Year Committee

- Event Planning Committee

Jefferson County Public Schools FRC Selection Panel

\section{PUBLICATIONS}

Robinson, D. M. (2003). Not your usual team training. Training and Development, 57, 19-21. 